University of Louisville

ThinkIR: The University of Louisville's Institutional Repository

Electronic Theses and Dissertations

$12-2010$

\title{
Tobacco-induced changes to Porphyromonas gingivalis gene expression, phenotype and host-pathogen interactions.
}

Juhi Bagaitkar

University of Louisville

Follow this and additional works at: https://ir.library.louisville.edu/etd

\section{Recommended Citation}

Bagaitkar, Juhi, "Tobacco-induced changes to Porphyromonas gingivalis gene expression, phenotype and host-pathogen interactions." (2010). Electronic Theses and Dissertations. Paper 60.

https://doi.org/10.18297/etd/60

This Doctoral Dissertation is brought to you for free and open access by ThinkIR: The University of Louisville's Institutional Repository. It has been accepted for inclusion in Electronic Theses and Dissertations by an authorized administrator of ThinkIR: The University of Louisville's Institutional Repository. This title appears here courtesy of the author, who has retained all other copyrights. For more information, please contact thinkir@louisville.edu. 
TOBACCO-INDUCED CHANGES TO PORPHYROMONAS GINGIVALIS GENE EXPRESSION, PHENOTYPE AND HOST-PATHOGEN INTERACTIONS.

\author{
Juhi Bagaitkar
}

A dissertation submitted to the faculty of the Graduate School of the University of Louisville in partial fulfillment of the Requirement for the degree of

Doctor of Philosophy

University of Louisville, School of Medicine Department of Microbiology and Immunology

December 2010 

TOBACCO-INDUCED CHANGES TO PORPHYROMONAS GINGIVALIS GENE EXPRESSION, PHENOTYPE AND HOST-PATHOGEN INTERACTIONS.

By

Juhi Bagaitkar

A Dissertation approved on December 2010 by the following Dissertation Committee

David A Scott (Dissertation Director)

-

Thomas C Mitchell (Co-mentor)

Pascale Alard

Donald R Demuth

Michael Martin

Jill Suttles 


\section{ACKNOWLEDGMENTS}

I would like to thank Dr. Scott for all his support and advice that he has given me for the past three years, which has greatly helped in my development as a future scientist. I depended on you numerous times to keep me on track and optimistic. You have been most patient with my writing and taught me how to think critically. Thank you for always being there for me.

I would also like to acknowledge my committee members, Drs. Jill Suttles, Tom Mitchell, Michael Martin, Donald Demuth and Pascale Alard not only for their comments on my work in every committee meeting, but also for their cordial encouragement, invaluable help, and positive response. I thank Drs Demuth and Martin especially for allowing me to use various reagents and equipment in their respective labs.

A special thanks to Diane Renaud for teaching lab techniques, critically reading my manuscripts, proposals, etc. It was a pleasure to work with you in the lab over the last few years. I also thank the present and past members of the lab especially Aronica Boyle, Hussain Arbab and Carol Patel. To Carlo, Huizhi, Liz, Chelsea and Deanne, thank you for your help with various experimental techniques, constant support and 
patience. Lastly I thank my family, especially Kunal for all the encouragement and support!

I would like to thank the department of Microbiology and Immunology faculty, staff and students that made it such a pleasure to work and learn here.

Thank you all!

-Juhi 


\begin{abstract}
TOBACCO-INDUCED CHANGES TO PORPHYROMONAS GINGIVALIS GENE EXPRESSION, PHENOTYPE AND HOST-PATHOGEN INTERACTIONS.

By
\end{abstract}

Juhi Bagaitkar

$15^{\text {th }}$ December, 2010

Tobacco smoke is a strong and independent risk factor for several chronic systemic diseases and also increases susceptibility to a multitude of bacterial infections, including periodontal infections. Periodontitis is a chronic inflammatory disease of the supporting tissues of the periodontium caused by its chief etiological agent, Porphyromonas gingivalis. Smokers are more prone to persistant infections by $P$. gingivalis, and harbor higher numbers of $P$. gingivalis than non-smokers. However, smokers show reduced clinical signs of inflammation compared to non-smokers, making diagnosis of periodontal disease in smokers problematic. While several studies delineate the different mechanisms of how tobacco smoke alters host response to periodontitis, 
very little is know about its effects on the virulence profile of $P$. gingivalis. We hypothesize, that tobacco smoke presents an environmental stress to which $P$. gingivalis adapts by altering its gene expression, which in turn will influence its interaction with the host.

Indeed, $P$. gingivalis microarray and $\mathrm{qRT}$-PCR data show that about $7 \%$ of $P$. gingivalis genes are differentially regulated on exposure to cigarette smoke extract (CSE) including major and minor fimbrial antigens (FimA and Mfal, respectively) and capsule. CSE- induced phenotypic alterations are consistent with increased biofim formation and reduced pro-inflammatory potential of intact $P$. gingivalis. Furthermore chronic exposure to $P$. gingivalis FimA leads to the abrogation of the pro-inflammatory response in a TLR2- and IRAK1 dependent manner.

These studies provide some of the first information to explain, mechanistically, how tobacco smoke changes the $P$. gingivalis phenotype in a manner likely to promote $P$. gingivalis colonization and infection while simultaneously reducing the host response to this major mucosal pathogen. 


\section{TABLE OF CONTENTS}

Acknowledgement..........................................................ii

Abstract............................................................................

Table of Contents............................................................vii

List of Figures.............................................................xi

List of Tables...............................................................xii

\section{Chapter 1: Introduction}

Chronic inflammatory disease and smoking........................2

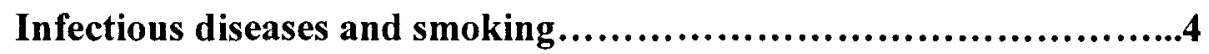

Periodontal diseases.....................................................7

Smoking and Periodontitis.............................................9

Porphyromonas gingivalis........................................11

Smoking and inflammatory response in Periodontitis.................17

Chapter 2: Materials and Methods

Reagents and antibodies...........................................19 
Bacterial culture and in vitro modeling of tobacco exposure...........21

Human PBMC, PMN, OBA-9 cell isolation and maintenance .........21

TNF- $\alpha$ release from $P$. gingivalis stimulated PBMCs...............23

$P$. gingivalis W83 microarrays...................................23

Validation of microarray data......................................25

$P$. gingivalis W83 outer membrane protein profiling................26

Expression of RagB in response to CSE..............................27

Analysis of capsule and FimA expression on CSE exposure...........27

Analysis of FimA binding activity and surface availability ..........27

Analysis of $P$. gingivalis biofilm formation.........................28

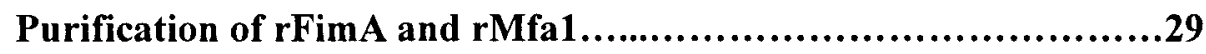

Proinflammatory profiling of FimA and Mfa1......................29

TLR specificity of FimA and Mfa1...............................29

Induction of TLR2 tolerance by FimA.............................30

NF-кB induction by FimA and Mfa1..............................30

TLR2 surface expression following chronic FimA stimulation.........30

Involvement of IRAK1 in FimA induced TLR2 tolerance.............31

Statistical Analysis...............................................31

Chapter 3: Tobacco Induced Alterations to $P$. gingivalis- host interactions

Introduction......................................................32

Results............................................................34

P. gingivalis growth in CSE conditioned medium.............34 
Induction of TNF- $\alpha$ release from PBMcs by CSE-exposed $P$. gingivalis................................................37

$P$. gingivalis genes up-regulated on CSE exposure.............37

$P$. gingivalis genes down-regulated on CSE exposure..........43

CSE alters expression of $P$. gingivalis outer membrane proteins RagA and RagB...........................................44

Discussion..........................................................46

Chapter 4: Tobacco Upregulates $P$. gingivalis Fimbrial Proteins that Induced TLR2 Hyposensitivity

Introduction.......................................................52

Results..........................................................55

Tobacco smoke exposure alters expression of $\boldsymbol{P}$. gingivalis fimbriae and capsule......................................55

CSE augments $P$. gingivalis biofilm formation...............58

FimA and Mfa1 exhibit differential pro-inflammatory potential....................................................60

FimA and Mfa1 are TLR2-specific agonists.................61

FimA induces TLR2 specific immune tolerance................64

FimA stimulation does not induce IкB $\alpha$ degradation but inhibits degradation by Mfa1...............................64

FimA induced innate tolerance is IRAK-1 mediated...........65

Discussion.........................................................68 
Chapter 5: Summary \& Future Directions

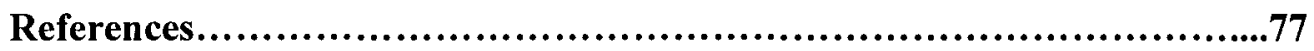

Curriculum vitae...........................................................99 


\section{LIST OF FIGURES}

\section{Chapter 1}

Figure 1: Immune response to oral biofilm bacteria.........................8

Figure 2: $\quad$ Summary of effects of cigarette smoke and cigarette smoke extract (CSE) on periodontal bacteria, host cells and tissues..............11

\section{Chapter 3}

Figure 3: $\quad$ Effect of CSE on $P$. gingivalis growth .............................

Figure 4: Reversible suppression of TNF- $\alpha$ release from human monocytes................................................38

Figure 5: Reversible suppression of multiple pro-inflammatory cytokines in human PBMcs stimulated with CSE-treated $P$. gingivalis.........41

Figure 6: $\quad P$. gingivalis genes up-regulated following CSE exposure..........43

Figure 7: $\quad P$. gingivalis genes down-regulated following CSE exposure......44

Figure 8: $\quad$ Upregulation of specific outer membrane proteins in CSEexposed $P$. gingivalis........................................47

Figure 9: $\quad$ CSE-induced RagB up-regulation in $P$. gingivalis is reversible....48

\section{Chapter 4}

Figure 10: CSE induces phenotypic surface changes in $P$. gingivalis........57

Figure 11: Visualization of homotypic biofilm formation by $P$. gingivalis grown in GAM or CSE .........................................58

Figure 12: Inflammatory potential of $\mathrm{rFimA}$ and $\mathrm{rMfa} 1 \ldots \ldots \ldots \ldots \ldots \ldots \ldots .60$

Figure 13: rFimA and rMfal signal preferentially through TLR2/6 ..........63

Figure 14: FimA induces TLR2 specific tolerance.......................64

Figure 15: FimA induced tolerance reduces $I \kappa B \alpha$ degradation..............67

Figure 16: Fim $A$ induced tolerance is IRAK-1 mediated...................68 


\section{LIST OF TABLES}

\section{Chapter 1}

Table 1: $\quad$ Bacterial infections associated with tobacco smoke..................5

\section{Chapter 3}

Table 2: $\quad$ Real-time PCR analysis of selected CSE-regulated $P$. gingivalis genes....................................................46

\section{Chapter 4}

Table 3: $\quad$ Quantitative characteristics of $P$. gingivalis biofilms..............59 


\section{CHAPTER ONE: INTRODUCTION}

Tobacco smoking is the single and most common preventable cause of premature mortality in the United States $(1,2)$. Tobacco users account for one third of the global adult population and it is estimated that tobacco-related health complications will result in premature death in 50\% of this group (3). About 5-6 million people are killed annually by tobacco use and most of these deaths ( $70 \%$ ) occur in middle- to low- income countries (4).

Tobacco smokers are at an increased risk for various types of cancers, stroke, vascular dysfunction, oral diseases, allergies and multiple chronic inflammatory and degenerative disorders (5). Cigarette smoke toxicity is attributed to the presence of more than 4000 chemicals, including multiple allergens, irritants, toxins, mutagens and carcinogens in the particulate/tar and gaseous phases of tobacco smoke (6). Polycyclic aromatic hydrocarbons, benzopyrenes, hydrozxyquinone, acrolein, formaldehyde, nitrogen oxides, acetone, ammonia, nicotine, heavy metals like lead and cadmium, free radicals etc, all contribute to the disease burden through multiple adverse effects on the innate and adaptive immune systems (7) . 
Active smoking is more hazardous than second hand smoke. Inhaled tobacco is associated with more diverse types of diseases than oral tobacco use. However, even second hand exposure is indicated in increased susceptibility to, and severity of, multiple diseases (8). Exposure to cigarette side stream smoke, a major environmental pollutant, for example, significantly increases risk for cardiovascular disease (9), adverse pregnancy outcomes $(10,11)$, infertility $(12,13)$, genetic aberrations (14) and persistent infections (15). Thus tobacco smoke contributes significantly to the global disease burden. However, there has been surprisingly little research focusing on how tobacco causes diseases, particularly chronic inflammatory and infectious diseases. Therefore, the specific underlying mechanisms are still largely unknown.

\section{Chronic Inflammatory Diseases and Smoking}

Tobacco smoking substantially increases the risk for chronic, inflammatory diseases (16-19). This is particularly true for atherosclerosis, acute myocardial infarction, stroke and peripheral vascular disease $(20,21)$, inflammatory bowel disease, chronic kidney disease $(5,19)$, and periodontal diseases $(22)$. Smokers are also pre-disposed to autoimmune inflammatory disorders such as systemic lupus erythematosus (SLE), rheumatoid arthritis (RA) and multiple sclerosis (MS). Again, it is important to point out that despite convincing epidemiological associations between tobacco use and such diseases, mechanistic insight is poor. For example, in RA, polycyclic aromatic hydrocarbons from cigarette smoke are known to induce a proinflammatory cytokine response from fibroblast-like synoviocytes (23). Moreover, there is a strong association between tobacco use and joint destruction in RA patients who smoke $(24,25)$. In SLE 
patients, the mutagenic nature of tobacco smoke is partly responsible for accumulation of DNA abnormalities, particularly double strand breaks and DNA-adduct formation, contributing to anti-DNA antibody production. In MS patients, nicotine interferes with axonal conduction, exacerbating disease (26). However, deeper mechanistic understanding is lacking.

Smoking induces alterations in several systemic inflammatory markers associated with chronic inflammation. Elevated levels of serum fibrinogen, C-reactive proteins (CRP), pro-inflammatory cytokines, aberrant expression of inflammatory markers and adhesion molecules are common in smokers with increased numbers and chemotaxis of neutrophils, monocytes and macrophages in the periphery (26). Such systemic changes could account for overt susceptibility to chronic inflammatory diseases in smokers.

The endothelial dysfunction associated with vascular diseases is induced by many tobacco smoke components, such as nicotine, carbon monoxide, nitric oxide and free radicals. Indeed, tobacco-induced increases in vascular permeability, adhesion molecule expression, leukocyte adherence, and platelet aggregation all contribute towards vascular disease progression and atherosclerotic lesion formation $(21,27,28)$. Even passive smoking increases cardiovascular disease risk by about $30 \%$ (29).

Cigarette smoking is also directly responsible for the majority of chronic inflammatory diseases of the airways, such as bronchitis, chronic obstructive pulmonary disease (COPD), and emphysema. Smoking is the main etiological factor associated with COPD, a progressive disease characterized by airway limitation (30). Increased proinflammatory cytokine expression by airway epithelial cells, immune cell sequestration, reactive oxygen species (ROS) generation and matrix metalloprotease (MMP) release, all 
contribute to perpetuation of inflammation that results in destruction of bronchial tissue, chronic lung injury and emphysema (as reviewed by MacNee et al (31)). Besides destructive lung diseases, both active and passive smoking has been associated with compromised renal function, nephropathies, and glomerular dysfunction (32) leading to chronic kidney disease $(5,19)$. Smoking also increases risk for inflammatory bowel disease, and several oral diseases particularly gingivitis and periodontitis (22).

\section{Infectious Diseases and Smoking}

Tobacco smoke adversely affects the immune response to pathogenic insults, making smokers more susceptible to a multitude of infectious diseases compared to nonsmokers (15). These include respiratory tract infections by several bacterial pathogens, including Streptococcus pneumoniae, Neisseria meningitidis, Haemophilus influenzae and Legionella pneumophila (33-37). Tuberculosis is also common in smokers and is often exacerbated in a dose-dependent manner $(38,39)$ with quicker rates of disease progression, relapse and higher mortality in smokers compared to non-smokers (40). Smoking is also significantly associated with the development of bronchitis and bacterial pneumonia (41).

Besides respiratory illnesses, smokers show higher prevalence of meningitis (42), post-surgical or nosocomial bacterial infections (43) and sexually-transmitted bacterial infections, such as chlamydia and gonorrhoea (44). Smokers also have an increased predisposition to bacterial-induced periodontal diseases $(45,46)$. Shifts in periodontal plaque composition from one primarily constituted by Gram positive, aerobic commensals to a more anaerobic, Gram negative microflora that includes overt and 
opportunistic pathogens is also common in smokers (47). A summary of bacterial infections associated with tobacco smoking is listed in Table 1.

Table 1: Bacterial infections associated with tobacco smoking.

\begin{tabular}{|c|c|c|}
\hline Infection & Odds Ratio $(95 \% \mathrm{CI})$ & $\begin{array}{l}\text { Additional } \\
\text { references }\end{array}$ \\
\hline $\begin{array}{l}\text { Nasopharyngeal and respiratory } \\
\text { pathogens (such as } S \text {. pneumonia, } N \text {. } \\
\text { meningitidis, H. influenzae, L. } \\
\text { pneumophila) }\end{array}$ & $2.5,(1.1-6.0)(36)$ & $\begin{array}{l}(33-35,37, \\
48-51)\end{array}$ \\
\hline Group A streptococcus sore throat & - & $(52)$ \\
\hline Legionnaires disease & $3.6(2.1-5.8)(37)$ & $(37,53)$ \\
\hline Cystic fibrosis & $\begin{array}{l}\text { Increased severity on } \\
\text { smoke exposure }(54,55)\end{array}$ & $(56,57)$ \\
\hline Pneumonia & $2.6(1.9-3.5)(58,59)$ & $(34,41,60)$ \\
\hline Tuberculosis & $\begin{array}{l}\text { 1.8 Light (38) } \\
3.2 \text { Moderate (38) } \\
3.7 \text { Heavy (38) } \\
4.1 \text { (2.4 to } 7.3) \text { Active (34) } \\
2.5 \text { (1.2 to } 5.1) \\
\text { Secondhand (34) }\end{array}$ & $\begin{array}{l}(39,40,61, \\
62)\end{array}$ \\
\hline Meningococcal carriage & $2.2(1.0-4.8)$ Light (63) & $(36,42,64-$ \\
\hline
\end{tabular}




\begin{tabular}{|l|l|l|}
\hline Bacterial vaginosis & $7.2(2.3-22.9$ Heavy $(63)$ & $68)$ \\
\hline Helicobacter pylori & $2.7(69)$ & $(44,70,71)$ \\
\hline Periodontitis & $1.9(1.4-2.5)(72)$ & $(73-76)$ \\
\hline Ulcerative colitis & $3.3(2.3-4.5)$ Light $(77)$ & $(78-89)$ \\
\hline Crohn's disease & $7.3(5.1-10.3)$ Heavy $(77)$ & $(91-93)$ \\
\hline Otitis media & $0.6(0.4-0.8)(90)$ & $(91,96,97)$ \\
\hline Surgical infections & $3.6(2.5-5.0)$ Active $(94)$ & $103)$ \\
\hline & $2.0(1.3-3.3)$ Secondhand & \\
\hline
\end{tabular}

* The specific OR $(95 \% \mathrm{CI})$ presented is selected from a single reference. The

“Additional references" column provides more complete information. 


\section{Periodontal diseases}

Tobacco smokers are more susceptible than non-smokers to plaqueinduced gingivitis and periodontitis. Periodontitis is a chronic inflammatory, infectious disease with a majority of the cases found in developing nations $(104,105)$. It is also highly prevalent in the US affecting, more than 100 million people (106) Inflammatory periodontal diseases represent a risk factor for several chronic and serious systemic conditions, such as vascular diseases including stroke (107-110), pulmonary disease (111-113), nephritis (114) and pre-term birth $(115,116)$.

Gingivitis is reversible and is characterized by redness, swelling, and bleeding (117). It can proceed into the more severe, chronic inflammatory periodontitis characterized by inflammatory destruction of the supporting soft tissues surrounding the teeth, loss of periodontal ligaments, and resorption of the alveolar bone that can lead to tooth loss and even edentulism $(105,118)$. Increased subgingival infection by several Gram negative species such as Aggregatibacter actinomycetemcomitans, Prevotella intermedia, Campylobacter rectus, and the red complex bacteria (Tannerella forsynthia, Treponema denticola and Porphyromonas gingivalis) inhabiting the largely anaerobic niche between the tooth surface and the junctional epithelium of the periodontium is a hallmark of inflammatory periodontal disease (119).

Subgingival colonization by pathogens is aided by several immune subverting virulence factors expressed by these periodontal pathogens. Bacterial persistence and the inflammatory response to such pathogens combine to promote inflammatory tissue destruction in periodontitis. Multiple pro-inflammatory cytokines (i.e. IL-1 $\beta$, IL-6, TNF $\alpha$, IL-8, and RANKL) lead to osteoclast activation and, subsequently, alveolar bone 
loss (120). The degree and extent of the inflammatory response to these pathogens is determined by several host-specific factors like age, race, genetic polymorphisms, underlying immune abnormalities, etc (121). However tobacco smoke is the most important environmental risk factor associated with chronic, inflammatory periodontal disease $(45,46,122)$.

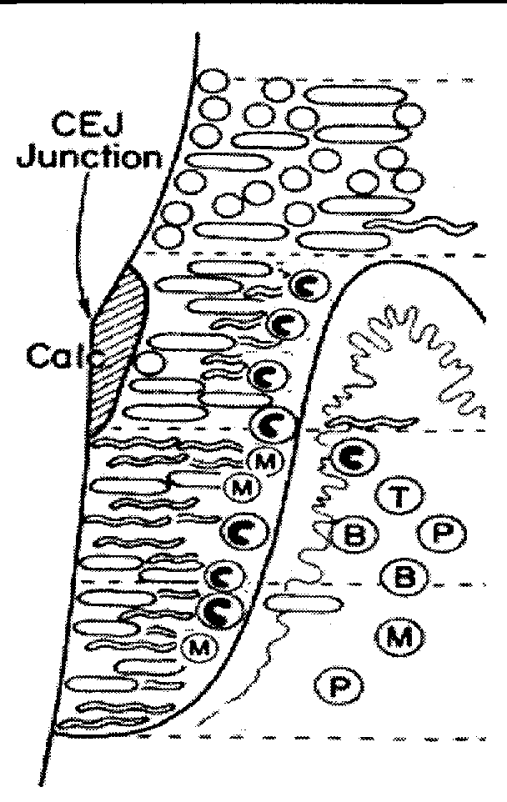

Figure 1: Immune response to oral biofilm bacteria: $T-T$ cells, B- B cells, $M-$ Monocytes/Macrophages, P- platelets and (C) -neutrophils. (Source Adapted from a figure appearing on the website of Dr. Loesche, University of Michigan) 


\section{Smoking and Periodontitis}

Smoking is the single most important risk factor for periodontitis (22). There is a dose dependent relationship between smoking status and deteriorating periodontal health (123). Smokers are highly susceptible to periodontitis and the disease is often more severe compared to non-smokers with increased alveolar bone loss (124), attachment loss, percentage of sites with significant attachment loss (125), tooth mobility, and tooth loss (126). Patients who smoke are also much more likely to be refractory to treatment than non-smokers $(88)$.

Although cigarette smoking causes both systemic and local changes, components of cigarette smoke are found at their highest concentrations intraorally and particularly in the gingival crevicular fluid - the serum-derived exudate that enters the mouth via the gingival crevice. Several studies report nicotine, and its primary metabolite cotinine, both adversely affect proliferation, attachment and chemotactic responsiveness in human periodontal ligament fibroblasts $(127,128)$. Nicotine induced stress response in these cells is characterized by elevated levels of c-fos expression (129). Arecoline, another toxic component in cigarette smoke, significantly inhibits cell proliferation in a dosedependent manner and depletes intracellular thiol levels. Thiols are protective against oxidative damage and their depletion may increase susceptibility to oxidative damage by oxidants present in cigarette smoke (130). In human gingival fibroblasts, nicotine and cigarette smoke condensate both promote membrane-associated MMPs-dependent collagen degradation, which may promote attachment loss $(131,132)$. Chronic angiogenic suppression and reduced oxygen tensions (133) also contributes to tobaccoinduced predisposition to periodontal disease. However, very little is known about how 
tobacco smoke affects periodontal pathogens and, particularly, host-pathogen interactions.

Despite some conflicting data that smoking may not influence the sub-gingival micoflora (134-137), the balance of recent data strongly suggests that tobacco-induced susceptibility to periodontitis is associated with shifts in the microbial composition of complex periodontal plaque communities $(72,138-145)$. For example, Zambon et al showed a higher prevalence of Aggregatibacter actinomycetemcomitans, Tannerella forsythia and Porphyromonas gingivalis in smokers (138). Umeda et al (142) reported an increased risk for harbouring Treponema denticola in smokers. Haffajee and Socransky (146) showed an increased prevalence of eight species, including $P$. gingivalis, in current smokers, while Eggert et al (141) have shown a higher prevalence and proportion of $T$. forsythia, Campylobacter rectus, P. gingivalis and Peptostreptococcus micros in plaque samples from smokers. $P$. gingivalis is found in significantly higher numbers in smokers compared to non-smokers and the infection is more persistent $(88,147)$. The evidence for tobacco smoke increasing susceptibility to $P$. gingivalis infection and in increasing the $P$. gingivalis infectious load is particularly strong.

Thus tobacco smoke alters the oral biofilm bacterial composition while simultaneously dysregulating host immune response. A summary of cigarette smoke induced alterations in the context of periodontal disease are shown in Figure 2. 


\section{CSE}

\section{Biofilm}

- Increased virulence factor

expression

- e.g. proteases

- e.g. fimbriae

- e.g. Rag antigens

- Altered LPS structure

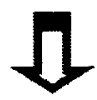

Effects

- Decreased innammatory potential

- Increased virulence

\section{Host Response}

- Increased MMP secretion

- Increased osteoclast activation

- Decreased phagocytic killing

- Decreased IgG production

- Decreased cytokine production

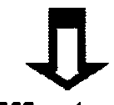

Effects

- Decreased inflammatory potential

- Increased destructive capacity
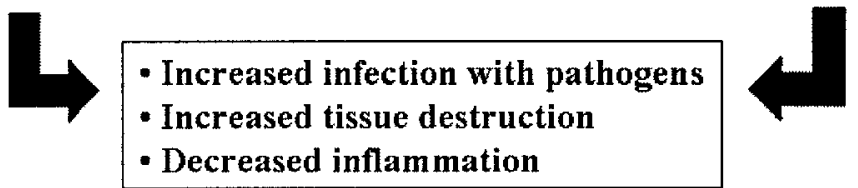

Figure 2: Summary of effects of cigarette smoke and cigarette smoke extract (CSE) on periodontal bacteria, host cells and tissues.

\section{Porphyromonas gingivalis}

Porphyromonas gingivalis is a Gram-negative, proteolytic, asaccharolytic anaerobe associated with chronic periodontitis in humans $(148,149)$. It is an opportunistic pathogen and colonizes the gingival cavity via several key virulence factors such as gingipains, fimbriae, lipopolysaccharide (LPS), capsule, hemagglutinins and other outer membrane proteins which aid in attachment and invasion, degradation of extracellular matrix proteins, and circumvention of a normally strong pro-inflammatory 
response to infection $(150,151)$. The major $P$. gingivalis virulence factors are discussed in the next section.

\section{Major fimbrial antigen (FimA)}

The major fimbriae of $P$. gingivalis are long $(0.5-1 \mu \mathrm{m}(152))$, hair-like, peritrichous, adhesive, filamentous structures that project away from the cell surface and are primarily comprised of a $41 \mathrm{kD}$ protein (FimA, fimbrillin) encoded by the FimA gene (153). Based on the genomic variations in FimA gene, fimbriae are classified into Types I, II, III, IV and V (150). P. gingivalis strains with Type II fimbriae are most commonly associated with periodontitis and have been found to be more virulent in mouse models of systemic infection compared to TypeI/IV carrying strains (154). Several accessory proteins also associate with the major fimbriae such as Fim C, D and E encoded by genes downstream of FimA gene in the FimA operon $(155,156)$. FimCDE deficient strains show reduced invasion and persistence in macrophages and induce diminished bone loss in mouse models of periodontitis (157).

P. gingivalis major fimbriae are essential virulence factors in host colonization. Fimbriae mediate adhesion to several host proteins such as fibronectin, laminin, collagen, and salivary proteins (158); aid attachment to, and invasion of, oral epithelial cells, endothelial cells and gingival fibroblasts $(159,160)$; co-aggregate with other plaque bacteria (161); are key in internalization and persistence in macrophages through exploitation of complement receptor 3 (CR3) (162); induce pro-inflammatory cytokines such as TNF- $\alpha$, IL-6, but inhibit IL-12 in monocytes and macrophages, thus limiting immune clearance (163). They are thought to directly induce alveolar bone loss in murine 
models $(164,165)$. Several studies have delineated their role in upregulating adhesion molecules such as ICAM-1, VCAM-1, P- and E-selectins in endothelial cells (166). However, their capacity to induce pro-inflammatory mediators from immune cells is controversial. The ability of FimA to generate an inflammatory response might be cell type dependent. Contrary to human monocytes, primary human gingival epithelial cells stimulated with purified FimA from $P$. gingivalis 33277 failed to generate a proinflammatory response as indicated by low levels of IL-6 and IL-8 (167). Fimbriaedeficient strains are also found to be as inflammatory as wildtype strains in mouse scalp challenge model indicating FimA is not entirely responsible for the inflammatory response associated with $P$. gingivalis (168).

Minor Fimbrial Antigen (Mfa1)

The minor fimbriae of $P$. gingivalis are shorter filaments $(18-120 \mathrm{~nm}-(169))$ composed of a $67-\mathrm{kDa}$ protein encoded by the $m f a l$ gene (170). Mfal is co-transcribed with Mfa2, the product of the $m f a 2$ gene, which is postulated to be important in anchoring Mfal in the $P$. gingivalis membrane and in regulating fimbrial length (171). Native minor fimbriae have been shown to contain several putative glycosylation sites (172).

The role of $\mathrm{Mfal}$ in $P$. gingivalis virulence is beginning to be elucidated. Mfal is key in co-adhesion to the primary periodontal colonizer, Streptococcus gordonii, through specific interaction between Mfal and the SspB protein expressed on the surface of $S$. gordonii (173). Mfal is also important in single species biofilm maturation and microcolony development (174). Unlike FimA, Mfal is highly inflammatory and 
induces IL-6, IL-1 $\beta$, TNF- $\alpha$ in mouse peritoneal macrophages, endothelial cells (175, 176) and is associated with alveolar bone loss in various mouse models of periodontitis

$(164,165)$. Zeituni et al have shown, using $m f a l$-deficient strains of $P$. gingivalis, that minor fimbriae are important in internalization by monocyte-derived dendritic cells through interaction with surface DC-SIGN. Such Mfal-dependent targeting into DCSIGN-rich intracellular compartments results in lowered inflammatory cytokine levels thus preventing DC maturation and inducing a Th2 biased immune response (177).

\section{$\underline{P . \text { gingivalis LPS }}$}

P. gingivalis is an important virulence factor recognized by the host receptors TLR4 and TLR2 $(178,179)$. It is associated with inflammatory cytokine production in human gingival fibroblasts (HGF) (180), macrophages (181), and neutrophils $(182,183)$, as well as direct osteoclast activation and promotion of bone resorption in several in vitro and in vivo models (184). It has also been implicated in increasing the risk for other systemic conditions in periodontitis patients such as atherosclerosis by inducing foam cell formation in murine macrophages (185).

$P$. gingivalis LPS is atypical in structure, consisting primarily of tetra- and pentaacylated Lipid A with one or two phosphate groups. Unlike E. coli LPS (the canonical TLR4 agonist), P. gingivalis LPS displays significant amount of Lipid A structural heterogeneity, such as differing numbers of phosphate groups, amounts and positions of fatty acids and variations in acyl chain lengths (178). These structural alterations can be strain specific and / or altered according to environmental conditions but are directly responsible for variations in the immune response to $P$. gingivalis LPS (186). Both 
penta- and tetracylated forms of lipidA present are recognized by TLR4, however it is the pentaacylated form that is associated with NF- $\mathrm{kB}$ activation and E-selectin upregulation in endothelial cells $(187,188)$. Tetraacylated forms can antagonize TLR4 activation and may be responsible for modulating and / or subverting the host inflammatory response (as reviewed by Hajishengallis (189)).

$P$. gingivalis LPS is significantly less inflammatory than $E$. coli LPS. Various mechanisms have been proposed to explain the lower biological activity of $P$. gingivalis LPS, such as decreased affinity for LPS-binding protein (LBP) and subsequent recognition by TLR4 (186); increased activation of transcriptionally inactive p50 subunit of NF- $\mathrm{kB}$ rather than $\mathrm{p} 65$ subunit which is associated with transcription of proinflammatory genes in Monocyte derived Dendritic cells (MoDCs) (190); reduced activation of IRAKI and increased production of IRAK-M (negative regulator of TLR signaling) (191).

\section{$\underline{P . \text { gingivalis Capsule }}$}

Some strains of $P$. gingivalis produce an extracellular capsule composed of negatively charged polysaccharide residues. This capsular layer provides resistance against phagocytic clearance by neutrophils (192) and complement-mediated lysis or opsonization (193). Except for a recent report by Brunner et al (194) stating that the presence of capsule reduced inflammatory response to $P$. gingivalis in human gingival fibroblasts, the literature ascribes highly pro-inflammatory potential to $P$. gingivalis capsule, which is associated with increased abscess formation, compared to nonencapsulated strains, in animal models of systemic infection $(195,196)$. Dentritic cells 
challenged in vitro with encapsulated strains of $P$. gingivalis (K1-K6 serotypes) produces a proinflammatory response associated with elevated levels of IL-1 $1 \beta$, IL-6, IL-12p35, IL$12 \mathrm{p} 40$, and IFN- $\gamma$. The $\mathrm{K} 1$ serotype of $P$. gingivalis W83, used in our microarray experiments, was found to be most inflammatory of all $P$. gingivalis capsule subtypes (197).

Long-term exposure to capsular polysaccharides is associated with a decreased ability of periodontal ligament fibroblasts to attach to the tooth root surface (198). $P$. gingivalis serotype K5 capsular polysaccharide mediates co-aggregation between $P$. gingivalis and another periodontal pathogen, Fusobacterium nucleatum (199). Furthermore, mice immunized with purified $P$. gingivalis capsular polysaccharides elicited a strong humoral response and were protected from oral bone loss on secondary challenge with the whole bacterium (196). The presence of capsular polysaccharides, thus, is important in $P$. gingivalis virulence and likely contributes to the progression of periodontitis.

\section{$\underline{P .}$ gingivalis Proteases (Gingipains)}

P. gingivalis produces trypsin-like cysteine proteases - the Arg- and Lysgingipains encoded by $\operatorname{rgp} A, \operatorname{rgp} B$, and $\operatorname{kgp}$ genes. Gingipains play a role in multiple virulence mechanisms of $P$. gingivalis. In addition to providing energy through degradation, and subsequent metabolism, of extracellular matrix proteins and stimulating the expression of matrix metalloproteinases (MMPs), they subvert the host response by degrading cytokines, complement proteins and several key immune receptors, including macrophage CD14 and T cell CD4 and CD8 receptors. Moreover they perpetuate 
inflammation and activate the blood coagulation system, enhancing vascular permeability, promoting gingival edema and inducing platelet aggregation (as reviewed by $(200,201))$.

\section{Smoking and inflammatory response in Periodontitis}

Chronic exposure to tobacco smoke adversely affects host reponse in periodontitis. More than $50 \%$ of cases of periodontitis are found in current or ex-smokers. Tooth and bone loss in smokers is directly influenced by tobacco consumption in a dose dependent manner (202). Contrary to the increased severity of disease, smokers consistently show reduced signs of clinical inflammation such as bleeding on probing, gingival redness (203) accompanied by reduced levels of pro-inflammatory markers (47, $133,204)$.

Inflammatory dysregulation in smokers can be attributed to the debilitating effects of tobacco smoke on both innate and adaptive immune responses. Smoking is associated with inappropritate activation of neutrophils (205), neutrophil elastase and matrix metalloproteinases release (206-208); inhibition of key endogenous protease inhibitors (al-antitrypsin and a2-macroglobulin) (209) contributing to destruction of gingival tissues. Periodontal breakdown in smoking patients has recently been associated with increased T-cell proliferation (210). Furthermore, smoking contributes to alveolar bone loss (and osteoporotic bone resorption) by promoting the differentiation and activation of osteoclasts (211-213) and it may also adversely influence fibroblasts by inhibiting cell proliferation and attachment $(127,130)$. Thus, inflammatory dysregulation is an 
important contributing factor to the increased severity of periodontitis and is likely to influence disease progression in periodontitis.

Tobacco smoke components are readily available in the gingival crevicular fluid and are likely to alter the host pathogen interactions of plaque bacteria. Smoking causes a shift in the normal microbial flora, increased prevalence, numbers and persistence of $P$. gingivalis in infected individuals (47). Thus it is likely that the tobacco smoke influences $P$. gingivalis virulence in smokers while maintaing inflammatory response suppression. While several studies delineate the different mechanisms of how tobacco smoke alters host response to periodontitis very little is known about its effects on the virulence profile of $P$. gingivalis.

Our main objective in this dissertation was to identify differentially expressed proteins and lipids of $P$. gingivalis regulated by cigarette smoke focusing primarily on secreted and cell surface components since these represent likely candidates that can influence virulence and interactions with host tissues. Membrane proteins play an essential role in colonization, biofilm formation and development of disease as well as the immune response to $P$. gingivalis while gingipain activity is central to many aspects of $P$. gingivalis physiology and contributes to nutrient acquisition, virulence and the processing of cell surface components. Thus cigarette smoke induced changes in the key pathogenic determinants of $P$. gingivalis are likely to alter host pathogen interactions in a manner that promotes reduced inflammatory response but increased infection.

Our main hypothesis is that tobacco smoke presents an environmental stress to which $P$. gingivalis adapts by altering its gene expression and altering phenotypic traits that are likely to influence host-pathogen interactions. Our studies would help determine 
how $P$. gingivalis responds to cigarette smoke at the molecular level and delineate the mechanisms that contribute to the observed suppression of inflammatory response in smokers. 


\section{CHAPTER TWO: MATERIALS AND METHODS}

\section{Reagents and antibodies:}

DMEM, RPMI 1640 and keratinocyte-serum-free (KSF) media, Dulbecco's PBS, bovine pituitary extract, Amphotericin B and Nu-Page 4-12\% Bis-Tris gels and all other SDS-PAGE chemicals were obtained from Invitrogen (Carlsbad, CA). FBS came from HyClone (Logan, UT). THP-1, THP-1 Blue, TLR-transfected Human Embryonic Kidney (HEK) 293 and vector control cells as well as Pam3CSK4, FSL, LPS, normocin, blastocidin, zeocin, hygrogold and QUANTI-Blue NF- $\mathrm{kB}$ assays were purchased from Invivogen (San Diego, CA). Penicillin-streptomycin came from Mediatech (Manassas, VA). RIPA buffer, PhosSTOP and complete Mini EDTA-free protease inhibitor cocktail tablets were bought from Roche (Indianapolis, IN). BCA Protein Assay kits came from Pierce (Rockford, IL). SuperSignal West Pico Chemiluminescent Substrate kits and Bacterial Protein Extraction Reagent (B-PER) were purchased from Thermo Scientific (Rockford, IL). FimA-specific antibodies were custom generated by Cocalico Biologicals, Reamstown, PA, while FITC-labeled mouse anti- human CD16b and mouse IgM-FITC isotype control antibodies came from AbD Serotec (Oxford, UK). The E38 
monoclonal anti-RagB antibody was a kind gift of Dr. Mike A. Curtis of The London, Queen Mary's School of Medicine and Dentistry, UK. Fibronectin pre-coated microplates were from BD Biosciences (San Jose, CA). Anti- $P$. gingivalis antibodies were generated in house, while HRP-linked anti-rabbit IgG and all other antibodies were purchased from Cell Signaling Technology (Beverly, MA). Gifu anaerobic medium (GAM) was bought from Nissui Pharmaceuticals (Tokyo, Japan). Lymphocyte separation medium (LSM) was purchased from MP Biologicals (Solon, OH). Dextran, PBS and tetramethylbenzidine were obtained from Fisher Scientific (Fair Lawn, NJ), EDTA from AA Hoefer Inc. (San Francisco, CA), while trypan blue, insulin, transferrin, 2mercaptoethanol, 2-aminoethanol, sodium selenite, proteinase $\mathrm{K}$ acrylic beads and phosphotongstic acid were purchased from Sigma-Aldrich (St. Louis, MO). HiTrap Chelating HP affinity columns came from Amersham Biosciences Corp., (Piscataway, NJ). Isopropyl-p-D-thiogalactopyranoside (IPTG) was bought from RPI Corporation (Prospect, IL). Limulus amoebocyte lysates assay kit was purchased from Cape Cod Inc. (Falmouth, MA). IL-8 ELISA kits were from Cell Sciences (Canton, MA). TNF- $\alpha$, IL-6 and IL-10 ELISA kits and FITC conjugated anti-human TLR2 and appropriate istoype control antibodies were purchased from eBioscience (San Diego, CA). Formavar coated copper grids were from Electon Microscopy Sciences (Hatfield, PA). Finally, standard reference cigarettes were obtained from the Kentucky Tobacco Research and Development Center (Lexington, KY).

Lysozyme was purchased from Sigma, St. Louis, MO; RNA Midi and PCR purification kits from Qiagen, Valencia, CA; random hexamers from Biosynthesis, Lewiston, TX; RT buffer, DTT, RT-PCR mastermix and Superscript II from Invitrogen, 
Carlsbad, CA; 2:3 aminoallyl dUTP:dTTP ratio labeling mix from Amersham Biosciences, Piscataway, NJ. P. gingivalis W83 microarrays were obtained from The J. Craig Venter Institute through the NIDCR Oral Microbe Microarray Initiative (NOMMI).

\section{Bacterial culture and in vitro modeling of tobacco exposure:}

Porphyromonas gingivalis W83 and ATCC 33277 were purchased from the American Type Culture Collection (Manassas, VA) and maintained as frozen stocks. $P$. gingivalis was grown in GAM or GAM conditioned with CSE (GAM-CSE) under anaerobic conditions $\left(80 \% \mathrm{~N}_{2}, 10 \% \mathrm{H}_{2}, 10 \% \mathrm{CO}_{2}\right)$ at $37^{\circ} \mathrm{C}$ in a Coy Laboratories anaerobic chamber. Bacteria were harvested at mid- to late-exponential phase (O.D. of 1 corresponds to $10^{9}$ cells $\mathrm{ml}^{-1}$ ). To prepare GAM-CSE, cigarette smoke was drawn through $50 \mathrm{ml}$ GAM by using a three-way stopcock and a syringe, with $35 \mathrm{ml}$ 'drags' performed over a period of $2 \mathrm{sec}$, one drag every $2 \mathrm{sec}$. Cigarette smoke extractconditioned medium was filtered $(0.22 \mu)$, and adjusted to $\mathrm{pH} 7.2$. The nicotine content of GAM-CSE was determined by gas-liquid chromatography, as previously described (214) and GAM-CSE adjusted to physiologically relevant doses (214-217). Unless otherwise noted, GAM-CSE was employed at a concentration of $4000 \mathrm{ng}$ nicotine equivalents $/ \mathrm{ml}$. For all experiments $P$. gingivalis was either cultured in GAM or CSE for two passages. CSE grown $P$. gingivalis was cultured back in GAM for two more passages for the reconditioned group.

\section{Human PBMC, neutrophil and gingival epithelial cell isolation and maintenance:}

Human peripheral blood mononuclear cells (PBMCs) were isolated from de- 
identified whole, citrated (10\%) venous blood obtained from healthy donors by separation and collection of buffy coat and elimination of erythrocyte contamination with Histopaque 1077 density gradients, as previously described (218). Written informed consent was obtained from all the donors, and studies performed in compliance with University of Louisville, Institutional Review Board, Human Subjects Protection Program, (study number 503.05). Viability of all cells was routinely $>98 \%$, as determined by trypan blue exclusion. PBMCs were maintained in RPMI-1640 supplemented with $10 \%$ heat inactivated FBS, $100 \mathrm{u} / \mathrm{ml}$ penicillin G and $100 \mu \mathrm{g} / \mathrm{ml}$ streptomycin, at $37^{\circ} \mathrm{C}, 5 \% \mathrm{CO}_{2}$. Cells were allowed to rest overnight before addition of agonists.

Neutrophils were isolated from the erythrocyte-neutrophil pellet by collection from 1\% Dextran- DPBS suspensions and elimination of erythrocyte contamination by hypotonic lysis. On restoring isotonicity, cells were washed once with cold DPBS and once with plasma buffer (2\% plasma in DPBS). Neutrophils were suspended in RPMI1640 supplemented with $10 \%$ heat inactivated FBS, $100 \mathrm{u} / \mathrm{ml}$ penicillin $\mathrm{G}$ and $100 \mu \mathrm{g} / \mathrm{ml}$ streptomycin, at $37^{\circ} \mathrm{C}, 5 \% \mathrm{CO}_{2}$. Viability was routinely $>98 \%$, as determined by trypan blue exclusion. Purity of neutrophils was routinely $>95 \%$, as determined by flow cytometry using FITC-labeled anti-CD16b.

The human gingival epithelial cell line, OBA-9, was obtained from Dr. Denis Kinane (University of Pennsylvania, PA) and maintained at $37^{\circ} \mathrm{C}, 5 \% \mathrm{CO}_{2}$ in $\mathrm{KSF}$ medium supplemented with $10 \mu \mathrm{g} / \mathrm{ml}$ of insulin, $5 \mu \mathrm{g} / \mathrm{ml}$ of transferrin, $10 \mu \mathrm{M} \mathrm{2-}$ mercaptoethanol, $10 \mu \mathrm{M}$ of 2-aminoethanol, $10 \mathrm{nM}$ of sodium selenite, $50 \mu \mathrm{g} / \mathrm{ml}$ of bovine pituitary extract, $100 \mathrm{units} / \mathrm{ml}$ of penicillin/streptomycin and $50 \mathrm{ng} / \mathrm{ml}$ 
Amphotericin B.

\section{TNF- $\alpha$ release from $P$. gingivalis-stimulated PBMCs:}

PBMCs $\left(0.5 \times 10^{6}\right.$ cells per well) were stimulated with $10^{6}-10^{9} P$. gingivalis grown in GAM or GAM-CSE. Cell-free supernatants were harvested by centrifugation and TNF- $\alpha$ cytokine levels were determined by ELISA.

\section{$P$. gingivalis W83 microarrays:}

P. gingivalis W83 microarrays were obtained from The J. Craig Venter Institute through the NIDCR Oral Microbe Microarray Initiative (NOMMI). To determine how exposure to CSE influences the activity of the $P$. gingivalis genome, we compared gene expression in $P$. gingivalis W83 grown in control (GAM) and conditioned (CSE-GAM) media. Microarrays were performed on triplicate GAM and GAM-CSE cultures. Total RNA from control and experimental cultures was isolated by extraction from washed cells with hot phenol followed by chloroform extraction and isopropanol precipitation. RNA was purified and genomic DNA was removed using a Qiagen Midi kit with oncolumn DNAse treatment followed by further digestion with RNAse-free DNAse to remove any trace contamination of genomic DNA. The synthesis of labeled cDNA was carried out by methods established by The J. Craig Venter Institute (www.jcvi.org). Briefly, 2-2.5 $\mu \mathrm{g}$ of total RNA was mixed with 500ng of random hexamers, incubated at $70^{\circ} \mathrm{C}$ for $10^{\prime}$ and transferred to ice. A $50 \times 2: 3$ aminoallyl dUTP:dTTP ratio labeling mix containing $25 \mathrm{mM}$ remaining nucleotides, $5 \mathrm{x}$ RT buffer, $3 \mu \mathrm{l}$ of $0.1 \mathrm{M}$ DTT and $2 \mu \mathrm{l}$ Superscript II $(200 \mathrm{U} / \mu \mathrm{l})$ were added. Samples were then incubated for $10^{\prime}$ at room temperature and transferred to $42^{\circ} \mathrm{C}$, overnight. Reactions were stopped with $10 \mu \mathrm{l}$ of $1 \mathrm{~N}$ 
$\mathrm{NaOH}$ and $10 \mu \mathrm{l}$ of $0.5 \mathrm{M}$ EDTA for $15^{\prime}$ at $65^{\circ} \mathrm{C}$ and neutralized with $25 \mu 11 \mathrm{M}$ Tris, pH 7.4. Unincorporated aa-dUTP and free amines were removed using a Qiagen QIAquick PCR purification kit protocol with phosphate buffers. The cDNA was then dried down in a speed vacuum and resuspended in $4.5 \mu \mathrm{l}$ of $0.1 \mathrm{M}$ sodium carbonate buffer, $\mathrm{pH}$ 9.0. The appropriate NHS-ester Cy3 or Cy 5 dye in DMSO was added $(4.5 \mu 1)$ and the reaction incubated at room temperature in the dark for 2 hours. The reaction was neutralized by adding $35 \mu \mathrm{l}$ of $100 \mathrm{mM}$ sodium acetate, $\mathrm{pH} 5.2$. The labeled cDNA was purified to remove any uncoupled dye using the Qiagen PCR purification kit with Minelute columns and an extra wash. The labeled cDNA was quantified and evaluated by spectrophotometry and equivalent pmol of $\mathrm{Cy} 3$ and Cy5 samples were combined, dried down, and stored at $-80^{\circ} \mathrm{C}$. Hybridization and subsequent analysis of the arrays was carried out following protocols established by The J. Craig Venter Institute, essentially as described by (219). Arrays were pre-hybridized at $42^{\circ} \mathrm{C}$ for $1 \mathrm{hr}$ in $5 \times \mathrm{SSC} / 0.1 \% \mathrm{SDS} /$ $1 \%$ BSA and washed several times with MilliQ water. Washed arrays were then dipped into isopropanol and dried by centrifugation at $1000 \mathrm{rpm}$ for 10 minutes. For hybridization, Cy $3 / \mathrm{Cy} 5$ probe mixtures were suspended in $50 \mu$ l hybridization buffer ( $50 \%$ formamide, $5 \times \mathrm{SSC}, 0.1 \% \mathrm{SDS}, 0.1 \mathrm{mM}$ DTT, $0.56 \mu \mathrm{g} / \mathrm{ml}$ sheared salmon sperm DNA), heated then applied to the array under a Lifter $^{\mathrm{TM}}$ cover slip. The array was incubated at $42^{\circ} \mathrm{C}$ in a sealed chamber for $15-20 \mathrm{hr}$. After hybridization, the array was washed twice in $2 \times \mathrm{SSC} / 0.1 \% \mathrm{SDS}$ at $55^{\circ} \mathrm{C}$, twice in $0.1 \times \mathrm{SSC} / 0.1 \% \mathrm{SDS}$, once with 0.1 x SSC, water rinsed, and dried. Arrays were then scanned using an Axon slide reader, scanning in the Cy5 channel and the Cy3 channel. Identification and calculation of spots was carried out using the TIGR Spotfinder software 
(http://www.jcvi.org/cms/research/software/). Subsequent normalization of fluorescent data was conducted using TIGR-MIDAS (also freely available from TIGR). Subtraction of local background and integration of $\mathrm{Cy} 5$ and $\mathrm{Cy} 3$ fluorescent intensities was calculated using Excel. Array experiments were carried out in triplicate using independently isolated RNA samples. Genes that are up- or down-regulated by greater than 2 -fold in the postnormalized consensus were classified as differentially expressed, as presented and further detailed in Figure 3.

\section{Validation of array data:}

Differentially expressed genes of interest were confirmed by quantitative realtime reverse transcription-PCR using an Applied Biosystems 7500 Real-Time PCR system, essentially as described previously (220). Primers were designed using the realtime PCR primer design software provided by GenScript (www.genscript.com/sslbin/app/primer):

PG1055 (F: CCTACAGATTGGAGGTGGCT, R: ATAGGCATGGTATGCTGCAA); PG2102 (F: ATCGTTTGGTCTGATACGCA, R: CTGCACGTTCAGCCTGTATT); PG2100 (F: ATTACAAGATGGCTGTGGCA, R: TGCTGTCATGACTGTCCAAA); PG2008 (F: ATTCTTAGGAACGAGCGCAT, R: GGGATTCCCTTGATCGAGTA); PG1286 (F: AGCGATCAATGACCAAATCA, R: CACGGCATCGATAGCTTCT); PG1552 (F: GATTTGAAGCCGGAGAAGAG, R: TAAGGCAGTACCACATTCGC); PG0111 (F: AGGCAACGGAGAAGTATCGT, R: AAAGCACCATCAATGACGAA); PG1432 (F: ACAGCTCGAACTGCATCAAC, R: CTGCATATAAGTGCGGGCTA); PG0117 (F: TCTCGAACGACCAATAGTGC, R: CATTCTCTGCAATCGGCTTA); 
PG2132 (F: GTAAATCTGGAGCCAACCGT, R: CGAGTAACGGCAAGAGGAGT); and

PG1548 (F: TGGAAGATGCCTCATGGATA, R: GTAATGCTGAAAGTCGGCAA).

\section{P. gingivalis $\mathrm{W} 83$ outer membrane protein profiling:}

Outer membrane preparations were obtained from $P$. gingivalis cells grown in GAM or GAM-CSE. Briefly, the cell pellet was suspended in $10 \mathrm{mM}$ Tris, pH 7.5, $1 \mathrm{mM}$ EDTA (TE) containing $100 \mu \mathrm{g} / \mathrm{ml}$ lysozyme and protease inhibitor cocktail and was incubated for 15 minutes at $25^{\circ} \mathrm{C}$. The cell suspension was sonicated three times on ice and cellular debris was removed by centrifugation at $1000 \mathrm{xg}$ for 10 minutes. The supernatant was subsequently centrifuged at $100,000 \mathrm{xg}$ for 60 minutes. The membrane pellet was suspended in $5 \mathrm{mls} \mathrm{TE}$ containing $0.5 \mathrm{M} \mathrm{NaCl}$ and centrifuged again at 100,000 $\mathrm{x} \mathrm{g}$ for 60 minutes. After discarding the supernatant, the membrane pellet was suspended in $5 \mathrm{ml} \mathrm{MgCl} 2$ containing $1 \%$ Triton X-100. Triton X-100 insoluble material was then collected by centrifugation at $100,000 \mathrm{xg}$. The resulting outer membrane fraction was suspended in TE containing $0.5 \%$ SDS and analyzed by PAGE. Outer membrane preparations ( $20 \mu \mathrm{g}$ protein) were electrophoresed through 4-15\% gradient SDS-PAGE gels and protein bands were visualized by staining with Coomassie brilliant blue R-250. Gel image analysis and densitometry were performed using the Kodak 4000MM Image Station system (Eastman Kodak, New Haven, CT). Protein identification was achieved by excision of the protein bands of interest (see Figure 8) from SDS-PAGE gels, followed by in-gel trypsin digestion, peptide preparation, MALDI-MS analysis, and 
bioinformatic identification by peptide mass fingerprinting using the core facilities at the University of Louisville core proteomics laboratory.

\section{Expression of RagB in response to CSE:}

$P$. gingivalis cells were sequentially passaged in GAM, GAM-CSE and or reconditioned back in GAM, respectively. Bacterial cells were lysed $(10 \mathrm{mN}$ Tris, $100 \mathrm{mM}$ $\mathrm{NaCl}$ and $1 \mathrm{mM}$ EDTA) and probed by western blot (20 $\mu \mathrm{g}$ protein per lane). Total protein estimated using a BCA protein assay kit. MAbE38, an anti-RagB antibody, was a kind gift from Mike A. Curtis. Anti-Rabbit HRP-linked IgG was used as the secondary antibody. Probing and visualization of immunoreactive bands was performed by chemiluminescence using SuperSignal West Pico Chemiluminescent Substrate kit as per the manufacturer's protocol. Gel image analysis and densitometry were performed using the Kodak 4000MM Image Station system.

\section{Analysis of capsule production and FimA expression on CSE-exposure:}

Mid- to late-log phase $P$. gingivalis, grown in GAM or GAM-CSE, were mounted on a formvar-coated copper grid, negatively stained with phosphotungstic acid at $\mathrm{pH} 7.0$, and the bacteria visualized using a Philips CM-10 Transmission Electron Microscope. Total $P$. gingivalis lysate $\left(1 \times 10^{5}\right.$ mid-late $\log$ cells $)$ for Western blots were obtained from cells passaged twice in GAM, twice in GAM-CSE, or twice in GAM-CSE then reconditioned in fresh GAM. Western blots were probed with rabbit anti-FimA sera and HRP-linked anti-rabbit IgG. Immunoreactive bands were visualized by chemiluminescence. Imaging and densitometry were performed using the Kodak 
4000MM Image station.

\section{Analysis of FimA binding activity and surface availability:}

Adhesion of mid- to late $\log$ phase CSE-exposed and control P. gingivalis cells to the extracellular matrix protein and FimA ligand, fibronectin, was measured by ELISA using fibronectin coated microplates plates, rabbit anti- $P$. gingivalis antibody followed by HRP-linked anti-rabbit IgG antibody and tetramethylbenzidine as the chromogenic substrate, essentially as previously described by Pierce et al (221). Similarly, surface accessibility of FimA presented on mid- to late- log phase CSE-exposed and control $P$. gingivalis cells was estimated by ELISA using rabbit anti-FimA antibody.

\section{Analysis of $P$. gingivalis biofilm formation:}

Formation of mono-species $P$. gingivalis biofilms was examined, using a similar procedure to that described by Daep et al for bi-species biofilms (222). Briefly, $P$. gingivalis cultures grown to late log phase either in GAM or GAM-CSE were introduced into BST FC 71 flow cells (Biosurface Technologies Corp., Bozeman, MT) with saliva coated cover slips at a flow rate of $6 \mathrm{ml} / \mathrm{hr}$ for $2 \mathrm{hr}$. Flow was maintained using a Manostat Carter 4/8 cassette peristaltic pump (Fisher Scientific, Suwanee, GA). Bacteria were then fed with either GAM or GAM-CSE for $48 \mathrm{hr}$. Resulting $P$. gingivalis biofilms were visualized by FITC staining. The depth of FITC-labeled $P$. gingivalis biofilm was determined on an Olympus Fluoview confocal laser scanning microscope (Olympus, Pittsburgh, PA) from 5 frames randomly chosen by FluoView (Olympus, Pittsburgh, PA). Microcolony depth was determined by performing Z-plane scans from $0 \mu \mathrm{m}$ to $50 \mu \mathrm{m}$ 
above the cover glass surface. Biofilm characteristics (depth, total surface area covered, substratum coverage, average and total thickness) were computed using Matlab v7.5.0 and Comstat (The Mathworks Inc., Natick, MA) (169).

\section{Purification of rFimA and rMfa1:}

Recombinant FimA and Mfal proteins were induced in Escherichia coli vectors containing FimA or Mfal cloned into pET-30 expression system, as previously described by Park et al. The C-terminal penta-histidine tagged recombinant proteins were induced in Escherichia coli by IPTG and purified using HiTrap chelating HP affinity columns. Purity of recombinant proteins was confirmed by SDS-PAGE. The lack of contamination by LPS, or other inflammatory mediators, was confirmed by several measures, that is, assessment of pro-inflammatory activity (TNF- $\alpha$ production by PBMCs) of recombinant proteins digested with proteinase $\mathrm{K}$ attached to acrylic beads; assessment of proinflammatory activity (TNF- $\alpha$ production by PBMCs) of recombinant proteins following boiling in $2 \%$ SDS; and the limulus amebocyte lysate assay.

\section{Pro-inflammatory profiling of FimA and Mfa1:}

$0.5 \times 10^{6}$ PBMCs or neutrophils per well were seeded in 96-well plates and stimulated with $1 \mu \mathrm{g} / \mathrm{ml} \mathrm{rFimA}$, rMfal, or TLR-specific agonists (E. coli LPS, Pam3CSK4 and FSL). TNF- $\alpha$, IL-6, and IL-10 (PBMC) and IL-8 (neutrophil) levels were determined in $24 \mathrm{hr}$ supernatants by ELISA. OBA-9 cells were seeded at $0.1 \times 10^{6}$ cells per well in 12-well plates. On reaching confluence (48 hr) the epithelial cells were 
stimulated with rFimA, rMfa1, LPS, Pam3CSK4 and FSL. 24 hr OBA-9 culture supernatants were assayed for IL-8 by ELISA.

\section{TLR-specificity of FimA and Mfa1:}

Human Embryonic Kidney (HEK) 293 cells expressing either TLR2/1, TLR2/6, TLR4, TLR4-CD14-MD2 and HEK TLR null cells were maintained at $37^{\circ} \mathrm{C}$ in $5 \% \mathrm{CO}_{2}$ in DMEM medium supplemented with $10 \% \mathrm{FBS}, 100 \mu \mathrm{g} / \mathrm{ml}$ normocin and $10 \mu \mathrm{g} / \mathrm{ml}$ blastocidin. $50 \mu \mathrm{g} / \mathrm{ml}$ hygrogold was added to the additionally to the above media for TLR4-CD14-MD2 cell maintenance. TLR activation in each cell line was measured as IL-8 induction $24 \mathrm{hr}$ post-stimulation with rFimA, rMfal or specific TLR positive control agonists.

\section{Induction of TLR2 tolerance by FimA:}

To determine if rFimA induced TLR2-specific tolerance, PBMCs $\left(1 \times 10^{6}\right.$ per well) were stimulated, or not, with $\mathrm{rFimA}(1 \mu \mathrm{g} / \mathrm{ml})$ in $5 \mathrm{ml}$ polypropylene tubes. $24 \mathrm{hr}$ culture supernatants were collected, PBMCs washed once with DPBS and re-suspended in RPMI. The cells were then restimulated with FimA, Mfa1, Pam3CSK4 or E. coli LPS (all $1 \mu \mathrm{g} / \mathrm{ml}$ ) for an additional $24 \mathrm{hrs}$. TNF- $\alpha$, IL- 6 secretion was measured by ELISA.

\section{NF-KB induction by FimA and Mfa1:}

$0.5 \times 10^{6} \mathrm{THP}-1$ Blue cells, maintained at $37^{\circ} \mathrm{C}, 5 \% \mathrm{CO}_{2}$ in RPMI supplemented with heat inactivated FBS, $100 \mathrm{u} / \mathrm{ml}$ penicillin $\mathrm{G}$ and $100 \mu \mathrm{g} / \mathrm{ml}$ streptomycin and $200 \mu \mathrm{g} / \mathrm{ml}$ zeocin, were stimulated with FimA, Mfal or TLR agonists in 96 well plates for 
24hrs. Nf-kB activation was quantified by using the QUANTI-Blue assay, according to the manufacturer's protocol.

\section{TLR2 surface expression following FimA stimulation:}

PBMCs $\left(1 \times 10^{6}\right.$ cells $)$ were treated with FimA $(1 \mu \mathrm{g} / \mathrm{ml})$ or left unstimulated for 24hrs. Surface expression or redistribution of TLR2 was quantified by flow cytometry using FITC-conjugated anti-TLR2 and istoype control antibodies.

\section{Involvement of IRAK-1, in FimA-induced TLR2 tolerization:}

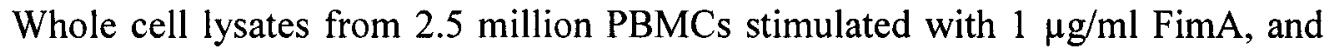
unstimulated controls, were prepared using RIPA lysis buffer with a phosphatase and protease inhibitor cocktail. Total protein was determined by BCA assay according to the manufacturer's protocol. Western blots ( $30 \mu \mathrm{g}$ protein) were probed for IRAK-1, IRAK$\mathrm{M}, \mathrm{I} \kappa \mathrm{B} \alpha$ and $\beta$-actin. Immunoreactive bands were visualized by chemiluminescence. Image analysis and densitometry were performed using the Kodak 4000MM Image Station. Band intensities were normalized to the loading control ( $\beta$-actin) and expressed as relative intensities.

\section{Statistical analysis:}

All experiments were carried out a minimum of three times, unless otherwise noted. Statistical significance between groups was evaluated by one-way nonparametric ANOVA and the Tukey multiple-comparison test using the InStat program (Graph-Pad Software, San Diego, CA). Differences between groups were considered significant at the 
level of $P<0.05$. 


\section{CHAPTER THREE: TOBACCO-INDUCED ALTERATIONS TO $P$. GINGIVALIS-HOST INTERACTIONS.}

\section{Introduction}

Cigarette smokers, and those exposed to secondhand smoke, are more susceptible to multiple infectious diseases than unexposed individuals $(58,223-227)$. Tobacco smoking is considered to be a major environmental risk factor for periodontitis, a common infectious oral disease that results in detachment of the gingival tissue cuff, destruction of the collagen attachment to the root surface of the tooth, and resorption of the supporting alveolar bone. Patients who smoke exhibit not only increased susceptibility to periodontitis but are also more likely than non-smokers to display severe disease and to be refractory to treatment (88). Although periodontitis is caused by a polymicrobial infection of the gingiva, the Gram negative, anaerobic bacterium, Porphyromonas gingivalis, has been strongly associated with diseased sites in the oral cavity and is considered to be a causative agent of chronic periodontitis $(146,228)$. In addition, $P$. gingivalis infection elicits systemic inflammation (229) and may increase susceptibility to systemic vascular diseases $(230,231)$. Multiple studies have shown that 
smokers are more likely to be infected with $P$. gingivalis, to harbor higher numbers of P. gingivalis, and to exhibit more persistent infection $(138-141,147)$ relative to nonsmokers.

Despite increased $P$. gingivalis infection rates and susceptibility to disease progression, smokers consistently display reduced clinical inflammation, measured as angiogenesis, edema, inflammatory index, and/or gingival bleeding compared to nonsmokers $(86,88,133,203,232)$. Smokers also exhibit lower levels of pro-inflammatory cytokines at diseased sites (233-237). This represents a clinical conundrum to oral health professionals who must diagnose periodontal diseases, and a scientific enigma to those attempting to understand the mechanisms underlying tobacco-induced and $/$ or exacerbated periodontitis.

It is known that tobacco smoke and specific smoke components and/or metabolites can exert a profound negative influence on the host response $(86,88,217$, 238-241). For example, previous work in the lab in myelocytic cells demonstrated that nicotine and/or its primary metabolite, cotinine, suppresses the pro-inflammatory cytokine response to $P$. gingivalis while promoting the release of the anti-inflammatory cytokine IL-10 (241). Nicotine also suppresses the production of reactive oxygen species in response to Gram negative stimuli, concomitant with a reduced capacity to kill phagocytosed $P$. gingivalis cells (242).

In contrast to what is known about host responses, there are essentially no data available on how components in cigarette smoke may influence the organisms that comprise the oral microbial biofilm. Thus, it is possible that smoking not only influences the host response but also the organisms in the dental biofilm and that the 
increased severity of periodontitis in smokers may be attributed to both of these effects. We hypothesized that cigarette smoke extract (CSE) represents an environmental stress to $P$. gingivalis and that the organism adapts to this stress by altering its pattern of gene expression. In this report, we show that the pro-inflammatory response of primary human peripheral blood mononuclear cells (PBMCs) against $P$. gingivalis is significantly reduced when the bacteria are pre-treated with CSE and that this effect was reversed when CSE treated bacteria were sub-cultured in fresh growth medium without CSE. The response of $P$. gingivalis to CSE exposure was examined using both biochemical and molecular biologic approaches. Numerous genes, including those encoding outer membrane proteins and virulence determinants were differentially expressed upon CSE exposure. These results may explain at least in part the altered virulence and hostpathogen interactions associated with cigarette smoking.

\section{Results}

\section{$P$. gingivalis growth in CSE-conditioned medium:}

To determine if a physiologically relevant dose of CSE (500 $\mathrm{ng} \mathrm{m}^{-1}$ nicotine equivalents [see Experimental Procedures]; (214-217) was overtly toxic to $P$. gingivalis W83 cells, we compared the growth rates of bacteria in CSE-conditioned and nonconditioned medium. As shown in Figure 3, similar growth characteristics were observed, suggesting that $P$. gingivalis W83 tolerates this level of CSE. Thus, for all subsequent experiments, $P$. gingivalis was cultured in medium containing $500 \mathrm{ng} \mathrm{ml}^{-1}$ nicotine equivalents. 


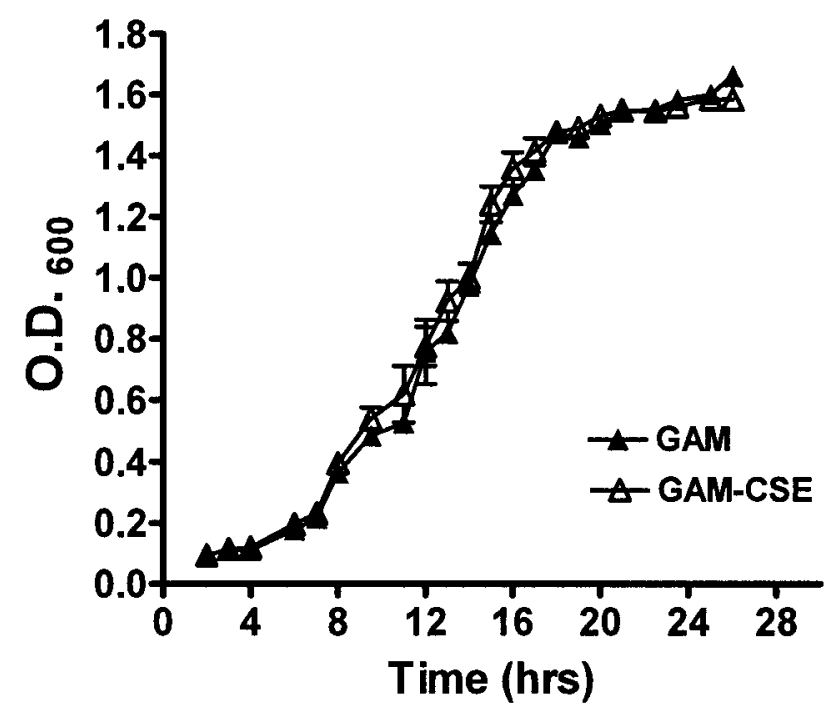

Figure 3. Effect of CSE on $\boldsymbol{P}$. gingivalis growth: Typical growth curves of $P$. gingivalis W83 in CSE conditioned and unconditioned medium. Growth of $P$. gingivalis was compared in GAM medium and GAM conditioned with CSE (500 ng ml-1 nicotine equivalents). Closed triangles represent growth in GAM. Open triangles represent growth in GAM-CSE. Error bars represent the mean (SD) of three experiments. There were no significant differences in the growth characteristics of $P$. gingivalis cultured in GAM or GAM-CSE $(P>0.05)$. 

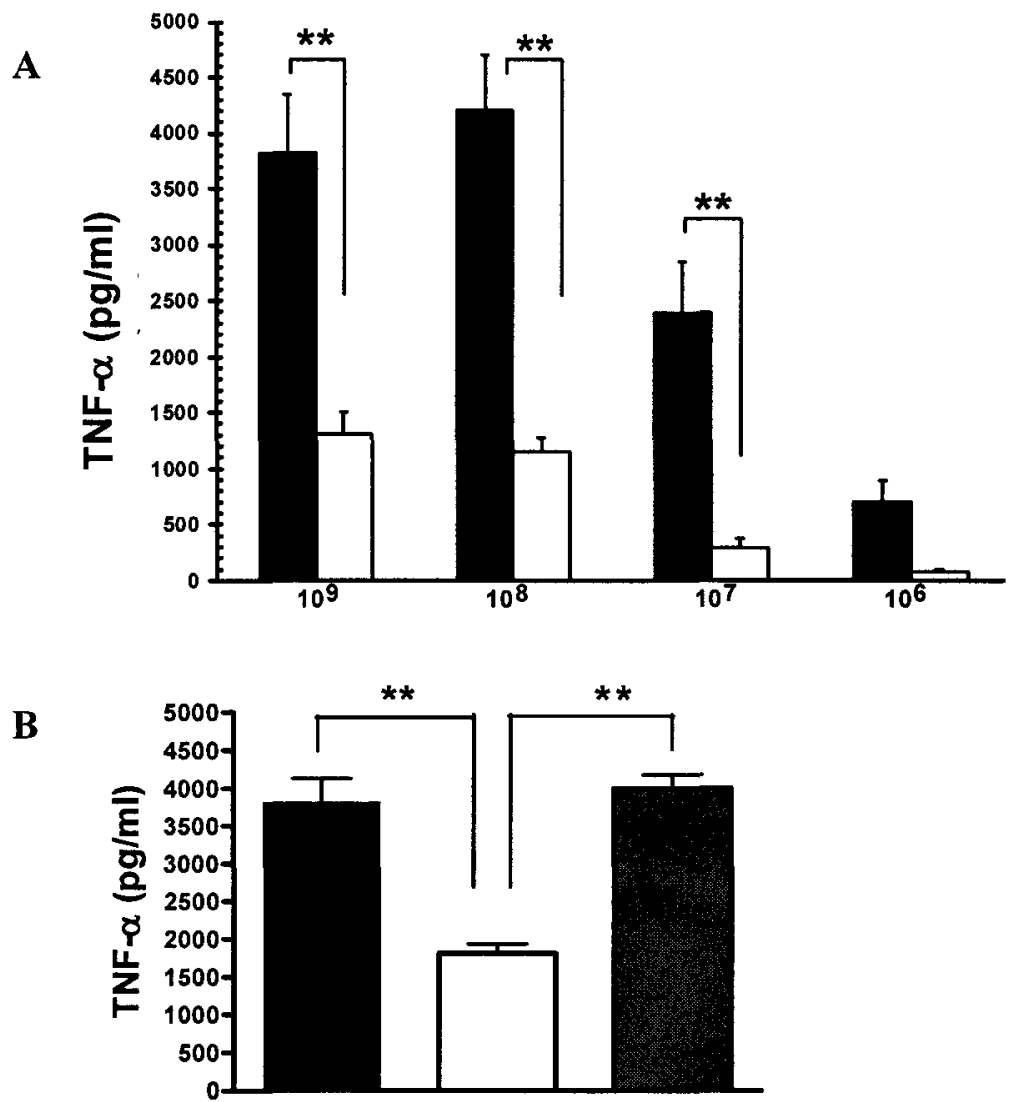

Figure 4. Reversible suppression of TNF- $\alpha$ release from human monocytes:

(A) Primary human monocytes $\left(0.5 \times 10^{6}\right)$ were stimulated with $10^{6}-10^{9}$ cells of control $P$. gingivalis (black bars) or GAM-CSE (white bars) for $20 \mathrm{~h}$ and TNF- $\alpha$ levels determined in cell-free supernatants by ELISA (** represents $P<0.01$ ). (B) Reconditioning of $P$. gingivalis in GAM rescuses pro-inflammatory potential: Primary human monocytes $\left(0.5 \times 10^{6}\right)$ were stimulated for $20 \mathrm{~h}$ with GAMcultured $P$. gingivalis (Black bars), CSE-treated $P$. gingivalis, or $P$. gingivalis cells that were first grown in GAM-CSE for two passages then reconditioned in untreated GAM for two passages (107 P. gingivalis cells). TNF- $\alpha$ levels were determined in cell-free supernatants by ELISA ( ${ }^{* *}$ represents $\left.P<0.01\right)$. 


\section{Induction of TNF- $\alpha$ release from PBMCs by CSE-exposed $P$. gingivalis:}

Evidence from in vivo studies in humans have shown that smokers exhibit reduced clinical inflammation in response to pathogenic plaque bacteria $(88,203)$ and exhibit decreased gingival crevicular fluid (GCF) concentrations of major proinflammatory mediators, such as TNF- $\alpha$ and IL-1 (233-237) and increased GCF levels of anti-inflammatory cytokines including IL-10 and TGF- $\beta 1(235,243)$. To determine if exposure of $P$. gingivalis to CSE alters its inflammatory potential, primary human PBMCs were challenged with control and CSE-treated bacteria. As shown in Figure 4a, the release of TNF- $\alpha$ was significantly lower when PMBCs were incubated with CSEtreated bacteria. Interestingly, when CSE-treated organisms were sub-cultured in fresh growth medium without CSE, their inflammatory potential increased back to the level of untreated bacteria (Figure $4 \mathrm{~b}$ ), suggesting that the CSE-induced effect is reversible. Thus, $P$. gingivalis appears to reversibly respond to CSE as an environmental stress. The production of multiple proinflammatory cytokines (TNF-a, IL-6 and IL-12 p40) by CSE-exposed and control $P$. gingivalis was also screened in PBMCs. Production of TNF- $\alpha$ and IL-12 p40 was reduced in PBMCs stimulated with CSE-exposed bacteria compared with untreated $P$. gingivalis controls and, again, the inflammatory potential of $P$. gingivalis was restored on reconditioning in fresh GAM (Fig. 5).

\section{$P$. gingivalis genes up-regulated on CSE-exposure:}

In order to further characterize the response of $P$. gingivalis to CSE-exposure, we performed microarray analyses to identify genes that are differentially expressed in CSE- 
treated versus control bacteria. A total of 104 genes (approximately $4.7 \%$ of the $P$. gingivalis genome) were found to be differentially expressed by 2-fold or more ( $\mathrm{p}<$ 0.05); 58 genes were induced and 46 were suppressed upon CSE treatment (see Figure 6). Of the 58 genes that were induced by CSE treatment, multiple genes within several predicted operons (based upon the gene annotation of the $P$. gingivalis genome sequence 
A

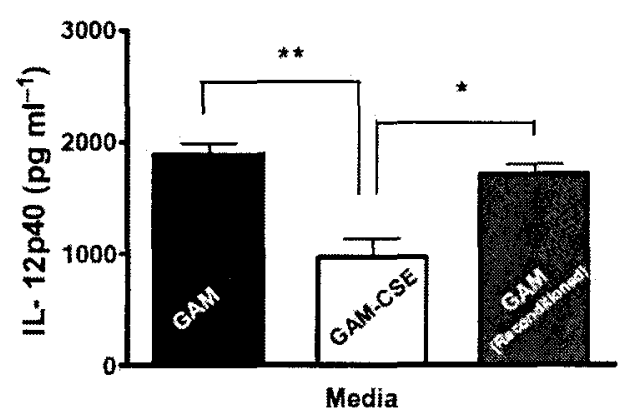

C

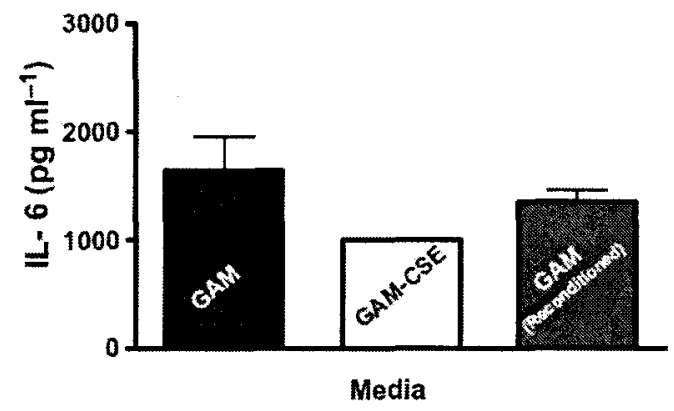

B

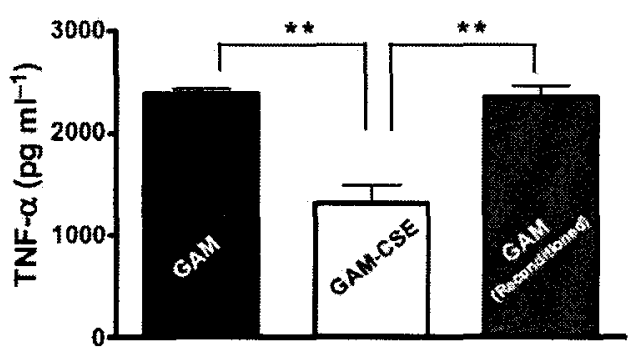

Media

Figure 5: Reversible suppression of multiple proinflammatory cytokines in human PBMCs stimulated with CSE-treated $\boldsymbol{P}$. gingivalis. Primary human PBMCs $\left(0.5 \times 10^{6}\right)$ were stimulated for $20 \mathrm{~h}$ with GAM-cultured $P$. gingivalis, CSE-treated $P$. gingivalis, or $P$. gingivalis cells that were first grown in GAM-CSE for two passages then reconditioned in untreated GAM for two passages $\left(10^{7} \mathrm{P}\right.$. gingivalis cells). PBMCs stimulated with reconditioned $P$. gingivalis produced levels of (A) IL-12p40 (B) TNF- $\alpha$ (C) IL-6, that were similar to PBMCs that were stimulated with bacteria from control cultures (not exposed to CSE). Error bars represent the mean (SD) of three experiments. One asterisk $\left(^{*}\right)$ indicates statistical significance at $P<0.05$; double asterisks $(* *)$ indicate statistical significance at $P$ $<0.01$. 
by TIGR) were identified, including the major fimbrial operon ( 2 genes), an operon encoding outer membrane antigenic lipoproteins ( 4 genes); the transfer (tra) gene cluster (4 genes) and an operon encoding an ABC transporter of unknown function [PG0682 PG0685; 3 genes]. Within the CSE-induced genes, several functional families predominate. One group of genes encode proteins that may be involved in DNA replication and repair (e.g. $\operatorname{ruvC}$ [PG1324, holliday junction endonuclease]; PG0817 encoding a putative integrase; and radC [PG0894, DNA repair protein]) or in the insertion and transposition of genetic material (e.g., traE [PG1483]; traF [PG1482]; and traK [PG1478], each encoding proteins associated with a conjugative transposon). Several other transfer genes (traG [PG1481] and traQ [PG1473]) from this same region of the P. gingivalis genome were differentially expressed but fell just below the 2-fold limit used in the analysis. In addition, several of the insertion sequences that are present in the P. gingivalis genome were differentially expressed (ISPg3 [PG0299]; ISPg5 [PG0943]; ISPg6 [PG1061].

A second group of CSE-induced genes encode proteins involved in potential pathogen-host interactions and virulence. These include several proteases (encoded by tpr, trpT and PG0317), an efflux transporter (PG0283) related to the bacterial secretion system I protein HlyD, and a putative polysaccharide transport protein related to $\mathrm{O}$ antigen flippase (PG0912). In addition, two genes encoding putative lipoproteins (PG2133 and PG2134) that are required for the assembly of the major fimbriae of $P$. gingivalis (244) were induced by CSE. These genes are co-expressed with fimA encoding the fimbrial subunit protein. Several other genes encoding cell surface or outer membrane polypeptides were also differentially expressed including the co-expressed 


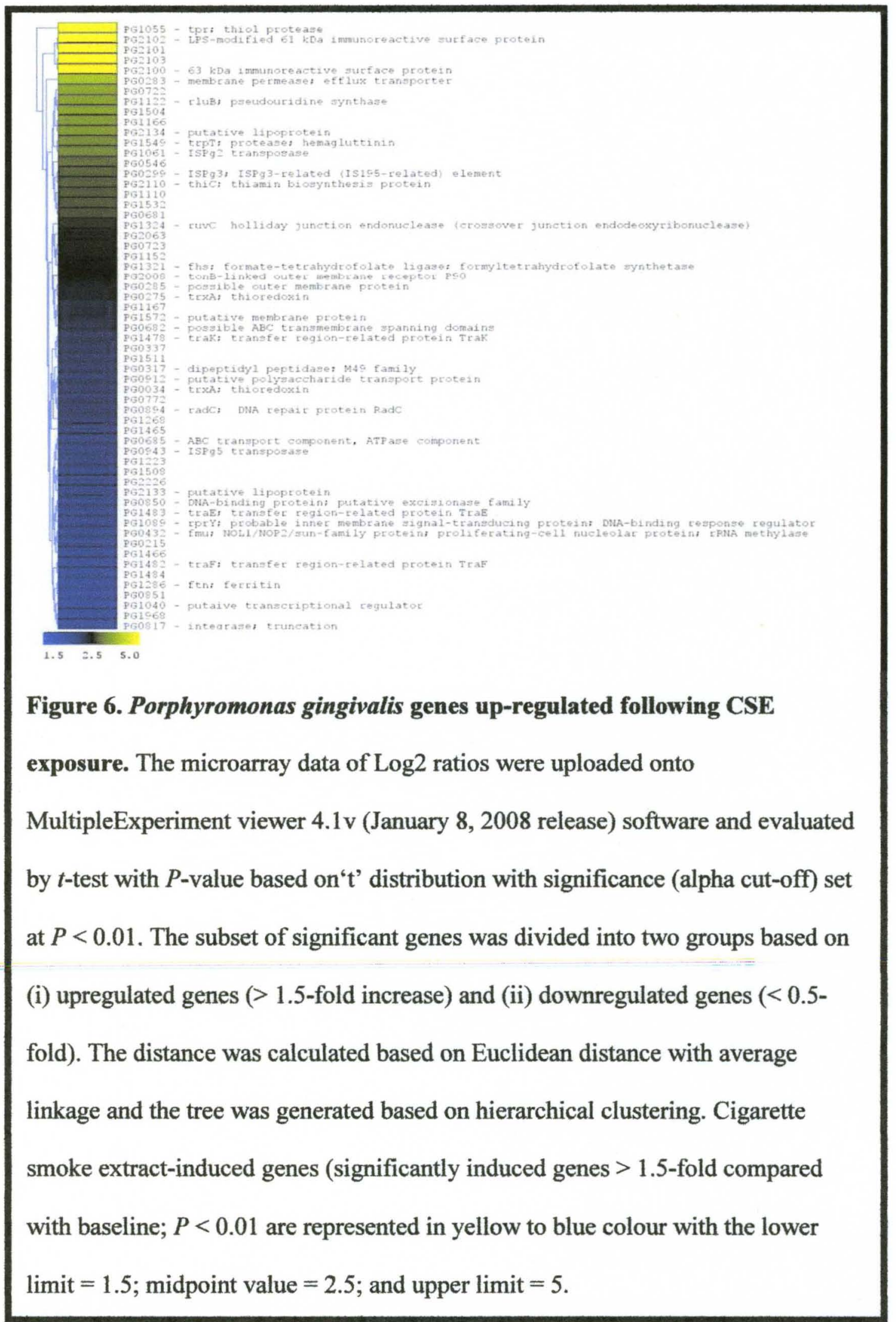



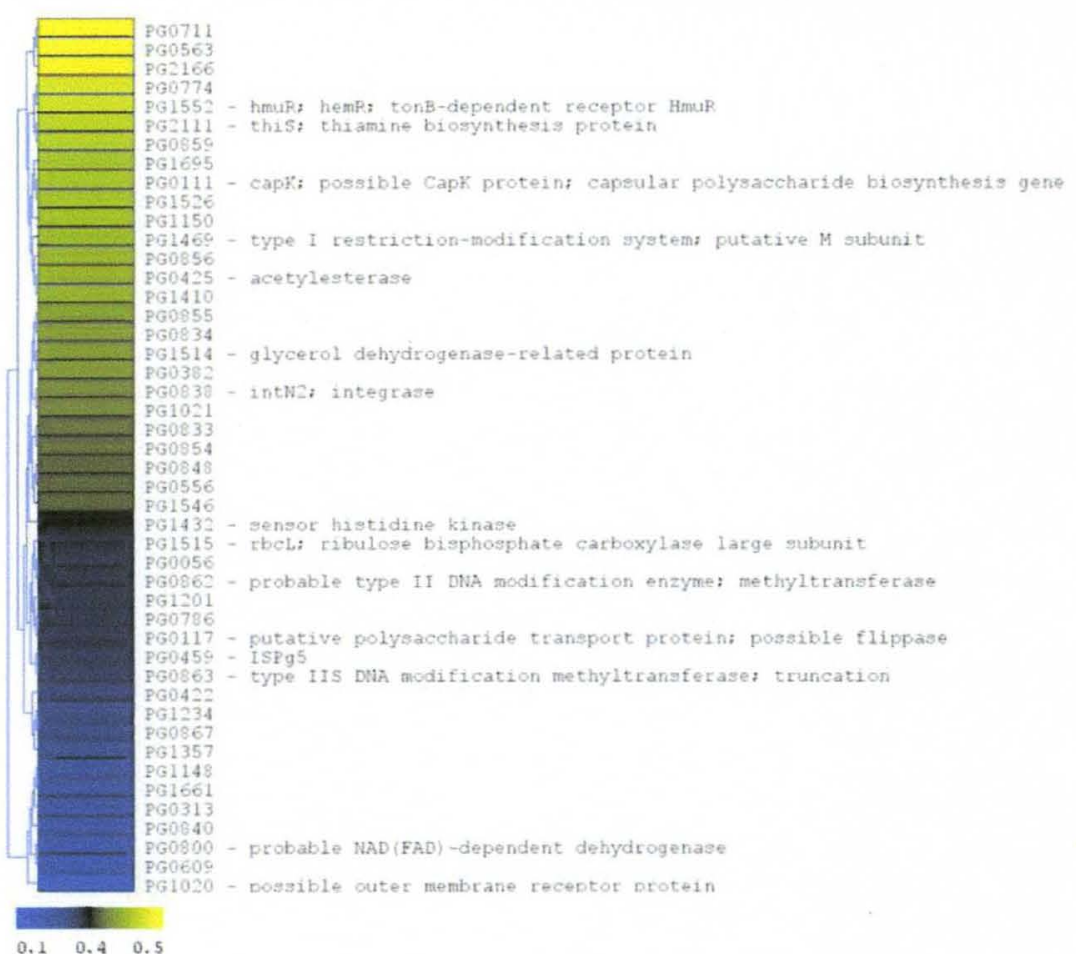

Figure 7. Porphyromonas gingivalis genes down-regulated following CSE exposure. The microarray data of $\log 2$ ratios were uploaded onto MultipleExperiment viewer 4.1v (January 8, 2008 release) software and evaluated by $t$-test with $P$-value based on't' distribution with significance (alpha cut-off) set at $P<0.01$. The subset of significant genes was divided into two groups based on (i) upregulated genes ( $>1.5$-fold increase) and (ii) downregulated genes $(<0.5-$ fold). The distance was calculated based on Euclidean distance with average linkage and the tree was generated based on hierarchical clustering. Cigarette smoke extract-suppressed genes (significantly downregulated genes $<0.5$-fold compared with baseline; $P<0.01$ ) are represented in yellow to blue colour with the lower limit $=0.1$; midpoint value $=0.4$; and upper limit $=0.5$. 
major immunoreactive 61 and $63 \mathrm{KDa}$ surface antigens encoded by PG2102 and PG2100, respectively, putative lipoproteins (PG1233, PG1234 and PG0722), and an outer membrane TonB-dependent receptor (PG2008). Other genes were differentially expressed but fell just below the 2-fold limit used in the analysis, including the lpt-1 (ptp1, PG1641) gene that has recently been shown to be a multifunctional regulator of virulence (245).

To verify the results of the microarray experiments, the expression of select genes from the array dataset were analyzed by RT-PCR. As shown in Table 2, the RT-PCR results of selected genes that were tested were consistent with the increased expression of these genes observed in the microarray analyses of CSE-treated cells.

\section{$P$. gingivalis genes down-regulated on CSE-exposure:}

Many of the 46 genes ( $2.1 \%$ of the $P$. gingivalis genome) that were suppressed by two-fold or more $(p<0.05)$ encode hypothetical proteins (see Figure 7 ) whose functions have yet to be determined. However, two genes in the capsular biosynthesis locus (246) were down-regulated - a putative capsular polysaccharide synthesis gene (capK, PG0111) and a polysaccharide transport protein related to a flippase (PG0117). The expression of two other genes in the capsular biosynthesis locus, encoding a glycosyltransferase (PG0118) and a UDP-N-acetyl-D-mannosaminuronic acid dehydrogenase (wecC, PG0108) were down-regulated just below the 2-fold limit used in the analysis. Also down-regulated in response to CSE was a sensor histidine kinase ( $f i m S$ ) which together with the co-expressed response regulator FimR has been reported to regulate the expression of the major and minor fimbrial operons of $P$. gingivalis (247). Lastly, the expression of $h m u R$ (PG1552) encoding a tonB-dependent hemoglobin 
receptor HmuR was reduced by approximately 2-fold by CSE treatment. Selected downregulated genes were analyzed by RT-PCR (see Table 2) with consistent results.

Table 2: Real time PCR analysis of selected CSE-regulated $\boldsymbol{P}$. gingivalis genes

\begin{tabular}{|c|c|c|c|}
\hline $\begin{array}{l}\text { Locus } \\
\text { name }^{\text {a }}\end{array}$ & $\begin{array}{l}\text { Putative identification in TIGR } \\
\text { and/or Oralgen database }\end{array}$ & $\begin{array}{l}\text { Microarray [fold } \\
\text { (mean, SD)] }\end{array}$ & $\begin{array}{l}\text { RT-PCR [fold } \\
\text { (mean, SD)] }\end{array}$ \\
\hline PG1055 & Thiol protease (Tpr) & $13.93,4.73$ & $108.69,21.43$ \\
\hline PG2102 & $\begin{array}{l}\text { Lipopolysaccharide-modified } \\
\text { immunoreactive } 61 \mathrm{kDa} \text { antigen }\end{array}$ & $10.58,1.47$ & $36.62,1.44$ \\
\hline PG2100 & Immunoreactive $63 \mathrm{kDa}$ antigen & $6.00,1.23$ & $30.79,1.47$ \\
\hline PG2008 & $\begin{array}{l}\text { tonB-linked outer membrane receptor } \\
\text { P90 }\end{array}$ & $2.50,2.00$ & $1.74,0.09^{b}$ \\
\hline PG1286 & Ferritin (ftn) & $2.02,0.85$ & $2.23,0.21$ \\
\hline PG1552 & $\begin{array}{l}\text { tonB-dependent receptor (HmuR, } \\
\text { HemR) }\end{array}$ & $0.47,0.29$ & $0.72,0.02^{c}$ \\
\hline PG0111 & $\begin{array}{l}\text { Putative capsular polysaccharide } \\
\text { biosynthesis gene (CapK) }\end{array}$ & $0.45,0.04$ & $0.78,0.02^{c}$ \\
\hline PG1432 & Sensor histidine kinase & $0.39,0.10$ & $0.62,0.05^{b}$ \\
\hline PG0117 & $\begin{array}{l}\text { Putative polysaccharide transport } \\
\text { protein }\end{array}$ & $0.36,0.14$ & $0.50,0.08$ \\
\hline
\end{tabular}

a. The J. Craig Venter Institute annotations; b. $>1.5,<2.0$-fold change in gene activity;

c. Reduced activity not reaching threshold $(<1.5$-fold $)$.

CSE alters expression of $\boldsymbol{P}$. gingivalis outer membrane proteins $\operatorname{RagA}$ and $\operatorname{RagB}$ :

In addition to the transcriptome analysis described above, a membrane fraction that was enriched for $P$. gingivalis outer membrane proteins was isolated from CSEtreated and control cells and analyzed by SDS gel electrophoresis. As shown in Figure 8, the Triton X-100 insoluble membrane fraction contained approximately ten major polypeptide bands, of which three were clearly overrepresented in the extract from CSE- 
treated bacteria. These bands were excised from the gel and analyzed by MALDI-MS after digestion with trypsin. Tryptic peptides were identified for the RagA $(43 \%$ sequence coverage), RagB (66\% coverage) and a putative lipoprotein (PG0179, 53\% coverage) that is likely co-expressed with the minor fimbrial antigen of $P$. gingivalis (248). Interestingly, western blots of RagB proteins revealed that reconditioning of $P$. gingivalis in GAM, following culture in GAM-CSE, resulted in RagB expression levels returning to control levels (Figure 9).

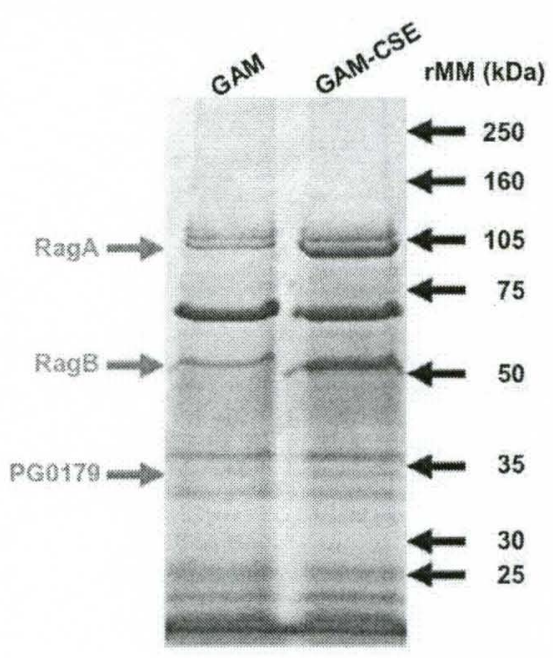

Figure 8: Upregulation of specific outer membrane protein in CSEexposed $\boldsymbol{P}$. gingivalis. Outer membrane proteins of $P$. gingivalis grown in GAM and GAM-CSE were isolated by differential extraction with Triton X100. $20 \mu \mathrm{g}$ of total outer membrane protein extracts was run through a $4-15 \%$ gradient gel. MALDI-MS of excised bands followed by comparison with the open reading frame database of $P$. gingivalis $\mathrm{W} 83$ from The J. Craig Venter Institute identified the major CSE upregulated bands, as shown. 


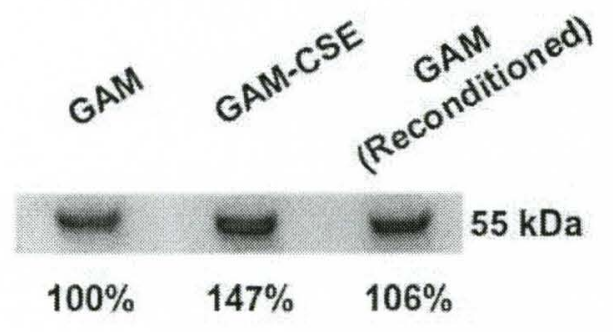

Figure 9: Cigarette smoke extract-induced RagB upregulation in $P$. gingivalis is reversible. A typical Western blot of RagB in lysates of cells sequentially passaged in GAM, GAM-CSE and GAM, respectively, is shown. Culture in GAM-CSE resulted in an increase in relative RagB expression levels (147\%). Relative RagB expression returned to near control levels on reconditioning in GAM.

\section{Discussion}

Cigarette smoking increases vulnerability to $P$. gingivalis infection and increases susceptibility to periodontitis, but reduces clinical signs of overt inflammation. The mechanisms that cause the apparent dichotomy between increased infection by $P$. gingivalis, increased severity of disease, but reduced inflammatory response in smokers remain to be determined. Our results provide some of the first information to explain such phenomena and are consistent with many previous in vivo observations.

We show that $P$. gingivalis exposed to physiologic concentrations of CSE induce a significantly lower pro-inflammatory response from PMBCs than control cultures grown without CSE. Furthermore, this effect is reversed when CSE-treated bacteria are 
sub-cultured in medium without CSE, suggesting that CSE exposure may represent an environmental stress that $P$. gingivalis is able to specifically respond to. Thus, the reduced inflammatory potential of CSE-exposed $P$. gingivalis cells represents a mechanism that may contribute, at least in part, to the reduced inflammation observed in periodontitis patients who smoke.

Such a reduced $P$. gingivalis-elicited inflammatory response is likely to aid these bacterial cells in immune evasion which, in turn, would help explain the increased levels of $P$. gingivalis infection and reduced clearance rates noted in smokers compared to nonsmokers (138-141, 147).

Our results showing suppressed TNF- $\alpha$ induction from innate cells by smokeexposed $P$. gingivalis are also in keeping with several in vivo reports of reduced levels of pro-inflammatory cytokines at diseased sites (233-237). Furthermore, the upregulation of several virulence factors in the periodontopathogen, $P$. gingivalis, are in keeping with the increased disease severity known to occur in smokers compared to non-smokers. Specific dysregulated virulence factors are discussed further below.

Our results clearly show that the response of $P$. gingivalis to CSE exposure is varied and genome wide. Approximately $7 \%$ of the genes in the $P$. gingivalis genome were found to be differentially expressed by transcriptome analyses. Furthermore, a number of the differentially expressed genes have been associated with aspects of $P$. gingivalis virulence. Several functionally-related genes were dysregulated, including multiple genes in the major fimbrial and capsular polysaccharide operons, as well as genes encoding transcriptional regulators; efflux pump and transport proteins; proteases and cell envelope proteins. The major fimbriae have been shown to be important for 
numerous aspects of $P$. gingivalis virulence, including bacterial adhesion and invasion of epithelial and endothelial cells (Lamont \& Jenkinson, 1998 and 2000). PG2133 and PG2134 encode putative lipoproteins that are co-expressed with FimA, the major fimbrial subunit protein. Wang et al. recently showed that inactivation of these genes results in the expression of significantly shorter fimbriae, suggesting that these putative lipoproteins play an essential role in fimbrial biogenesis. The mutant strains also exhibited reduced invasion and intracellular persistence in macrophages and were less virulent in a mouse model of periodontitis (244).

There are at least six different capsular serotypes (K1 to K6) expressed by $P$. gingivalis and altered virulence has been associated with $\mathrm{K}^{+}$and $\mathrm{K}^{-}$strains $(195,249-$ 251). While the contribution of $P$. gingivalis capsule to inflammation is poorly understood, recent evidence shows that capsular polysaccharide from several strains of $P$. gingivalis, including W83 elicits a substantial pro-inflammatory cytokine response from murine innate cells (252). The down regulation of several genes in the capsular biosynthesis operon (PG0111 and PG0117) suggests that capsule synthesis may be reduced upon exposure to CSE, consistent with the reduced inflammatory potential of CSE-treated bacteria.

In addition to the differential expression of genes described above, several other cell surface or outer membrane proteins, i.e., RagA, RagB and PG0179 were shown by biochemical approaches to be present at higher levels after CSE treatment. Interestingly, the genes encoding for these components were not identified as being differentially expressed in the micro array experiments. This suggests that post-transcriptional events may also be involved in the response to CSE, or alternatively may reflect inherent 
limitations in the microarray approach. Each of the differentially expressed proteins has been associated with aspects of $P$. gingivalis virulence. The $\operatorname{rag} A B$ locus was likely acquired by horizontal gene transfer (253). RagA is a putative tonB-dependent outer membrane receptor whereas RagB is an immunodominant lipoprotein. Both genes have reported to be up-regulated under conditions of thermal stress (254) and both represent significant $P$. gingivalis virulence factors $(255,256)$, although their specific contribution to periodontal disease remains to be determined. However, it is interesting that the RagA homolog (designated OmpA) from the closely related bacterium Bacteroides caccae has been associated with inflammatory mucosal (bowel) disease (257). PG0179 is a gene that is co-expressed with the minor fimbrial antigen ( $m f a l)$. The minor fimbriae play a key role in $P$. gingivalis autoaggregation (174) and are critical mediators of the interspecies interactions between Porphyromonas gingivalis and oral streptococci that facilitate biofilm formation $(173,218,258)$. Thus, stimulation of the minor fimbrial operon by CSE may facilitate increased $P$. gingivalis colonization of the periodontia.

Lastly, a number of genes that were differentially expressed encoded proteins involved in DNA replication, DNA repair and the transfer or mobilization of genetic material. Comparison of the recently completed genome sequence of $P$. gingivalis ATCC 33277 with that of strain W83 indicates that mobile genetic elements have contributed greatly to genomic diversity among $P$. gingivalis strains (Naito et al., DNA Res. 2008). The up regulation of transfer genes and several insertion sequence elements in CSEexposed cells suggests that the environmental stress imposed by cigarette smoke may stimulate genetic rearrangements. In addition, considering the highly carcinogenic potential of cigarette smoke, the up-regulation of DNA-repair and -control genes is not 
surprising. Cigarette smoke is also a major oxidative stressor $(259,260)$. A single cigarette is estimated to contain $10^{16}$ oxidant molecules (261). Thus, the up regulation of ferritin [PG1286], an iron sequestrator, may provide protection against free-iron-related oxidative stress (262). In addition, the response regulator, RprY (also up regulated after CSE treatment) has recently been shown to be responsive to reactive oxygen species and iron (263). It is also interesting to note that several other anti-oxidant genes were differentially expressed $(p<0.05)$ when the threshold for induction in the array experiment was reduced from 2-fold to 1.5 -fold. In addition, the up-regulation of efflux pump and other $\mathrm{ABC}$ transport systems may confer resistance to potentially harmful chemicals present in CSE. Taken together, these results suggest that CSE may represent a potent environmental stressor that induces a protective response from $P$. gingivalis.

In summary, smokers are more prone to infection with $P$. gingivalis and to develop periodontitis, yet exhibit reduced clinical inflammation. Consistent with this, we have found that CSE-exposed $P$. gingivalis exhibits a reduced capacity to elicit an inflammatory response from immune cells. $P$. gingivalis responds globally to CSE exposure and multiple virulence associated genes are differentially expressed. These results may explain in part the altered virulence and host-pathogen interactions that occur in smokers with periodontal disease and provide some of the first information illustrating how $P$. gingivalis responds at the molecular level to cigarette smoke. 


\section{CHAPTER FOUR: TOBACCO UPREGULATES P. GINGIVALIS FIMBRIAL PROTEINS THAT INDUCE TLR2 HYPOSENSITIVITY.}

\section{Introduction}

Tobacco smokers are more susceptible than non-smokers to multiple infectious diseases, particularly mucosal infections such as tuberculosis, pneumonia, Chlamydiasis, gonorrhoea, otitis media and periodontitis (264). The mechanisms underlying such increased susceptibility are not well understood. Several groups have shown that tobacco smoke as well as individual smoke components induce physiological and structural changes, e.g. reduction of mucociliary clearance $(265,266)$, and dysregulate specific elements of immune function, e.g. inhibition of the respiratory burst and phagocytosis $(242,267,268)$ and interference in antigen presentation $(269,270)$. However, the influence of tobacco on bacterial virulence is - essentially - unstudied.

Periodontitis is a bacteria-induced, irreversible chronic inflammatory mucosal disease characterized by the destruction of the soft and hard supporting structures of the teeth. Tobacco smokers are more susceptible than non-smokers to infections with periodontal pathogens (264) and are more likely to develop severe periodontitis and to 
prove refractory to treatment (88). Paradoxically, smokers show reduced clinical signs of inflammation in response to dental plaque than non-smokers, particularly the key diagnostic indices of gingival bleeding on probing and edema $(88,203)$. Again, the mechanisms underlying this phenomenon are poorly characterized.

Porphyromonas gingivalis, a Gram negative, asaccharolytic anaerobe, is a key periodontal pathogen whose numbers are increased in tobacco smokers $(88,203)$. There is some evidence that components of tobacco smoke augment $P$. gingivalis pathogenesis. Nicotine and its primary metabolite - cotinine - have been shown to increase the lethality of cell-free extracellular toxins and cell lysates from $P$. gingivalis in the chick embryo model $(271,272)$. The combination of benzopyrene, a tobacco smoke aryl hydrocarbon, and P. gingivalis lipopolysaccharide (LPS) significantly increase the inhibition of osteogenesis in a rat bone marrow cell model, compared to either agonist alone (273).

We have recently shown that $P$. gingivalis adapts to the environmental stress presented by cigarette smoke extract (CSE) by altering the expression of several genes and outer membrane proteins (274). Concomitant with this adaptive response to CSE, $P$. gingivalis induces a lower inflammatory response (TNF- $\alpha$, IL-6 and IL-12 p40) from human innate cells compared to unexposed, control bacteria (274). Furthermore, the inflammation-inducing potential of $P$. gingivalis is restored when cells are subcultured back into fresh medium without CSE. Interestingly, microarray analyses determined that specific genes (PG2133 and PG2134) in operons coding for the synthesis and assembly of major and minor fimbrial antigens (FimA and Mfal) of $P$. gingivalis were induced on exposure to CSE, while several genes in the capsular biosynthesis locus (capK, PG0117, PG0118 and wecC) were suppressed (274). 
It is important to note that capsule polysaccharides and major fimbrial protein will be the two $P$. gingivalis features that first engage the host response and, thus, are likely to play critical roles in directing initial host-pathogen interactions. Capsule production is associated with tissue invasiveness (195) and has been reported to be inversely related to biofilm growth (275), while capsular polysaccharides represent potent cytokine-inducing stimuli (252). The major fimbrial antigen or FimA is also an important virulence factor that facilitates the adhesion and initial attachment of $P$. gingivalis to junctional epithelial cells, thus aiding sub-gingival colonization (276). FimA appears to signal via TLR2 and induces the expression of several pro-inflammatory cytokines such as TNF- $\alpha$, IL-6 and IL-1 $\beta$ in innate immune cells (150). However, the potency of FimA as a proinflammatory agonist is controversial $(157,168,277,278)$. Thus, alterations in $P$. gingivalis capsule and fimbriae production would be expected to exert marked effects on virulence and host-pathogen interaction.

We hypothesized that CSE-regulation of capsule and fimbrial genes is reflected at the ultrastructural and functional levels, alters the nature of host-pathogen interactions, and contributes to the reduced pro- inflammatory potential of smoke exposed $P$. gingivalis. We establish that CSE up-regulates $P$. gingivalis FimA at the protein level, suppresses the production of capsular polysaccharides at the ultrastructural level, and creates conditions that promote biofilm formation. We further show that while FimA is recognized by TLR $2 / 6$, it has only minimal inflammatory activity in several cell types (PBMCs, neutrophils, and epithelial cells) and, furthermore, FimA stimulation chronically abrogates the pro-inflammatory response to subsequent TLR2 stimulation by other TLR2-specific agonists (Pam3CSK4, Mfa1) in an IRAK-1-dependent but NF-kB- 
independent manner. These studies provide some of the first information to explain, mechanistically, how tobacco smoke changes the $P$. gingivalis phenotype in a manner likely to promote $P$. gingivalis colonization and infection while simultaneously reducing the host response to this major mucosal pathogen.

\section{Results}

\section{Tobacco smoke exposure alters expression of $\boldsymbol{P}$. gingivalis fimbriae and capsule:}

Our previous microarray data indicated that CSE induced the expression of genes key to the synthesis and assembly of FimA (PG2133 and PG2134), concomitant with a suppression expression of several genes in capsular biosynthesis locus (capK, PG0117, PG0118 and wecC) (274). We now show that CSE-exposure reversibly increases FimA protein, as shown in Figures $10 \mathrm{~A}$ and $\mathrm{B}$. Transmission electron micrographs clearly establish that these CSE-regulated transcriptional and translational activities are reflected at the ultrastructural level, as shown in Figures $10 \mathrm{C}$ and $10 \mathrm{D}$. Furthermore, CSE-induced FimA is both surface exposed, as assessed by availability to FimA-specific antibodies (Figure $10 F$ ) and functional, as assessed by binding to the established FimA ligand fibronectin (155) (Figure 10E). 
A

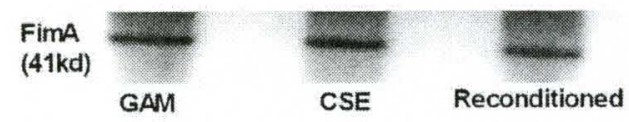

B

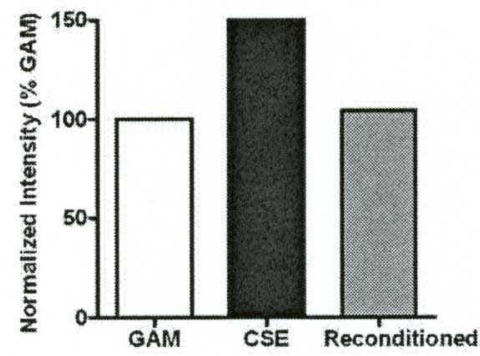

E

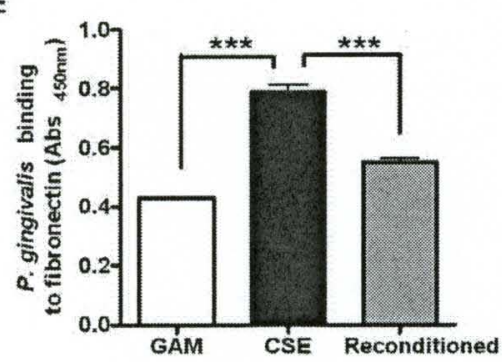

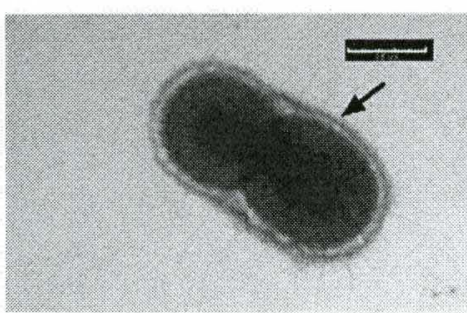

D

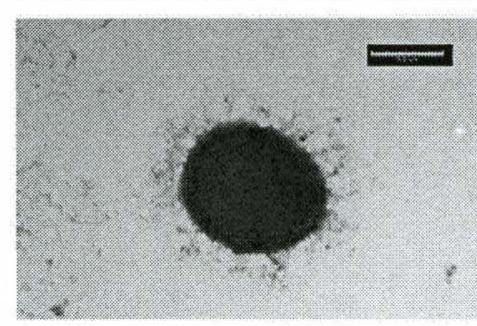

$\mathbf{F}$

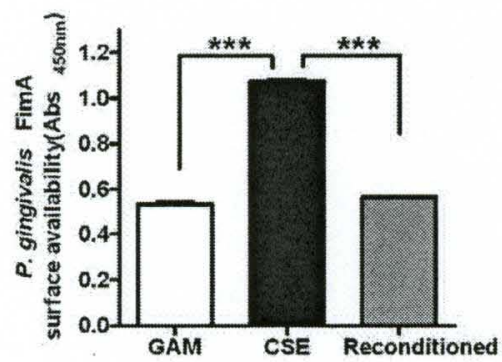

Figure 10: CSE induces phenotypic surface changes in $P$. gingivalis. (A) Typical Western blot of FimA in lysates of $1 \times 10^{6} \mathrm{P}$. gingivalis cells sequentially passaged in GAM, GAM-CSE, and then fresh GAM, respectively. (B) Typical relative band intensities establish that FimA expression is increased on CSE-exposure, but that FimA expression reverts to control levels upon sub-culturing $P$. gingivalis back into fresh GAM. Representative transmission electron images of $P$. gingivalis grown in GAM (C) or GAM-CSE (D). The black arrow indicates the $P$. gingivalis capsule, which is greatly reduced in presence of CSE. These CSE-induced phenotypic changes are concomitant with an increased binding of $P$. gingivalis to the FimA ligand, fibronectin (E) and surface availability of FimA (F). 


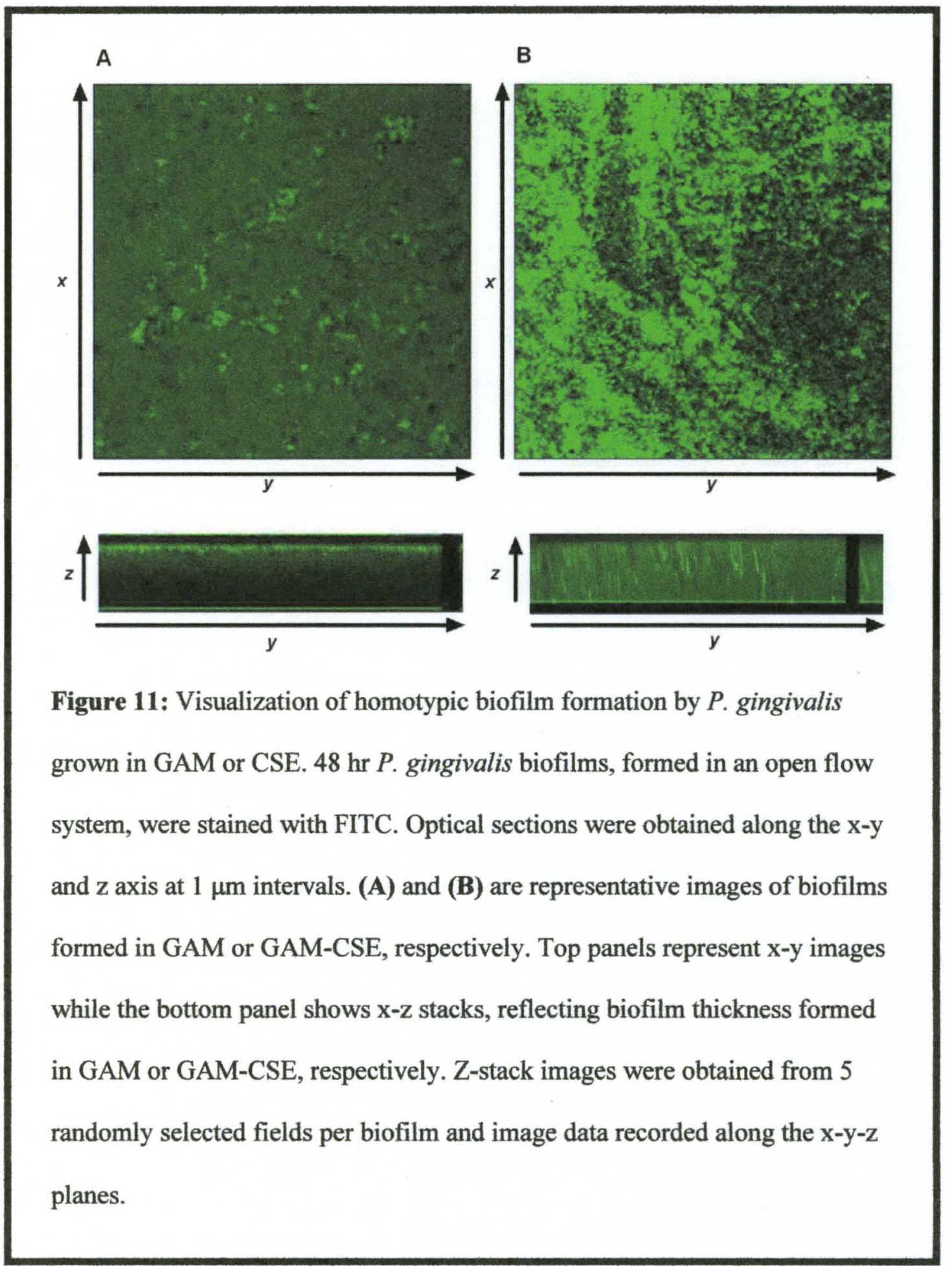




\section{CSE augments $P$. gingivalis biofilm formation:}

Biofilms play an important role in the pathology of periodontal disease by mechanisms that include protection of plaque bacteria against phagocytosis and against antibiotics (249). FimA plays a critical role in $P$. gingivalis biofilm formation. Indeed, $P$. gingivalis strains lacking FimA cannot form biofilms (279). Furthermore capsule synthesis has been shown to inversely correlate with biofilm growth (275). To establish if our initial discoveries that CSE upregulates FimA production but downregulates capsule production (274) influence biofilm formation, CSE-exposed and unexposed $P$. gingivalis was grown in an open flow biofilm system. Representative biofilm images are presented in Figure 11A-B. There was a significant increase in overall homotypic biofilm formation in the presence of CSE (Table 3), with increased biomass, substratum coverage, maximum and mean thickness apparent (all $p<0.01$ ).

Table 3: Quantitative characteristics of $P$. gingivalis biofilms

\begin{tabular}{|l|c|c|c|}
\hline 48h Biofilm & \multicolumn{1}{|c|}{$\begin{array}{c}\text { Biomass } \\
\left(\boldsymbol{\mu m}^{3} / \mu^{2}\right)\end{array}$} & $\begin{array}{c}\text { Substratum } \\
\text { coverage }\left(\boldsymbol{\mu m}^{2}\right)\end{array}$ & $\begin{array}{c}\text { Average } \\
\text { thickness }(\boldsymbol{\mu m})\end{array}$ \\
\hline P. gingivalis GAM & $1.869 \pm 1.15$ & $0.315 \pm 0.11$ & $2.505 \pm 0.443$ \\
\hline P. gingivalis GAM-CSE & $5.708 \pm 0.38^{* * *}$ & $0.679 \pm 0.06$ & $12.66 \quad \pm$ \\
& & $1.487^{* *}$ \\
\hline
\end{tabular}




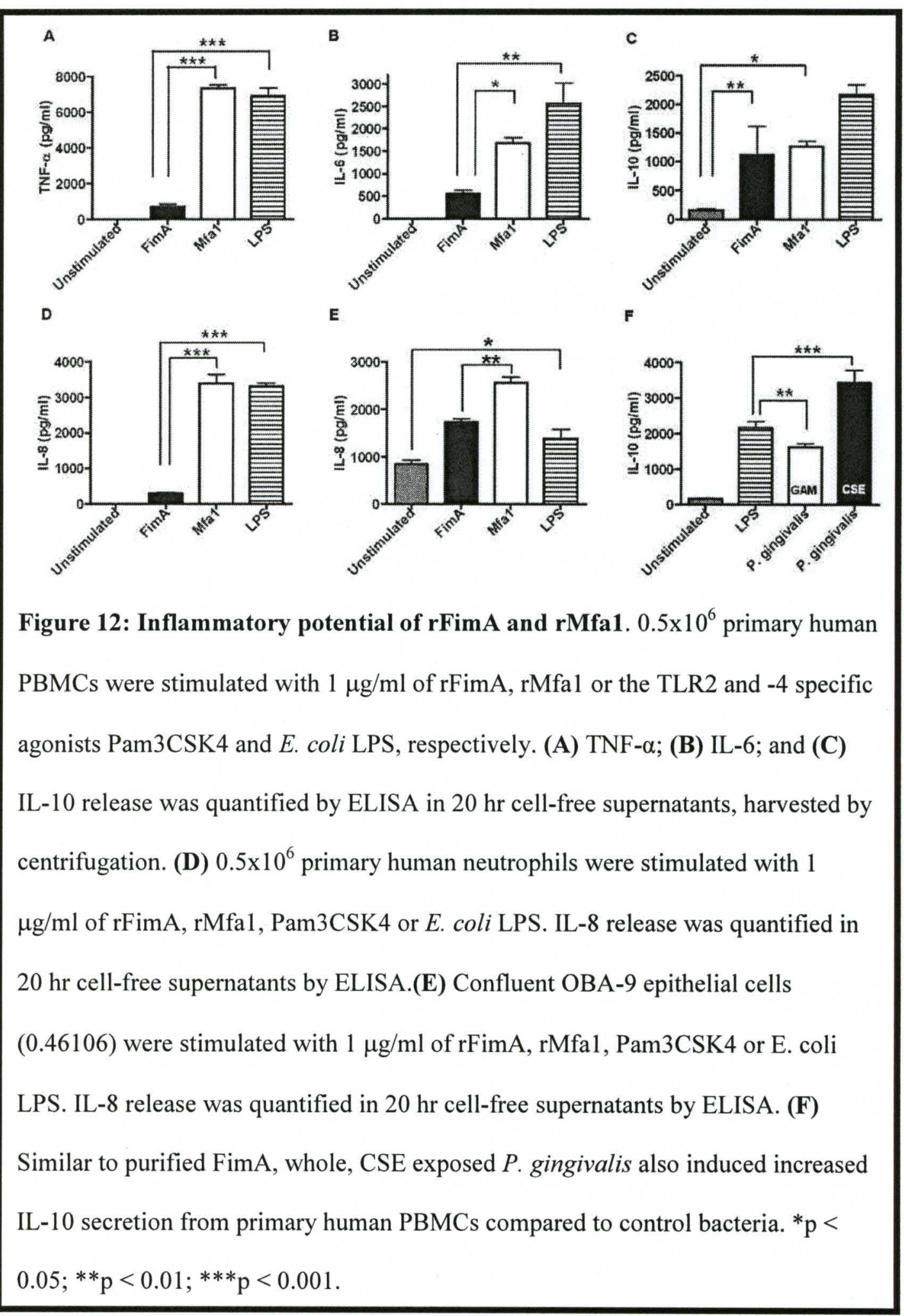




\section{FimA and Mfa1 exhibit differential pro-inflammatory potential:}

While the innate response to the major fimbrial antigen of $P$. gingivalis, FimA, has been partially characterized (45) the inflammatory potential of the minor fimbrial antigens (Mfal) are not well understood. Therefore, to better understand the relevance of CSE-upregulation of FimA and Mfal, particularly in the context of the reduced inflammatory response to plaque that is consistently observed in human smokers (280), we quantified the cytokine production elicited by these predominant, CSE-regulated surface antigens in PBMCs (Figure 12A-C), neutrophils (Figure 12D) and gingival epithelial cell line OBA-9 (Figure 12E). While FimA did promote a cytokine response from each cell type tested, the concentration of pro-inflammatory cytokines induced (TNF- $\alpha$; IL-6; IL-8) was minimal when compared to the classic bacterial-derived proinflammatory agonists, LPS and Pam3CSK4. In contrast, FimA did induce high levels of the anti-inflammatory cytokine, IL-10 (Figure 12C). Mfal, on the other hand, induced a robust pro-inflammatory response that was comparable or greater in magnitude to that of LPS in PBMC's (Figures 12A and 12B), neutrophils (Figure 12D) and epithelial cells (Figure 12E). These results are similar to those seen with intact bacteria. We have previously shown that whole, smoke-exposed $P$. gingivalis exhibit reduced inflammatory potential than control (unexposed) cells, as measured by decreased induction of multiple pro-inflammatory cytokines (TNF- $\alpha$, IL-6 and IL-12 p40) (281). We extend these observations to show that CSE-exposed $P$. gingivalis induce increased IL-10 in innate cells, compared to unexposed bacteria (Figure 12F). 


\section{Fim $A$ and Mfa1 are TLR2-specific agonists:}

In order to understand the differential pro-inflammatory potential of FimA and Mfal at the mechanistic level, we first established the TLR-specificity of each of these two specific CSE-dysregulated $P$. gingivalis surface proteins. IL-8 production by rFimA or rMfal stimulated HEK293 cells stably expressing variant TLRs was quantified. As shown in Figure 13A, significantly higher levels of IL-8 were produced by HEK clones expressing TLR2/1 and, particularly, TLR2/6 compared to all other clones (both $\mathrm{p}>$ $0.001)$

As FimA induced lower levels of pro-inflammatory cytokines in innate immune cells than Mfal we hypothesized that FimA may not be a strong activator of NF- $\mathrm{kB}$. However, in the THP-1 blue cell model, FimA and Mfal each proved to be effective inducers of NF-kB transcription (see Figure 13B). 

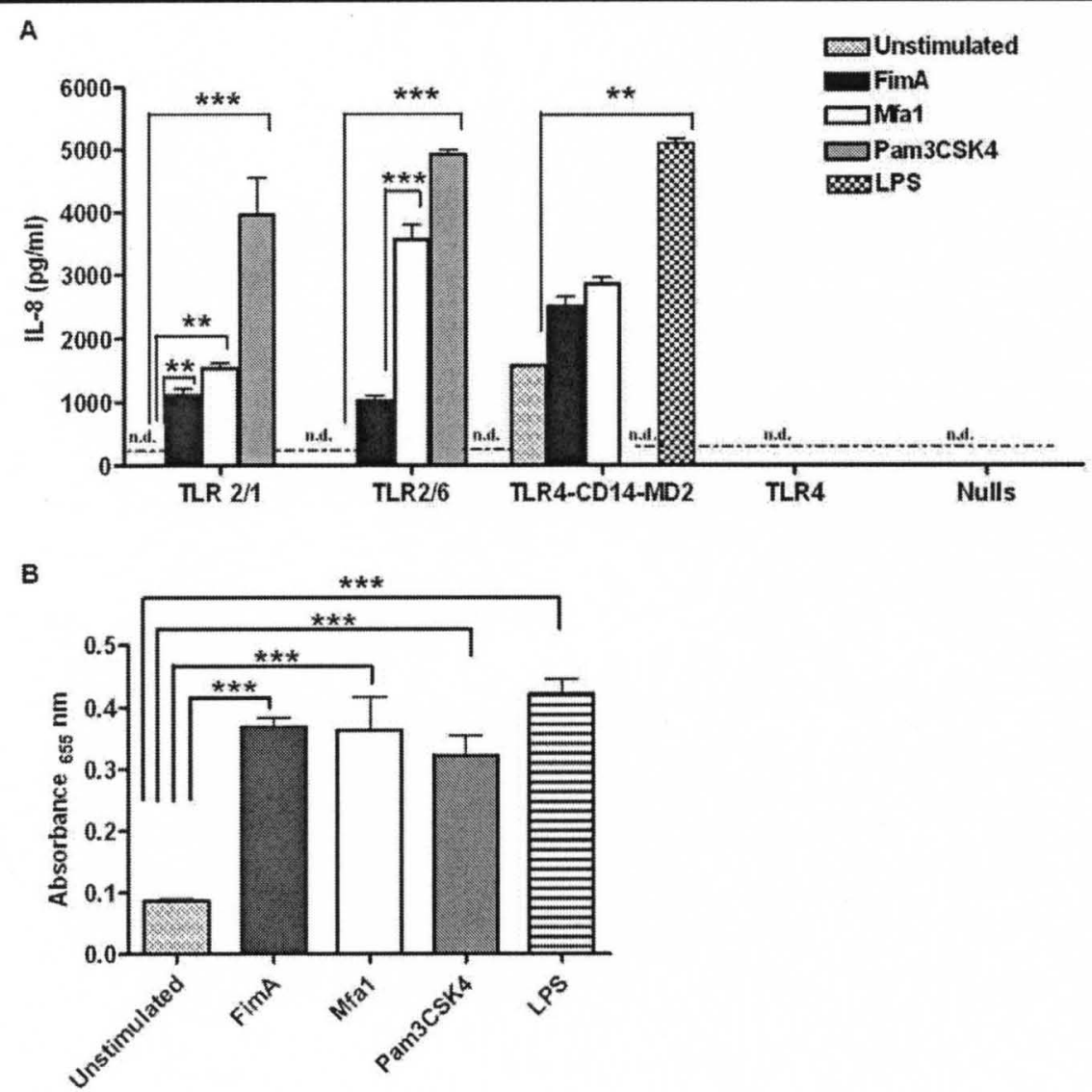

Figure 13: rFimA and rMfa1 signal preferentially through TLR2/6. (A) HEK 293 cells stably expressing TLR2, 4, 2/1, 2/6 or TLR4-CD14-MD2 were stimulated with 1 $\mu \mathrm{g} / \mathrm{ml}$ of $\mathrm{rFimA}$, rMfa1, the classic TLR2-specific agonist, Pam3CSK4 or the classic TLR4-specific agonist E. coli LPS. IL-8 release was quantified in $20 \mathrm{hr}$ cell-free supernatants by ELISA. n.d. = not detected (below assay threshold); ${ }^{*} \mathrm{p}<0.05$; ${ }^{* *} \mathrm{p}<0.01 ; * * * \mathrm{p}<0.001$. (B) THP-1 Blue cells were stimulated with $1 \mu \mathrm{g} / \mathrm{ml}$ of $\mathrm{rFimA}$, rMfa1, Pam3CSK4 or E. coli LPS. Relative expression levels of SEAP (reflecting NF$\mathrm{kB}$ ) in cell-free supernatants were determined by spectrophotometric analysis of SEAP activity at $655 \mathrm{~nm}$. Unstimulated cells represent the $100 \%$ control. Here we show that all TLR-agonists employed are equally capable of inducing NF-kB. ${ }^{* * *} \mathrm{p}<0.001$ compared to unstimulated cells. 


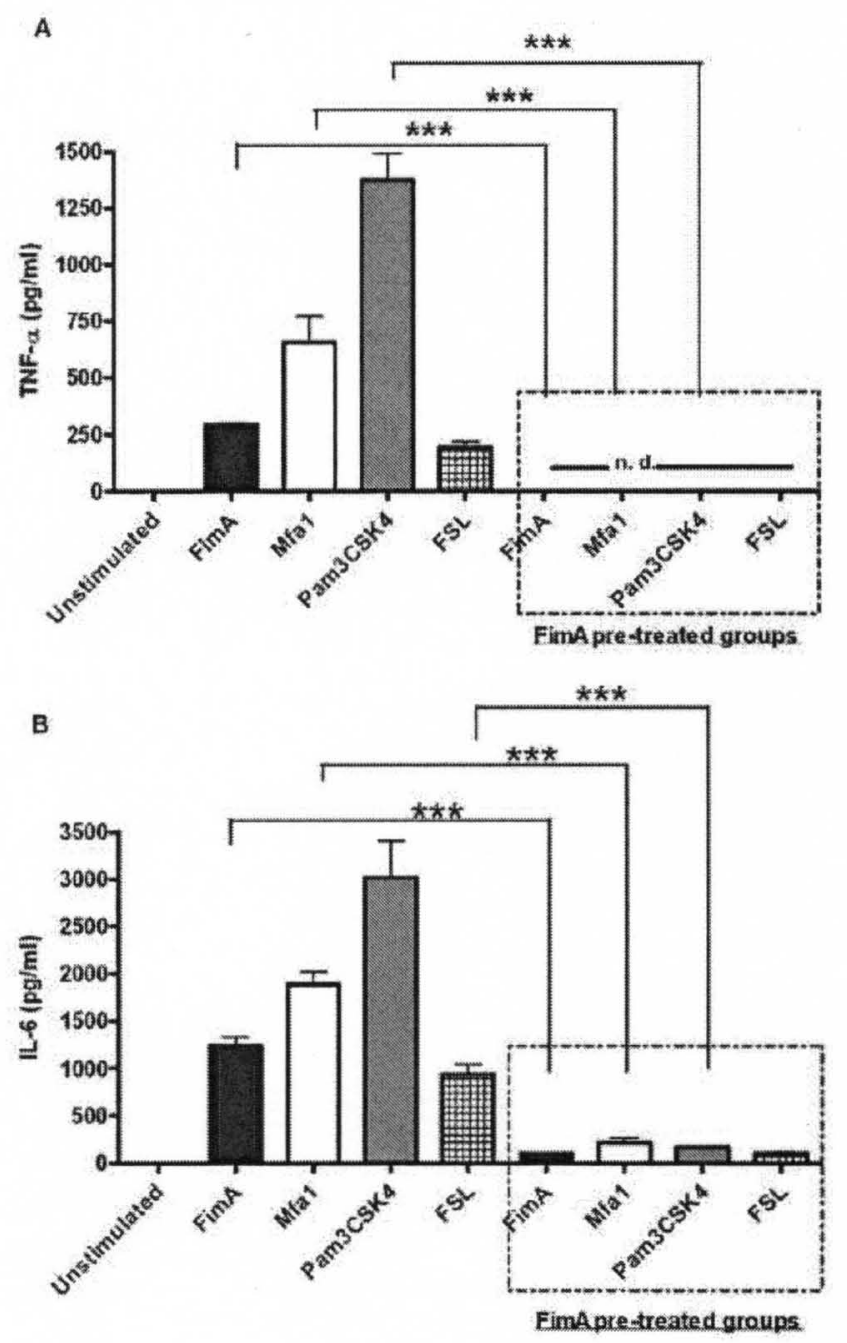

Figure 14: FimA induces TLR2-specific innate tolerance. $0.5 \times 10^{6}$ primary human PBMCs were pre-incubated with rFimA for $24 \mathrm{hrs}$ before stimulation with $1 \mu \mathrm{g} / \mathrm{ml}$ of rFimA, rMfal or the TLR2 and -4 specific agonists Pam3CSK4 and E. coli LPS.

Responses were compared to cells treated with the same agonists without any preincubation. (A) TNF- $\alpha$; (B) IL-6. n.d. = not detected (below assay threshold); ${ }^{* * *}$ p $<$ 0.001 . 


\section{FimA induces TLR2-specific innate tolerance:}

We next examined if exposure to low-activity FimA influenced cytokine production (IL-6, TNF- $\alpha$ ) in PBMCs on subsequent TLR stimulation by potent proinflammatory agonists (Mfa1 and the TLR2/1 and TLR2/6 specific agonists, Pam3CSk4 and FSL respectively). Pre-incubation with FimA inhibited cytokine production in response to all TLR2 specific agonists tested, as shown in Figure 14. Thus, FimA induces a state of inflammatory hypo-responsiveness in PBMCs. TLR2 surface expression by PBMCs in response to FimA stimulation was monitored by flow cytometry. There was no significant difference in TLR2 surface expression levels up to $24 \mathrm{hrs}$ post-FimA engagement (data not shown). Thus, FimA stimulation does not alter surface expression of TLR2 in PBMCs.

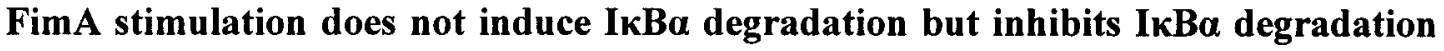
by Mfa1:

$\mathrm{NF}-\kappa \mathrm{B}$ transcription factors are complexed with I $\mathrm{B}$ proteins in the cytosol. On receiving specific, but varied, extracellular signals $\mathrm{I} \kappa \mathrm{B} \alpha$ is phosphorylated and targeted for proteasome-mediated degradation, resulting in the release and nuclear translocation of transcriptionally effective NF-kB $(82,88,203,232,282,283)$. We compared Ik-B $\alpha$ protein levels in PBMCs exposed to $\mathrm{rMfa}$, with or without pre-incubation with $\mathrm{rFimA}$. As shown in Figure 15, while the potent pro-inflammatory agonist, Mfa1, induced rapid and extensive I $\mathrm{I}-\mathrm{B} \alpha$ degradation, pre-incubation with $\mathrm{rFimA}$ efficiently abrogated this Mfal-triggered Iא-B $\alpha$ degradation. Thus, FimA appears to promote TLR2 hyposensitivity 
by inhibiting TLR2 agonist-induced degradation of Iא-B $\alpha$. Essentially identical results were found for a second TLR2 agonist, FSL (data not shown).

\section{FimA induced innate tolerance is IRAK-1-mediated:}

To further understand mechanisms underlying FimA-induced TLR hyporesponsiveness, we monitored cytosolic IRAK-M and IRAK-1 in PBMCs. In unstimulated PBMCs, exposure to TLR2 agonists resulted in the rapid (within minutes) degradation of the upstream NF- $\mathrm{kB}$ regulator, IRAK-1, as shown for Mfal in (Figure 16A). However, FimA stimulation not only degrades IRAK-1, without leading to induction of pro-inflammatory cytokine production (Figure 12) but IRAK-1 levels remain minimal 24 hours after FimA stimulation and, therefore, unavailable for signaling on secondary TLR2 stimulation, as is shown for Mfal in (Figure 16b). Essentially identical results were found for IRAK-M (data not shown). 


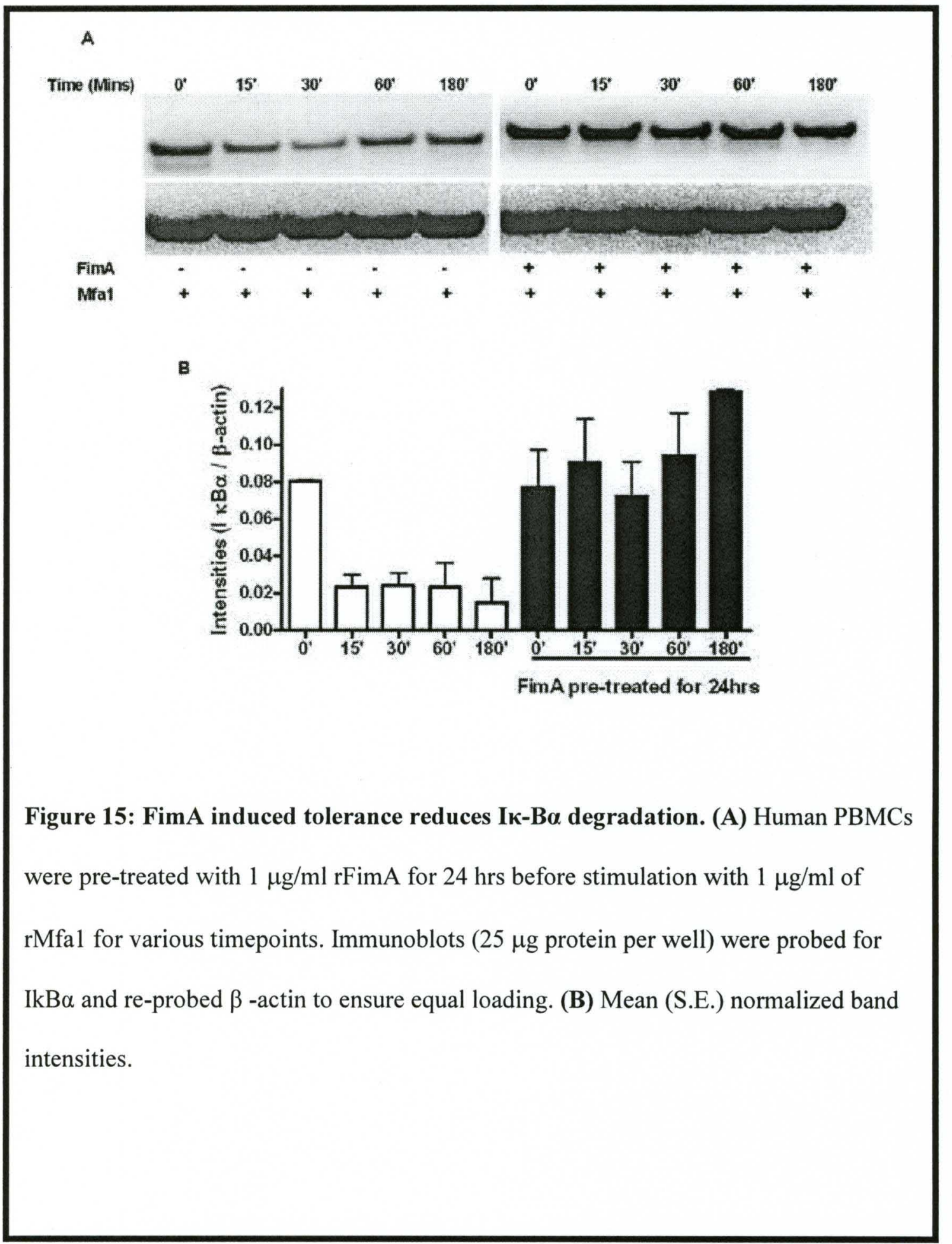




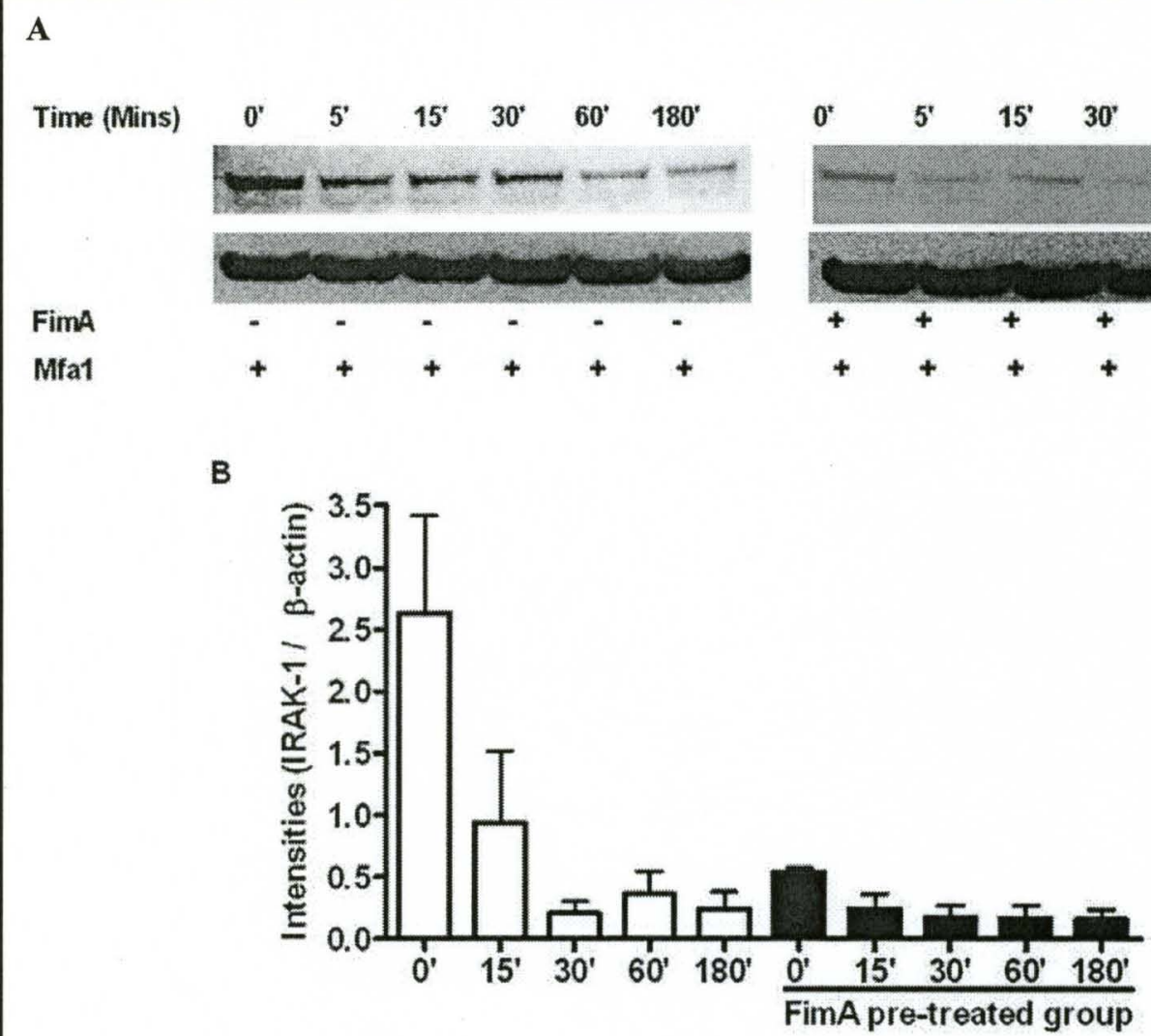

Figure 16: FimA induced tolerance is IRAK-1-mediated. (A) Human PBMCs were pre-treated or not with $1 \mu \mathrm{g} / \mathrm{ml} \mathrm{rFimA}$ for $24 \mathrm{hrs}$ before stimulation with $1 \mu \mathrm{g} / \mathrm{ml}$ of rMfal for various timepoints. Immunoblots ( $30 \mu \mathrm{g}$ protein per well) were probed for IRAK-1 and subsequently re-probed for Iא-B $\alpha$ and $\beta$-actin. (C) Mean (s.e.) normalized band intensities 


\section{Discussion}

Smokers are more susceptible to periodontitis and exhibit more severe disease, yet the normally overt inflammatory response to plaque bacteria is suppressed (274). We have previously shown that human monocytes challenged with tobacco smoke-exposed P. gingivalis respond with reduced levels of pro-inflammatory cytokines (274) and now show that tobacco smoke-exposed $P$. gingivalis promote increased IL-10 production. However, the specific mechanisms of tobacco-induced innate immune suppression remain unknown. Initial microarray data suggested that cigarette smoke extract suppressed the production of $P$. gingivalis capsular polysaccharides while promoting the expression of fimbrial proteins $(155,158)$. As both capsular polysaccharides and fimbrial proteins of this key periodontal pathogen have been reported to influence cytokine production and because these specific bacterial structures will be the first to engage the host response, we hypothesized that such smoke-induced changes to $P$. gingivalis surface may contribute to the lower pro-inflammatory potential of smoke-exposed bacteria.

We have herein established that tobacco smoke increases expression of FimA, the major fimbrial protein, reduces $P$. gingivalis capsular layer, and promotes the growth of P. gingivalis biofilms of increased biomass. FimA has been shown to play a critical role in $P$. gingivalis colonization of the periodontium through strong interactions with several host proteins, including collagen, laminin and fibronectin (284), and by promoting adherence to other plaque bacteria, such as Streptococcus spp. $(285,286)$, and the oral epithelia (279). Furthermore, it is long established that biofilms represent immunoprotective structures. FimA is an important player in $P$. gingivalis biofilm formation (287). Indeed, FimA deficient strains show reduced biofilm formation (275), 
while non-encapsulated mutants of $P$. gingivalis W83 exhibit enhanced biofilm formation $(138,139,264)$. These results are clearly in keeping with, and provide mechanisms to support, established clinical observations that show that, compared to non-smokers, smokers are more likely to be infected with $P$. gingivalis $(140,141)$, to harbor higher numbers of $P$. gingivalis (141), and for such $P$. gingivalis infections to be more persistent (288).

It has been previously shown that $P$. gingivalis FimA interacts with TLR2 (175, $277,278,289)$. However, the capacity of FimA to subsequently elicit an inflammatory response is controversial. Some research groups have shown that FimA induces the production of pro-inflammatory cytokines from mononuclear innate cells $(158,175)$ and have hypothesized that this contributes to the development of pathological inflammation $(277,289,290)$. However, other studies suggest that the pro-inflammatory response to FimA in mononuclear innate cells may be significantly lower than that expected from comparable doses of classic TLR agonists (168) and is unlikely to play a major role in $P$. gingivalis-induced inflammation (244). Moreover, FimA has even been suggested to be anti-inflammatory (280). We now show that the CSE upregulated $P$. gingivalis fimbrial proteins, rFimA and rMfa1, each signal though TLR2/1, and particularly, TLR 2/6; both strongly activate NF- $\mathrm{KB}$ transcription; but that $\mathrm{rFimA}$ induces a minimal proinflammatory cytokine (TNF- $\alpha$, IL-6) response in multiple innate cell types (human PBMCs, neutrophils and gingival epithelial cells) compared to rMfa1 and to classic TLR2 agonists; and also induces significant quantities of the potent anti-inflammatory cytokine, IL-10. These results mimic the cytokine profiles that we have previously shown in innate cells stimulated with intact, CSE-exposed $P$. gingivalis (88, 203, 291). 
Furthermore, these observations are in keeping with multiple in vivo studies in smokers that have shown that, despite increased susceptibility to plaque-induced periodontitis, the inflammatory response is suppressed in smokers compared to non-smokers $(233,234$, $236,237)$. This inflammatory suppression is reflected in lower concentrations of proinflammatory mediators (IL-1 $\beta$, IL-6 and, perhaps, TNF- $\alpha$ ) in the gingival crevicular fluid and periodontal tissues of smokers, compared to non-smokers $(292,293)$. Inefficient TLR stimulation and the promotion of a less vigorous inflammatory response is an established means of immune evasion for several pathogens, including Bordetella, Shigella and pathogenic Escherichia (294-297) .

While CSE-induces functional, surface-exposed FimA expression, we further demonstrate that FimA induces a state of hyporesponsiveness, or tolerance, to secondary stimulation with Mfal, and other TLR2 specific agonists, in PBMC's - as demonstrated by an ablation of TNF- $\alpha$ and IL-6. This FimA-induced hyporesponsiveness was not associated with an alteration to TLR2 expression on the surface of innate cells. Rather, we show that FimA-induced, TLR2-specific tolerance is mediated by a suppression of $\mathrm{I} \kappa \mathrm{B} \alpha$ degradation, which is expected to be concomitant with reduced NF- $\mathrm{B}$ translocation.

TLR2 activation leads to the rapid recruitment of MyD88 to TLR2 and the subsequent recruitment of IRAK-1 and IRAK-4 (298, 299). IRAK-4 phosphorylates IRAK-1 that is in association with TLR2, allowing IRAK-1 to interact with TRAF6 (295), leading to $\mathrm{I} \kappa \mathrm{B} \alpha$ degradation, NF- $\mathrm{KB}$ nuclear translocation and the induction of multiple pro-inflammatory cytokine genes (300). We show, however, that stimulation with FimA, leads to rapid IRAK-1 degradation and the long-term unavailability of this 
positive regulator of the TLR-2/MyD88 pathway, helping to explain FimA-induced tolerance. IRAK-M is a negative regulator of NF- $\mathrm{kB}$ translocation that acts by preventing the dissociation of IRAK-1 and IRAK4 from MyD88 (301). While FimA stimulation also leads to the rapid degradation and chronic suppression of IRAK-M, this would appear inconsequential with respect to NF- $\mathrm{KB}$ activation because of the unavailability of IRAK-1.

This FimA-induced, IRAK-1- and I $\mathrm{B} \alpha$-involved suppression of TLR2 proinflammatory cytokine signaling provides one mechanism by which tobacco smoke dysregulates the inflammatory response and suppresses cytokine production in smokers, as discussed above. This mechanism of suppression may be similar to what has been previously reported for Pam3CSK4 (301). Monocytes stimulated with Pam3CSK4 have been shown to be refractory to secondary stimulation with the same agonist (280). This occurs due to reduced IRAK-1 protein in these cells, just as we show in FimA-tolerized PBMCs.

It is important to note that there are limitations inherent in using recombinant proteins, particularly as they may behave entirely different outside the context of the whole bacterium and because of potential vector-specific alterations in the processing of the recombinant protein. The advantages, however, are that recombinant technology is long established and allows simple purification of a large amount of protein that can be readily characterized, that is free of accessory molecules (such as associated fimbrial proteins FimB through $\mathrm{E}$ ) and that allows for effective and reproducible elucidation of signaling pathways. Moreover FimA and Mfal are simultaneously expressed $(150,287)$, raising the possibility that Mfal may nullify the anti-inflammatory effectiveness of 
FimA. However, FimA-comprised fimbriae are much longer appendages than the minor Mfal fimbriae $(150,287)$ and are, thus, likely to interact with host cells prior to Mfal. Furthermore, it is been suggested that FimA appendages may be shed from the $P$. gingivalis surface (302) further increasing the likelihood of early FimA host interaction. Importantly, intact CSE-exposed $P$. gingivalis that, presumably, express both Mfal and FimA, exhibit similar anti-inflammatory properties to recombinant FimA. While tobacco smoke produces multiple phenotypic and genotypic changes in P. gingivalis (280) and, thus, other yet to be identified mechanisms way well contribute to the overall reduced inflammatory response, the anti-inflammatory effects of recombinant FimA are potent and are likely to be a major factor in CSE-induced inflammatory suppression.

In summary, CSE-exposure results in the upregulation of FimA. FimA suppresses the inflammatory response by at least two different mechanisms. One is passive, i.e. FimA itself engages TLR2 but has minimal inflammatory potential. The second is active, i.e., FimA induces TLR2 hyporesponsiveness by a mechanism involving IRAK-1 degradation and the stabilization of $\mathrm{I} \kappa \mathrm{B} \alpha$.

CSE mediated stress induces alterations in key virulence factors of $P$. gingivalis. While down-regulated capsular polysaccharides increased biofilm formation, upregulated fimbriae promoted TLR2 hyposensitivity in an IאB $\alpha-$, IRAK-1- dependent manner. Both mechanisms, contribute towards altering host-pathogen interactions and reducing hostinduced inflammatory response consistent with both our prior observations that CSEexposed whole P. gingivalis cells have reduced inflammatory potential compared to control bacteria (274). These observations are also consistent with the clinical profiles of 
smokers of severe periodontal disease who lack overt signs of clinical inflammation (88, 203). 


\section{CHAPTER FIVE: SUMMARY \& FUTURE DIRECTIONS}

Tobacco smoking is a major risk factor for multiple and varied types of diseases, including persistent infections, cancers, autoimmune disorders, and chronic inflammatory diseases - such as chronic periodontitis. The toxicity and / or carcinogenic nature of various chemicals found in cigarette smoke is compounded by their composite debilitating effects on host innate and adaptive immune responses.

Tobacco smoke is the single most important environmental risk factor associated with periodontal diseases with more than $50 \%$ of cases of periodontitis found in current or former smokers. Compared to non-smokers, smokers show increased severity and incidence of periodontal disease and are highly susceptible to persistent periodontal infections by the Gram negative bacterial pathogen, $P$. gingivalis. Seemingly contrary to increased severity, smokers exhibit reduced signs of clinical inflammation (bleeding on probing, redness and edema). This thesis explains the underlying mechanisms that might play a role in this apparent contradiction.

While several studies delineate the role of tobacco smoke in the skewing of immune response to infection very little is known about how it affects the virulence of 
potential periodontal pathogens such as $P$. gingivalis and its subsequent interaction with host. Components of tobacco smoke are available systemically and compromise host immune response. However they are readily available in the oral cavity for interaction with both host tissue and resident pathogenic bacteria. In this dissertation, we show that tobacco smoke presents an environmental stress to $P$. gingivalis and it adapts to this stress by suppressing its inflammatory profile and altering the expression of several genes and outer membrane proteins. Tobacco induced changes to $P$. gingivalis gene expression, phenotype and host pathogen interactions were determined to help better understand why exacerbated disease is accompanied by a reduced inflammatory response in smokers.

Gross, tobacco-induced alterations caused to the $P$. gingivalis genome, transcriptional profile and phenotype were identified. We have found that $P$. gingivalis cells exposed to cigarette smoke extract (CSE) induce a reduced inflammatory profile (reduced levels of proinflammatory cytokines like TNF- $\alpha$, IL-6, IL-12p40) in monocytes and peripheral blood mononuclear cells than unexposed bacteria. This inflammatory suppression was consistent with identified cigarette smoke-induced transcriptional and post-transcriptional alterations. Microarray analysis of CSE exposed $P$. gingivalis revealed altered expression of several genes including detoxification and oxidative stressrelated genes; DNA repair genes; and multiple genes related to $P$. gingivalis virulence, including genes in the major fimbrial and capsular operons. Exposure to CSE also altered the expression of outer membrane proteins, most notably by inducing the virulence factors RagA and RagB, and a putative lipoprotein cotranscribed with the minor fimbrial antigen. 
CSE exposure also resulted in phenotypic alterations such as increased fimbrial expression and downregulated capsular layer. Upregulated fimbriae play an important role in increasing persistence by forming significantly more robust biofilms. We further show that, while FimA is recognized by TLR2/6, the major fimbrial antigen has minimal inflammatory activity in several cell types. Furthermore, FimA stimulation chronically abrogates the pro-inflammatory response to subsequent TLR2 stimulation by other TLR2-specific agonists (Pam3CSK4, FSL, and Mfal) in an IKB $\alpha$ - and IRAK-1-dependent manner. These changes may explain, in part, the altered virulence and host-pathogen interactions that have been documented in vivo in smokers with periodontal disease.

Our studies demonstrate that the recombinant Mfal (rMfa1) is highly proinflammatory. However recent work by Chris Cutler's group $(172,177)$ demonstrates that native Mfal, isolated from $P$. gingivalis 381 is a glycosylated protein and is important in binding to DC-SIGN receptors on Monocyte derived Dendritic cells (MoDC). When these cells are stimulated with either wild-type $\mathrm{Pg} 381$ or isogenic major (DPG-3)-, minor (MFI)-, or double fimbriae (MFB)-deficient mutant $P$. gingivalis strains, MFI was the most potent inducer of proinflammatory cytokines (IL-1 $\beta$, IL-8, IL-6, and TNF- $n$ ) while DPG-3 induced significantly lower levels of TNF- $n$ and IL-1 $\beta$ indicating a role of Mfa1 in lowering proinflammatory cytokine induction from these cells. It would be important to determine whether glycosylation is important in reducing the inflammatory potential Mfal and to determine whether the glycosylation patterns found in rMfal which was expressed in $E$. coli are different than those expressed by $P$. gingivalis strains. Alternatively, CSE exposure might result in addition of different 
types/amounts of sugars on Mfal resulting in shifts in glycosylation patterns $P$. gingivalis proteins in a manner that promotes reduced inflammatory potential of the pathogen.

Glycosylation of several proteins in $P$. gingivalis is carried out by the vim family of genes and inactivation of genes in the vim operon such as vimA or vimE results in inactivation of gingipain activity due to ineffective glycosylation of these key virulenceassociated proteases (303). Particularly, inactivation of the vimA gene, which codes for a $39 \mathrm{kD}$ putative acyl-CoA $\mathrm{N}$-acyltransferase, resulted in a loss of Arg-gingipain activity, downregulation of capsule and detection of FimA protein in the vim $A$ defective mutant strain (FLL92). This is an interesting finding as the wildtype W83 strain has been previously shown to lack functional fimbriae and is often cited as a non-fimbriated strain (304). The authors also suggested that the presence of capsule might actually interfere with the production of fimbriae in $P$. gingivalis. Thus the lack of a capsular layer might allow for fimbrial presentation on the surface and allow for subsequent fimbriae dependent interactions such as biofilm formation, adherence, invasion etc. In the context of our studies we find that CSE exposure downregulates capsular polysaccharides while simultaneously promoting major fimbrial expression which is consistent with the $\operatorname{vim} A$ defective mutant strain (FLL92) phenotype. Thus it is likely that CSE alters the expression or activity of $\operatorname{vim} A$ gene product.

Gingipains have been shown to play an important role in the processing of fimbrillin, the monomeric unit of the major fimbriae that is essential for the formation of functional fimbriae on $P$. gingivalis surface (305). Gingipain activity is central to $P$. gingivalis virulence and they are essentially involved in several degradative processes (host tissue associated proteins as well as immune response proteins such as complement 
components and specific cytokines). Although gingipain expression was not altered in microarray data it is possible that the components found is CSE might alter their enzymatic activity. Toxic chemicals found in cigarette smoke have an inhibitory effect on the enzyme activity of several host enzymes like alkaline phosphatase, gluoce-6phosphatase, 5'-nucleotidase, and cholinesterase in mouse liver and small intestine (306). While alpha, beta-unsaturated aldehydes (acrolein, crotonaldehyde) and saturated aldehydes (acetaldehyde) significantly inhibited salivary amylase activity due to the interaction between aldehydes and - $\mathrm{SH}$ groups of these enzymes (307). Thus it is likely that noxious chemicals found in cigarette smoke might alter the enzymatic activity of gingipains which are extracellular secreted proteases and are likely to interface with cigarette smoke associated toxins.

$P$. gingivalis major fimbriae have been shown to be essential for inducing such $\mathrm{Nf}-\mathrm{\kappa B}$ downregulation and reducing the inflammatory response from macrophages that is associated with pathogen clearance by inducing TLR2-CXCR4 crosstalk (157). Induction of TLR2-CXCR4-C5aR crosstalk promotes cAMP production and subsequent cAMP dependent activation of protein kinase A (PKA) that is associated with downregulation of NF- $\mathrm{kB}$ activity $(308,309)$. In this thesis we show that $\mathrm{rFimA}$ has modest inflammatory activity but induces significantly higher amounts of IL-10 compared to Mfal. The downstream signaling mechanisms behind such induction remain to be determined. One possible mechanism causing FimA dependent IL-10 activation could be cAMP/cAMPdependent PKA activation that has been previously shown to induce IL-10 production in monocytes via phosphorylation of cAMP response element binding protein (CREB) (310, 311). Thus competition between NF- $\mathrm{KB}$ and CREB for binding to the coactivator CREB- 
binding protein $(\mathrm{CBP})$ is important in regulating transcription of proinflammatory cytokines (TNF $\alpha$, IL-6, IL-8, IL-1 $\beta$ ) or the anti-inflammatory cytokine IL-10. Whole $P$. gingivalis cells passaged in CSE also induced significantly lower levels of proinflammatory cytokines (IL-6, TNF- $\alpha$ ) and higher levels of IL-10 than control nonexposed cells. Thus it is possible that FimA upregulation contributes towards IL-10 production by CSE-exposed $P$. gingivalis in a cAMP-PKA-CREB dependent manner and downregulation of $\mathrm{Nf}-\mathrm{\kappa B}$ associated transcription of proinflammatory genes.

There are several other negative-feedback mechanisms and signaling molecules that regulate TLR associated signal transduction to avert chronic TLR activation which might cause harmful immunological responses. In our studies we looked at one such regulator IRAK-M that prevents TRAF6 induced activation of IRAK1 by preventing its dissociation from IRAK1-IRAK4 complex (300). FimA stimulation also leads to the rapid degradation and chronic suppression of IRAK-M. However this would appear inconsequential with respect to NF- $\mathrm{KB}$ activation because of the unavailability of IRAK1. It is possible that FimA in addition to IRAKI and IRAK-M degradation might induce TLR2 hyporesponsivensess through other negative regulators like Suppressor of cytokine signalling-1 (SOCS-1) that has been shown to regulate TLR2 and 4 by targeting Mal, the adaptor protein important for Myd88 signaling, for polyubiquitination and subsequent proteosomal degradation (312).

Besides inducing inflammatory suppression, $P$. gingivalis fimbriae are important in persistence. Persistence, in the context of the oral cavity, would not only involve host inflammatory suppression but also successful interaction with other colonizers of oral plaque by effective recruitment into oral biofilms. We have shown that the phenotypic 
alterations caused by CSE promote $P$. gingivalis existence in a biofilm. Specifically CSE induced loss of capsular layer and upregulated fimbriae. While presence of a capsular layer is inversely proportional to biofilm formation (275) fimbriae are important in biofilm formation and FimA deficient strains cannot form effective biofilms (287). In mature dental plaque $P$. gingivalis clearly interacts with multiple middle and late colonizers, such as Actinomyces viscosus (313), Treponema denticola $(314,315)$ and Tannerella forsynthus (316). However, adhesive interactions with primary colonizers, such as Streptococcus gordonii, are critical for $P$. gingivalis colonization of the supragingival niche $(284,317)$. The early colonizers, like $S$. gordonii, initiate biofilm formation by binding to the tooth pellicle and providing an attachment surface for bacterial secession through multimodal receptor-ligand mediated coadhesive interactions. For example, the long fimbriae (FimA) of $P$. gingivalis bind to $S$. gordonii Glyceraldehyde-3 phosphate deydrogenase (GAPDH) $(284,318)$ while the shorter fimbriae (Mfal) bind to streptococcal SspB protein (169). An 80 amino acid sequence on the S. gordonii surface protein, $\mathrm{SspB}$, is critical for Mfal adhesion, with a synthetic peptide of this SspB region, named BAR, a potent inhibitor of Mfal-dependent $P$. gingivalis-S. gordonii biofilms formation (319). As CSE upregulates fimA gene activity, it would be of interest to determine CSE exposure augments $P$. gingivalis - S. gordonii biofilms formation via a FimA-dependent mechanism.

Presence of a persistent $P$. gingivalis infection leads to gingival ulceration and local vascular changes that promote transient, low level bacteremias (106) that help spread $P$. gingivalis and other periodontal bacteria from the oral cavity making periodontitis an important risk factor for heart disease. Viable $P$. gingivalis cells, as well 
as $P$. gingivalis DNA, have been found in atheromatous plaques $(320,321)$ while $P$. gingivalis can invade endothelial cells as well as smooth muscle cells and spread from infected cells to uninfected cells (322). Tobacco smoke-mediated changes to $P$. gingivalis are important contributing factors to the increased persistence of this pathogen in smokers and, subsequently, an increased risk for vascular inflammation and atherosclerotic progression.

These studies provide some of the first information to explain, mechanistically, how tobacco smoke changes the $P$. gingivalis phenotype in a manner likely to promote $P$. gingivalis colonization and infection while simultaneously reducing the host response to this major mucosal pathogen. The mechanisms responsible for periodontal disease induction and progression may actually be different in smokers compared to nonsmokers, demonstrating a need for differential treatment regimens. 


\section{REFERENCES}

1. 2002. Annual smoking-attributable mortality, years of potential life lost, and economic costs--United States, 1995-1999. MMWR Morb Mortal Wkly Rep 51:300-303.

2. 2005. Annual smoking-attributable mortality, years of potential life lost, and productivity losses--United States, 1997-2001. MMWR Morb Mortal Wkly Rep 54:625-628.

3. Petersen, P. E. 2003. Tobacco and oral health--the role of the world health organization. Oral Health Prev Dent 1:309-315.

4. Jha, P., F. J. Chaloupka, M. Corrao, and B. Jacob. 2006. Reducing the burden of smoking world-wide: effectiveness of interventions and their coverage. Drug Alcohol Rev 25:597-609.

5. Stampfli, M. R., and G. P. Anderson. 2009. How cigarette smoke skews immune responses to promote infection, lung disease and cancer. Nat Rev Immunol 9:377-384.

6. Gilmour, M. I., M. S. Jaakkola, S. J. London, A. E. Nel, and C. A. Rogers. 2006. How exposure to environmental tobacco smoke, outdoor air pollutants, and increased pollen burdens influences the incidence of asthma. Environ Health Perspect 114:627-633.

7. Mehta, H., K. Nazzal, and R. T. Sadikot. 2008. Cigarette smoking and innate immunity. Inflamm Res 57:497-503.

8. Jha, P. 2009. Avoidable global cancer deaths and total deaths from smoking. Nat Rev Cancer 9:655-664.

9. Vardavas, C. I., and D. B. Panagiotakos. 2009. The causal relationship between passive smoking and inflammation on the development of cardiovascular disease: a review of the evidence. Inflamm Allergy Drug Targets 8:328-333.

10. Salmasi, G., R. Grady, J. Jones, and S. D. MeDonald. Environmental tobacco smoke exposure and perinatal outcomes: a systematic review and metaanalyses. Acta Obstet Gynecol Scand 89:423-441.

11. El-Mohandes, A. A., M. Kiely, S. M. Blake, M. G. Gantz, and M. N. ElKhorazaty. An intervention to reduce environmental tobacco smoke exposure improves pregnancy outcomes. Pediatrics 125:721-728.

12. Talbot, $P$., and $K$. Riveles. 2005. Smoking and reproduction: the oviduct as a target of cigarette smoke. Reprod Biol Endocrinol 3:52. 
13. Sepaniak, S., T. Forges, and P. Monnier-Barbarino. 2005. [Consequences of cigarette smoking on male fertility]. J Gynecol Obstet Biol Reprod (Paris) 34 Spec No 1:3S102-111.

14. Husgafvel-Pursiainen, K. 2004. Genotoxicity of environmental tobacco smoke: a review. Mutat Res 567:427-445.

15. Bagaitkar, J., D. R. Demuth, and D. A. Scott. 2008. Tobacco use increases susceptibility to bacterial infection. Tob Induc Dis 4:12.

16. Schroeter, M. R., M. Sawalich, T. Humboldt, M. Leifheit, K. Meurrens, A. Berges, H. Xu, S. Lebrun, T. Wallerath, S. Konstantinides, R. Schleef, and K. Schaefer. 2008. Cigarette smoke exposure promotes arterial thrombosis and vessel remodeling after vascular injury in apolipoprotein E-deficient mice. $J$ Vasc Res 45:480-492.

17. Ezzati, M., S. J. Henley, M. J. Thun, and A. D. Lopez. 2005. Role of smoking in global and regional cardiovascular mortality. Circulation 112:489-497.

18. Wolf, P. A., R. B. D'Agostino, W. B. Kannel, R. Bonita, and A. J. Belanger. 1988. Cigarette smoking as a risk factor for stroke. The Framingham Study. JAMA 259:1025-1029.

19. Mercado, C., and E. A. Jaimes. 2007. Cigarette smoking as a risk factor for atherosclerosis and renal disease: novel pathogenic insights. Curr Hypertens Rep 9:66-72.

20. Bullen, C. 2008. Impact of tobacco smoking and smoking cessation on cardiovascular risk and disease. Expert Rev Cardiovasc Ther 6:883-895.

21. Rahman, M. M., and I. Laher. 2007. Structural and functional alteration of blood vessels caused by cigarette smoking: an overview of molecular mechanisms. Curr Vasc Pharmacol 5:276-292.

22. Rota, M. T., P. Poggi, L. Baratta, E. Gaeta, R. Boratto, and A. Tazzi. 1999. Tobacco smoke in the development and therapy of periodontal disease: progress and questions. Bull Group Int Rech Sci Stomatol Odontol 41:116122.

23. Onozaki, K. 2009. Etiological and biological aspects of cigarette smoking in rheumatoid arthritis. Inflamm Allergy Drug Targets 8:364-368.

24. Wolfe, F. 2000. The effect of smoking on clinical, laboratory, and radiographic status in rheumatoid arthritis. $J$ Rheumatol 27:630-637.

25. Saag, K. G., J. R. Cerhan, S. Kolluri, K. Ohashi, G. W. Hunninghake, and D. A. Schwartz. 1997. Cigarette smoking and rheumatoid arthritis severity. Ann Rheum Dis 56:463-469.

26. Costenbader, K. H., and E. W. Karlson. 2006. Cigarette smoking and autoimmune disease: what can we learn from epidemiology? Lupus 15:737745.

27. Michael Pittilo, R. 2000. Cigarette smoking, endothelial injury and cardiovascular disease. Int $J$ Exp Pathol 81:219-230.

28. Lehr, H. A. 2000. Microcirculatory dysfunction induced by cigarette smoking. Microcirculation 7:367-384.

29. Tong, E. K., and S. A. Glantz. 2007. Tobacco industry efforts undermining evidence linking secondhand smoke with cardiovascular disease. Circulation 116:1845-1854. 
30. Roth, M. 2008. Pathogenesis of COPD. Part III. Inflammation in COPD. Int J Tuberc Lung Dis 12:375-380.

31. Macnee, W. 2007. Pathogenesis of chronic obstructive pulmonary disease. Clin Chest Med 28:479-513, v.

32. Cooper, R. G. 2006. Effect of tobacco smoking on renal function. Indian $J$ Med Res 124:261-268.

33. Murphy, T. F. 2006. Otitis media, bacterial colonization, and the smoking parent. Clin Infect Dis 42:904-906.

34. Nuorti, J. P., J. C. Butler, M. M. Farley, L. H. Harrison, A. McGeer, M. S. Kolczak, and R. F. Breiman. 2000. Cigarette smoking and invasive pneumococcal disease. Active Bacterial Core Surveillance Team. $N$ Engl $J$ Med 342:681-689.

35. Fischer, M., K. Hedberg, P. Cardosi, B. D. Plikaytis, F. C. Hoesly, K. R. Steingart, T. A. Bell, D. W. Fleming, J. D. Wenger, and B. A. Perkins. 1997. Tobacco smoke as a risk factor for meningococcal disease. Pediatr Infect Dis $J$ 16:979-983.

36. Iles, K., N. K. Poplawski, and R. T. Couper. 2001. Passive exposure to tobacco smoke and bacterial meningitis in children. J. Paediatr. Child Health 37:388-391.

37. Straus, W. L., J. F. Plouffe, T. M. File, Jr., H. B. Lipman, B. H. Hackman, S. J. Salstrom, R. F. Benson, and R. F. Breiman. 1996. Risk factors for domestic acquisition of legionnaires disease. Ohio legionnaires Disease Group. Arch. Intern. Med. 156:1685-1692.

38. Kolappan, C., and P. G. Gopi. 2002. Tobacco smoking and pulmonary tuberculosis. Thorax 57:964-966.

39. Kolappan, C., P. G. Gopi, R. Subramani, and P. R. Narayanan. 2007. Selected biological and behavioural risk factors associated with pulmonary tuberculosis. Int J Tuberc Lung Dis 11:999-1003.

40. Chiang, C. Y., K. Slama, and D. A. Enarson. 2007. Associations between tobacco and tuberculosis. Int $J$ Tuberc Lung Dis 11:258-262.

41. Bansal, S., S. Kashyap, L. S. Pal, and A. Goel. 2004. Clinical and bacteriological profile of community acquired pneumonia in Shimla, Himachal Pradesh. Indian J Chest Dis Allied Sci 46:17-22.

42. Gold, R. 1999. Epidemiology of bacterial meningitis. Infect. Dis. Clin. North Am. 13:515-525, v.

43. Luksamijarulkul, P., N. Parikumsil, V. Poomsuwan, and W. Konkeaw. 2006. Nosocomial surgical site infection among Photharam Hospital patients with surgery: incidence, risk factors and development of risk screening form. $J$. Med. Assoc. Thai. 89:81-89.

44. Miller, G. C., R. McDermott, B. McCulloch, C. K. Fairley, and R. Muller. 2003. Predictors of the prevalence of bacterial STI among young disadvantaged Indigenous people in north Queensland, Australia. Sex Transm Infect 79:332-335.

45. Calsina, G., J. M. Ramon, and J. J. Echeverria. 2002. Effects of smoking on periodontal tissues. J Clin Periodontol 29:771-776. 
46. Baljoon, M., S. Natto, and J. Bergstrom. 2005. Long-term effect of smoking on vertical periodontal bone loss. J Clin Periodontol 32:789-797.

47. Bagaitkar, J., D. R. Demuth, and D. A. Scott. 2008. Tobacco use and susceptibility to bacterial infection. Tob Induc Dis 4:12.

48. Brook, I., and A. E. Gober. 2005. Recovery of potential pathogens and interfering bacteria in the nasopharynx of smokers and nonsmokers. Chest 127:2072-2075.

49. Brook, I., and A. E. Gober. 2007. Effect of smoking cessation on the microbial flora. Arch. Otolaryngol. Head Neck Surg. 133:135-138.

50. Segala, C., D. Poizeau, F. Neukirch, M. Aubier, J. Samson, and P. Gehanno. 2004. Air pollution, passive smoking, and respiratory symptoms in adults. Arch. Environ. Health 59:669-676.

51. Wakefield, M., L. Trotter, M. Cameron, A. Woodward, G. Inglis, and D. Hill. 2003. Association between exposure to workplace secondhand smoke and reported respiratory and sensory symptoms: cross-sectional study. J. Occup. Environ. Med. 45:622-627.

52. Nandi, S., R. Kumar, P. Ray, H. Vohra, and N. K. Ganguly. 2001. Group A streptococcal sore throat in a periurban population of northern India: a oneyear prospective study. Bull. World Health Organ. 79:528-533.

53. Doebbeling, B. N., and R. P. Wenzel. 1987. The epidemiology of Legionella pneumophila infections. Semin. Respir. Infect. 2:206-221.

54. Kovesi, T., M. Corey, and H. Levison. 1993. Passive smoking and lung function in cystic fibrosis. Am. Rev. Respir. Dis. 148:1266-1271.

55. Smyth, A., U. O'Hea, G. Williams, R. Smyth, and D. Heaf. 1994. Passive smoking and impaired lung function in cystic fibrosis. Arch. Dis. Child. 71:353-354.

56. Collaco, J. M., L. Vanscoy, L. Bremer, K. McDougal, S. M. Blackman, A. Bowers, K. Naughton, J. Jennings, J. Ellen, and G. R. Cutting. 2008. Interactions between secondhand smoke and genes that affect cystic fibrosis lung disease. $J A M A$ 299:417-424.

57. Verma, A., D. Clough, D. McKenna, M. Dodd, and A. K. Webb. 2001. Smoking and cystic fibrosis. J. R. Soc. Med. 94 Suppl 40:29-34.

58. Arcavi, L., and N. L. Benowitz. 2004. Cigarette smoking and infection. Arch. Intern. Med. 164:2206-2216.

59. Pastor, P., F. Medley, and T. V. Murphy. 1998. Invasive pneumococcal disease in Dallas County, Texas: results from population-based surveillance in 1995. Clin. Infect. Dis. 26:590-595.

60. Greene, C. M., M. H. Kyaw, S. M. Ray, W. Schaffner, R. Lynfield, N. L. Barrett, C. Long, K. Gershman, T. Pilishvili, A. Roberson, E. R. Zell, C. G. Whitney, and N. M. Bennett. 2006. Preventability of invasive pneumococcal disease and assessment of current polysaccharide vaccine recommendations for adults: United States, 2001-2003. Clin. Infect. Dis. 43:141-150.

61. Altet-Gomez, M. N., J. Alcaide, P. Godoy, M. A. Romero, and I. Hernandez del Rey. 2005. Clinical and epidemiological aspects of smoking and tuberculosis: a study of 13,038 cases. Int. J. Tuberc. Lung Dis. 9:430-436. 
62. Slama, K., C. Y. Chiang, D. A. Enarson, K. Hassmiller, A. Fanning, P. Gupta, and C. Ray. 2007. Tobacco and tuberculosis: a qualitative systematic review and meta-analysis. Int. J. Tuberc. Lung Dis. 11:1049-1061.

63. Riordan, T., K. Cartwright, N. Andrews, J. Stuart, A. Burris, A. Fox, R. Borrow, T. Douglas-Riley, J. Gabb, and A. Miller. 1998. Acquisition and carriage of meningococci in marine commando recruits. Epidemiol. Infect. 121:495-505.

64. Stanwell-Smith, R. E., J. M. Stuart, A. O. Hughes, P. Robinson, M. B. Griffin, and K. Cartwright. 1994. Smoking, the environment and meningococcal disease: a case control study. Epidemiol. Infect. 112:315-328.

65. Stuart, J. M., K. A. Cartwright, J. A. Dawson, J. Rickard, and N. D. Noah. 1988. Risk factors for meningococcal disease: a case control study in south west England. Community Med. 10:139-146.

66. Stuart, J. M., K. A. Cartwright, P. M. Robinson, and N. D. Noah. 1989. Effect of smoking on meningococcal carriage. Lancet 2:723-725.

67. Tappero, J. W., R. Reporter, J. D. Wenger, B. A. Ward, M. W. Reeves, T. S. Missbach, B. D. Plikaytis, L. Mascola, and A. Schuchat. 1996. Meningococcal disease in Los Angeles County, California, and among men in the county jails. $N$. Engl. J. Med. 335:833-840.

68. Melles, D. C., D. Bogaert, R. F. Gorkink, J. K. Peeters, M. J. Moorhouse, A. Ott, W. B. van Leeuwen, G. Simons, H. A. Verbrugh, P. W. Hermans, and A. van Belkum. 2007. Nasopharyngeal co-colonization with Staphylococcus aureus and Streptococcus pneumoniae in children is bacterial genotype independent. Microbiology 153:686-692.

69. Evans, A. L., A. J. Scally, S. J. Wellard, and J. D. Wilson. 2007. Prevalence of bacterial vaginosis in lesbians and heterosexual women in a community setting. Sex. Transm. Infect. 83:470-475.

70. Larsson, P. G., L. Fahraeus, B. Carlsson, T. Jakobsson, and U. Forsum. 2007. Predisposing factors for bacterial vaginosis, treatment efficacy and pregnancy outcome among term deliveries; results from a preterm delivery study. BMC Womens Health 7:20.

71. Nelson, D. B., S. Bellamy, A. Odibo, I. Nachamkin, R. B. Ness, and L. AllenTaylor. 2007. Vaginal symptoms and bacterial vaginosis (BV): how useful is self-report? Development of a screening tool for predicting BV status. Epidemiol. Infect. 135:1369-1375.

72. Cardenas, V. M., and D. Y. Graham. 2005. Smoking and Helicobacter pylori infection in a sample of U.S. adults. Epidemiology 16:586-590.

73. Regula, J., E. Hennig, T. Burzykowski, J. Orlowska, K. Przytulski, M. Polkowski, A. Dziurkowska-Marek, T. Marek, A. Nowak, E. Butruk, and J. Ostrowski. 2003. Multivariate analysis of risk factors for development of duodenal ulcer in Helicobacter pylori-infected patients. Digestion 67:25-31.

74. Menzel, M., J. Hogel, G. Allmendinger, and E. Schmid. 1995. Relative risks of age, gender, nationality, smoking, and Helicobacter-pylori-infection in duodenal and gastric ulcer and interactions. Z. Gastroenterol. 33:193-197.

75. De Francesco, V., A. Zullo, M. Margiotta, S. Marangi, O. Burattini, P. Berloco, F. Russo, M. Barone, A. Di Leo, M. F. Minenna, V. Stoppino, S. 
Morini, C. Panella, A. Francavilla, and E. Ierardi. 2004. Sequential treatment for Helicobacter pylori does not share the risk factors of triple therapy failure. Aliment. Pharmacol. Ther. 19:407-414.

76. Suzuki, T., K. Matsuo, H. Ito, A. Sawaki, K. Hirose, K. Wakai, S. Sato, T. Nakamura, K. Yamao, R. Ueda, and K. Tajima. 2006. Smoking increases the treatment failure for Helicobacter pylori eradication. Am. J. Med. 119:217224.

77. Grossi, S. G., R. J. Genco, E. E. Machtei, A. W. Ho, G. Koch, R. Dunford, J. J. Zambon, and E. Hausmann. 1995. Assessment of risk for periodontal disease. II. Risk indicators for alveolar bone loss. J. Periodontol. 66:23-29.

78. Ah, M. K., G. K. Johnson, W. B. Kaldahl, K. D. Patil, and K. L. Kalkwarf. 1994. The effect of smoking on the response to periodontal therapy. J. Clin. Periodontol. 21:91-97.

79. Apatzidou, D. A., M. P. Riggio, and D. F. Kinane. 2005. Impact of smoking on the clinical, microbiological and immunological parameters of adult patients with periodontitis. J. Clin. Periodontol. 32:973-983.

80. Bergstrom, J. 2004. Tobacco smoking and chronic destructive periodontal disease. Odontology 92:1-8.

81. Bergstrom, J. 2004. Influence of tobacco smoking on periodontal bone height. Long-term observations and a hypothesis. J. Clin. Periodontol. 31:260-266.

82. Bergstrom, J. 2006. Periodontitis and smoking: an evidence-based appraisal. $J$ Evid Based Dent Pract 6:33-41.

83. Bergstrom, J., S. Eliasson, and J. Dock. 2000. A 10-year prospective study of tobacco smoking and periodontal health. J. Periodontol. 71:1338-1347.

84. Gonzalez, Y. M., A. De Nardin, S. G. Grossi, E. E. Machtei, R. J. Genco, and E. De Nardin. 1996. Serum cotinine levels, smoking, and periodontal attachment loss. J. Dent. Res. 75:796-802.

85. Haffajee, A. D., and S. S. Socransky. 2001. Relationship of cigarette smoking to attachment level profiles. J. Clin. Periodontol. 28:283-295.

86. Kinane, D. F., and I. G. Chestnutt. 2000. Smoking and periodontal disease. Crit. Rev. Oral Biol. Med. 11:356-365.

87. MacFarlane, G. D., M. C. Herzberg, L. F. Wolff, and N. A. Hardie. 1992. Refractory periodontitis associated with abnormal polymorphonuclear leukocyte phagocytosis and cigarette smoking. J. Periodontol. 63:908-913.

88. Palmer, R. M., R. F. Wilson, A. S. Hasan, and D. A. Scott. 2005. Mechanisms of action of environmental factors--tobacco smoking. J Clin Periodontol 32 Suppl 6:180-195.

89. Tomar, S. L., and S. Asma. 2000. Smoking-attributable periodontitis in the United States: findings from NHANES III. National Health and Nutrition Examination Survey. J. Periodontol. 71:743-751.

90. Mahid, S. S., K. S. Minor, R. E. Soto, C. A. Hornung, and S. Galandiuk. 2006. Smoking and inflammatory bowel disease: a meta-analysis. Mayo Clin. Proc. 81:1462-1471.

91. Tuvlin, J. A., S. S. Raza, S. Bracamonte, C. Julian, S. B. Hanauer, D. L. Nicolae, A. C. King, and J. H. Cho. 2007. Smoking and inflammatory bowel 
disease: trends in familial and sporadic cohorts. Inflamm. Bowel Dis. 13:573579.

92. Lakatos, P. L., T. Szamosi, and L. Lakatos. 2007. Smoking in inflammatory bowel diseases: good, bad or ugly? World J Gastroenterol 13:6134-6139.

93. Mokbel, M., F. Carbonnel, L. Beaugerie, J. P. Gendre, and J. Cosnes. 1998. [Effect of smoking on the long-term course of ulcerative colitis]. Gastroenterol. Clin. Biol. 22:858-862.

94. Bridger, S., J. C. Lee, I. Bjarnason, J. E. Jones, and A. J. Macpherson. 2002. In siblings with similar genetic susceptibility for inflammatory bowel disease, smokers tend to develop Crohn's disease and non-smokers develop ulcerative colitis. Gut 51:21-25.

95. Mahid, S. S., K. S. Minor, A. J. Stromberg, and S. Galandiuk. 2007. Active and passive smoking in childhood is related to the development of inflammatory bowel disease. Inflamm. Bowel Dis. 13:431-438.

96. Johnson, G. J., J. Cosnes, and J. C. Mansfield. 2005. Review article: smoking cessation as primary therapy to modify the course of Crohn's disease. Aliment. Pharmacol. Ther. 21:921-931.

97. Kane, S. V., M. Flicker, and F. Katz-Nelson. 2005. Tobacco use is associated with accelerated clinical recurrence of Crohn's disease after surgically induced remission. J. Clin. Gastroenterol. 39:32-35.

98. Hammaren-Malmi, S., H. Saxen, J. Tarkkanen, and P. S. Mattila. 2007. Passive smoking after tympanostomy and risk of recurrent acute otitis media. Int. J. Pediatr. Otorhinolaryngol. 71:1305-1310.

99. Brook, I., and A. E. Gober. 2005. Recovery of potential pathogens and interfering bacteria in the nasopharynx of otitis media-prone children and their smoking and nonsmoking parents. Arch. Otolaryngol. Head Neck Surg. 131:509-512.

100. Ilicali, O. C., N. Keles, K. De er, O. F. Sa un, and Y. Guldiken. 2001. Evaluation of the effect of passive smoking on otitis media in children by an objective method: urinary cotinine analysis. Laryngoscope 111:163-167.

101. Neumayer, L., P. Hosokawa, K. Itani, M. El-Tamer, W. G. Henderson, and S. F. Khuri. 2007. Multivariable predictors of postoperative surgical site infection after general and vascular surgery: results from the patient safety in surgery study. J. Am. Coll. Surg. 204:1178-1187.

102. Cheadle, W. G. 2006. Risk factors for surgical site infection. Surg Infect (Larchmt) 7 Suppl 1:S7-11.

103. Haas, J. P., A. M. Evans, K. E. Preston, and E. L. Larson. 2005. Risk factors for surgical site infection after cardiac surgery: the role of endogenous flora. Heart Lung 34:108-114.

104. Brown, L. J., B. A. Johns, and T. P. Wall. 2002. The economics of periodontal diseases. Periodontol 2000 29:223-234.

105. Pihlstrom, B. L., B. S. Michalowicz, and N. W. Johnson. 2005. Periodontal diseases. Lancet 366:1809-1820.

106. Gibson, F. C., 3rd, T. Ukai, and C. A. Genco. 2008. Engagement of specific innate immune signaling pathways during Porphyromonas gingivalis 
induced chronic inflammation and atherosclerosis. Front Biosci 13:20412059.

107. Dietrich, T., and R. I. Garcia. 2005. Associations between periodontal disease and systemic disease: evaluating the strength of the evidence. $J$ Periodontol 76:2175-2184.

108. Nibali, L., F. D'Aiuto, G. Griffiths, K. Patel, J. Suvan, and M. S. Tonetti. 2007. Severe periodontitis is associated with systemic inflammation and a dysmetabolic status: a case-control study. J Clin Periodontol 34:931-937.

109. Demmer, R. T., and $M$. Desvarieux. 2006. Periodontal infections and cardiovascular disease: the heart of the matter. J Am Dent Assoc 137 Suppl:14S-20S; quiz 38S.

110. Cengiz, M. I., S. Bal, S. Gokcay, and K. Cengiz. 2007. Does periodontal disease reflect atherosclerosis in continuous ambulatory peritoneal dialysis patients? J Periodontol 78:1926-1934.

111. Okuda, K., R. Kimizuka, S. Abe, T. Kato, and K. Ishihara. 2005. Involvement of periodontopathic anaerobes in aspiration pneumonia. $J$ Periodontol 76:2154-2160.

112. Paju, S., and F. A. Scannapieco. 2007. Oral biofilms, periodontitis, and pulmonary infections. Oral Dis 13:508-512.

113. Robert, R., G. Grollier, J. P. Frat, C. Godet, M. Adoun, J. L. Fauchere, and P. Dore. 2003. Colonization of lower respiratory tract with anaerobic bacteria in mechanically ventilated patients. Intensive Care Med 29:10621068.

114. Thorman, R., M. Neovius, and B. Hylander. 2009. Clinical findings in oral health during progression of chronic kidney disease to end-stage renal disease in a Swedish population. Scand J Urol Nephrol 43:154-159.

115. Khader, Y. S., and Q. Ta'ani. 2005. Periodontal diseases and the risk of preterm birth and low birth weight: a meta-analysis. $J$ Periodontol 76:161165.

116. Ikegami, A., P. Chung, and Y. W. Han. 2009. Complementation of the fadA mutation in Fusobacterium nucleatum demonstrates that the surfaceexposed adhesin promotes cellular invasion and placental colonization. Infection and immunity 77:3075-3079.

117. Armitage, G. C. 1995. Clinical evaluation of periodontal diseases. Periodontol 2000 7:39-53.

118. Baelum, V., and R. Lopez. 2003. Defining and classifying periodontitis: need for a paradigm shift? Eur J Oral Sci 111:2-6.

119. Lovegrove, J. M. 2004. Dental plaque revisited: bacteria associated with periodontal disease. $J N Z$ Soc Periodontol:7-21.

120. Kinane, D. F., D. R. Demuth, S. U. Gorr, G. N. Hajishengallis, and M. H. Martin. 2007. Human variability in innate immunity. Periodontol 2000 45:1434.

121. Borrell, L. N., and P. N. Papapanou. 2005. Analytical epidemiology of periodontitis. J Clin Periodontol 32 Suppl 6:132-158.

122. Mullally, B. H. 2004. The influence of tobacco smoking on the onset of periodontitis in young persons. Tob Induc Dis 2:53-65. 
123. Bergstrom, J., S. Eliasson, and J. Dock. 2000. Exposure to tobacco smoking and periodontal health. Journal of Clinical Periodontology 27:61-68.

124. Grossi, S. G., R. J. Genco, E. E. Machtei, A. W. Ho, G. Koch, R. Dunford, J. J. Zambon, and E. Hausmann. 1995. Assessment of risk for periodontal disease. II. Risk indicators for alveolar bone loss. Journal of Periodontology 66:23-29.

125. Grossi, S. G., J. J. Zambon, A. W. Ho, G. Koch, R. G. Dunford, E. E. Machtei, O. M. Norderyd, and R. J. Genco. 1994. Assessment of risk for periodontal disease. I. Risk indicators for attachment loss. J Periodontol 65:260-267.

126. McGuire, M. K., and M. E. Nunn. 1996. Prognosis versus actual outcome. III. The effectiveness of clinical parameters in accurately predicting tooth survival. J Periodontol 67:666-674.

127. Giannopoulou, C., A. Geinoz, and G. Cimasoni. 1999. Effects of nicotine on periodontal ligament fibroblasts in vitro. J. Clin. Periodontol. 26:49-55.

128. James, J. A., N. M. Sayers, D. B. Drucker, and P. S. Hull. 1999. Effects of tobacco products on the attachment and growth of periodontal ligament fibroblasts. $J$ Periodontol 70:518-525.

129. Chang, Y. C., Y. S. Hsieh, C. K. Lii, F. M. Huang, K. W. Tai, and M. Y. Chou. 2003. Induction of c-fos expression by nicotine in human periodontal ligament fibroblasts is related to cellular thiol levels. $J$ Periodontal $R e s$ 38:4450.

130. Chang, Y. C., C. K. Lii, K. W. Tai, and M. Y. Chou. 2001. Adverse effects of arecoline and nicotine on human periodontal ligament fibroblasts in vitro. $J$ Clin Periodontol 28:277-282.

131. Zhou, J., B. L. Olson, and L. J. Windsor. 2007. Nicotine increases the collagen-degrading ability of human gingival fibroblasts. $J$ Periodontal Res 42:228-235.

132. Zhang, W., F. Song, and L. J. Windsor. 2009. Cigarette smoke condensate affects the collagen-degrading ability of human gingival fibroblasts. $J$ Periodontal Res 44:704-713.

133. Rezavandi, K., R. M. Palmer, E. W. Odell, D. A. Scott, and R. F. Wilson. 2002. Expression of ICAM-1 and E-selectin in gingival tissues of smokers and non-smokers with periodontitis. J Oral Pathol Med 31:59-64.

134. Bostrom, L., J. Bergstrom, G. Dahlen, and L. E. Linder. 2001. Smoking and subgingival microflora in periodontal disease. $J$ Clin Periodontol 28:212-219.

135. Darby, I. B., P. J. Hodge, M. P. Riggio, and D. F. Kinane. 2005. Clinical and microbiological effect of scaling and root planing in smoker and non-smoker chronic and aggressive periodontitis patients. $J$ Clin Periodontol 32:200-206.

136. Preber, H., J. Bergstrom, and L. E. Linder. 1992. Occurrence of periopathogens in smoker and non-smoker patients. $J$ Clin Periodontol 19:667-671.

137. Stoltenberg, J. L., J. B. Osborn, B. L. Pihlstrom, M. C. Herzberg, D. M. Aeppli, L. F. Wolff, and G. E. Fischer. 1993. Association between cigarette smoking, bacterial pathogens, and periodontal status. J Periodontol 64:12251230. 
138. Zambon, J. J., S. G. Grossi, E. E. Machtei, A. W. Ho, R. Dunford, and R. J. Genco. 1996. Cigarette smoking increases the risk for subgingival infection with periodontal pathogens. $J$ Periodontol 67:1050-1054.

139. Haffajee, A. D., and S. S. Socransky. 2001. Relationship of cigarette smoking to the subgingival microbiota. J Clin Periodontol 28:377-388.

140. Kamma, J. J., M. Nakou, and P. C. Baehni. 1999. Clinical and microbiological characteristics of smokers with early onset periodontitis. $J$ Periodontal Res 34:25-33.

141. Eggert, F. M., M. H. McLeod, and G. Flowerdew. 2001. Effects of smoking and treatment status on periodontal bacteria: evidence that smoking influences control of periodontal bacteria at the mucosal surface of the gingival crevice. $J$ Periodontol 72:1210-1220.

142. Umeda, M., C. Chen, I. Bakker, A. Contreras, J. L. Morrison, and J. Slots. 1998. Risk indicators for harboring periodontal pathogens. $J$ Periodontol 69:1111-1118.

143. van Winkelhoff, A. J., C. J. Bosch-Tijhof, E. G. Winkel, and W. A. van der Reijden. 2001. Smoking affects the subgingival microflora in periodontitis. $J$ Periodontol 72:666-671.

144. Shiloah, J., M. R. Patters, and M. B. Waring. 2000. The prevalence of pathogenic periodontal microflora in healthy young adult smokers. $J$ Periodontol 71:562-567.

145. Gomes, S. C., F. B. Piccinin, R. V. Oppermann, C. Susin, C. I. Nonnenmacher, R. Mutters, and R. A. Marcantonio. 2006. Periodontal status in smokers and never-smokers: clinical findings and real-time polymerase chain reaction quantification of putative periodontal pathogens. $J$ Periodontol 77:1483-1490.

146. Socransky, S. S., and A. D. Haffajee. 2005. Periodontal microbial ecology. Periodontol 2000 38:135-187.

147. Grossi, S. G., J. M. Goodson, J. C. Gunsolley, J. Otomo-Corgel, P. S. Bland, F. Doherty, and J. Comiskey. 2007. Mechanical therapy with adjunctive minocycline microspheres reduces red-complex bacteria in smokers. $J$ Periodontol 78:1741-1750.

148. Kamma, J. J., M. Nakou, and F. A. Manti. 1995. Predominant microflora of severe, moderate and minimal periodontal lesions in young adults with rapidly progressive periodontitis. $J$ Periodontal Res 30:66-72.

149. Kamma, J. J., M. Nakou, and F. A. Manti. 1994. Microbiota of rapidly progressive periodontitis lesions in association with clinical parameters. $J$ Periodontol 65:1073-1078.

150. Amano, A., I. Nakagawa, N. Okahashi, and N. Hamada. 2004. Variations of Porphyromonas gingivalis fimbriae in relation to microbial pathogenesis. $J$ Periodontal Res 39:136-142.

151. Yoshimura, F., Y. Murakami, K. Nishikawa, Y. Hasegawa, and S. Kawaminami. 2008. Surface components of Porphyromonas gingivalis. $J$ Periodontal Res. 
152. Hamada, N., K. Watanabe, C. Sasakawa, M. Yoshikawa, F. Yoshimura, and T. Umemoto. 1994. Construction and characterization of a fimA mutant of Porphyromonas gingivalis. Infect Immun 62:1696-1704.

153. Dickinson, D. P., M. A. Kubiniec, F. Yoshimura, and R. J. Genco. 1988. Molecular cloning and sequencing of the gene encoding the fimbrial subunit protein of Bacteroides gingivalis. J Bacteriol 170:1658-1665.

154. Amano, A., M. Kuboniwa, I. Nakagawa, S. Akiyama, I. Morisaki, and S. Hamada. 2000. Prevalence of specific genotypes of Porphyromonas gingivalis fim $A$ and periodontal health status. $J$ Dent Res 79:1664-1668.

155. Nishiyama, S., Y. Murakami, H. Nagata, S. Shizukuishi, I. Kawagishi, and F. Yoshimura. 2007. Involvement of minor components associated with the FimA fimbriae of Porphyromonas gingivalis in adhesive functions. Microbiology 153:1916-1925.

156. Watanabe, K., T. Onoe, M. Ozeki, Y. Shimizu, T. Sakayori, H. Nakamura, and $F$. Yoshimura. 1996. Sequence and product analyses of the four genes downstream from the fimbrilin gene (fimA) of the oral anaerobe Porphyromonas gingivalis. Microbiol Immunol 40:725-734.

157. Wang, M., M. A. Shakhatreh, D. James, S. Liang, S. Nishiyama, F. Yoshimura, D. R. Demuth, and G. Hajishengallis. 2007. Fimbrial proteins of porphyromonas gingivalis mediate in vivo virulence and exploit TLR2 and complement receptor 3 to persist in macrophages. Journal of Immunology 179:2349-2358.

158. Hamada, S., A. Amano, S. Kimura, I. Nakagawa, S. Kawabata, and I. Morisaki. 1998. The importance of fimbriae in the virulence and ecology of some oral bacteria. Oral Microbiol Immunol 13:129-138.

159. Lamont, R. J., A. Chan, C. M. Belton, K. T. Izutsu, D. Vasel, and A. Weinberg. 1995. Porphyromonas gingivalis invasion of gingival epithelial cells. Infect Immun 63:3878-3885.

160. Amano, A. 2007. Disruption of epithelial barrier and impairment of cellular function by Porphyromonas gingivalis. Front Biosci 12:3965-3974.

161. Amano, A., T. Fujiwara, H. Nagata, M. Kuboniwa, A. Sharma, H. T. Sojar, R. J. Genco, S. Hamada, and S. Shizukuishi. 1997. Prophyromonas gingivalis fimbriae mediate coaggregation with Streptococcus oralis through specific domains. J Dent Res 76:852-857.

162. Hajishengallis, G., M. Wang, E. Harokopakis, M. Triantafilou, and K. Triantafilou. 2006. Porphyromonas gingivalis fimbriae proactively modulate beta 2 integrin adhesive activity and promote binding to and internalization by macrophages. Infect Immun 74:5658-5666.

163. Hajishengallis, G., M. A. Shakhatreh, M. Wang, and S. Liang. 2007. Complement receptor 3 blockade promotes IL-12-Mediated Clearance of Porphyromonas gingivalis and Negates Its Virulence In Vivo. J Immunol 179:2359-2367.

164. Umemoto, T., and N. Hamada. 2003. Characterization of biologically active cell surface components of a periodontal pathogen. The roles of major and minor fimbriae of Porphyromonas gingivalis. $J$ Periodontol 74:119-122. 
165. Malek, R., J. G. Fisher, A. Caleca, M. Stinson, C. J. van Oss, J. Y. Lee, M. I. Cho, R. J. Genco, R. T. Evans, and D. W. Dyer. 1994. Inactivation of the Porphyromonas gingivalis fimA gene blocks periodontal damage in gnotobiotic rats. $J$ Bacteriol 176:1052-1059.

166. Khlgatian, M., H. Nassar, H. H. Chou, F. C. Gibson, 3rd, and C. A. Genco. 2002. Fimbria-dependent activation of cell adhesion molecule expression in Porphyromonas gingivalis-infected endothelial cells. Infect Immun 70:257267.

167. Eskan, M. A., G. Hajishengallis, and D. F. Kinane. 2007. Differential activation of human gingival epithelial cells and monocytes by Porphyromonas gingivalis fimbriae. Infection and Immunity 75:892-898.

168. Graves, D. T., G. Naguib, H. Lu, T. Desta, and S. Amar. 2005. Porphyromonas gingivalis fimbriae are pro-inflammatory but do not play a prominent role in the innate immune response to $P$. gingivalis. $J$ Endotoxin Res 11:13-18.

169. Park, Y., M. R. Simionato, K. Sekiya, Y. Murakami, D. James, W. Chen, M. Hackett, F. Yoshimura, D. R. Demuth, and R. J. Lamont. 2005. Short fimbriae of Porphyromonas gingivalis and their role in coadhesion with Streptococcus gordonii. Infect Immun 73:3983-3989.

170. Hamada, N., H. T. Sojar, M. I. Cho, and R. J. Genco. 1996. Isolation and characterization of a minor fimbria from Porphyromonas gingivalis. Infect Immun 64:4788-4794.

171. Hasegawa, Y., J. Iwami, K. Sato, Y. Park, K. Nishikawa, T. Atsumi, K. Moriguchi, Y. Murakami, R. J. Lamont, H. Nakamura, N. Ohno, and F. Yoshimura. 2009. Anchoring and length regulation of Porphyromonas gingivalis Mfa1 fimbriae by the downstream gene product Mfa2. Microbiology 155:3333-3347.

172. Zeituni, A. E., W. McCaig, E. Scisci, D. G. Thanassi, and C. W. Cutler. The native 67-kilodalton minor fimbria of Porphyromonas gingivalis is a novel glycoprotein with DC-SIGN-targeting motifs. $J$ Bacteriol 192:4103-4110.

173. Lamont, R. J., A. El-Sabaeny, Y. Park, G. S. Cook, J. W. Costerton, and D. R. Demuth. 2002. Role of the Streptococcus gordonii SspB protein in the development of Porphyromonas gingivalis biofilms on streptococcal substrates. Microbiology 148:1627-1636.

174. Lin, X., J. Wu, and H. Xie. 2006. Porphyromonas gingivalis minor fimbriae are required for cell-cell interactions. Infect Immun 74:6011-6015.

175. Hamada, N., K. Watanabe, M. Arai, H. Hiramine, and T. Umemoto. 2002. Cytokine production induced by a $67-\mathrm{kDa}$ fimbrial protein from Porphyromonas gingivalis. Oral Microbiol Immunol 17:197-200.

176. Davey, M., X. Liu, T. Ukai, V. Jain, C. Gudino, F. C. Gibson, 3rd, D. Golenbock, A. Visintin, and C. A. Genco. 2008. Bacterial fimbriae stimulate proinflammatory activation in the endothelium through distinct TLRs. $J$ Immunol 180:2187-2195.

177. Zeituni, A. E., R. Jotwani, J. Carrion, and C. W. Cutler. 2009. Targeting of DC-SIGN on human dendritic cells by minor fimbriated Porphyromonas 
gingivalis strains elicits a distinct effector $T$ cell response. $J$ Immunol 183:5694-5704.

178. Bainbridge, B. W., and R. P. Darveau. 2001. Porphyromonas gingivalis lipopolysaccharide: an unusual pattern recognition receptor ligand for the innate host defense system. Acta Odontol Scand 59:131-138.

179. Ogawa, T., Y. Asai, Y. Makimura, and R. Tamai. 2007. Chemical structure and immunobiological activity of Porphyromonas gingivalis lipid A. Front Biosci 12:3795-3812.

180. Wang, $P$. L., and K. Ohura. 2002. Porphyromonas gingivalis lipopolysaccharide signaling in gingival fibroblasts-CD14 and Toll-like receptors. Crit Rev Oral Biol Med 13:132-142.

181. Shapira, L., S. Takashiba, S. Amar, and T. E. Van Dyke. 1994. Porphyromonas gingivalis lipopolysaccharide stimulation of human monocytes: dependence on serum and CD14 receptor. Oral Microbiol Immunol 9:112-117.

182. Aida, Y., T. Kukita, H. Takada, K. Maeda, and M. J. Pabst. 1995. Lipopolysaccharides from periodontal pathogens prime neutrophils for enhanced respiratory burst: differential effect of a synthetic lipid a precursor IVA (LA-14-PP). J Periodontal Res 30:116-123.

183. Shapira, L., B. Gordon, M. Warbington, and T. E. Van Dyke. 1994. Priming effect of Porphyromonas gingivalis lipopolysaccharide on superoxide production by neutrophils from healthy and rapidly progressive periodontitis subjects. J Periodontol 65:129-133.

184. Iino, Y., and R. M. Hopps. 1984. The bone-resorbing activities in tissue culture of lipopolysaccharides from the bacteria Actinobacillus actinomycetemcomitans, Bacteroides gingivalis and Capnocytophaga ochracea isolated from human mouths. Arch Oral Biol 29:59-63.

185. Qi, M., H. Miyakawa, and H. K. Kuramitsu. 2003. Porphyromonas gingivalis induces murine macrophage foam cell formation. Microb Pathog 35:259-267.

186. Dixon, D. R., and R. P. Darveau. 2005. Lipopolysaccharide heterogeneity: innate host responses to bacterial modification of lipid a structure. $J$ Dent Res 84:584-595.

187. Reife, R. A., S. R. Coats, M. Al-Qutub, D. M. Dixon, P. A. Braham, R. J. Billharz, W. N. Howald, and R. P. Darveau. 2006. Porphyromonas gingivalis lipopolysaccharide lipid $A$ heterogeneity: differential activities of tetra- and penta-acylated lipid A structures on E-selectin expression and TLR4 recognition. Cell Microbiol 8:857-868.

188. Darveau, R. P., T. T. Pham, K. Lemley, R. A. Reife, B. W. Bainbridge, S. R. Coats, W. N. Howald, S. S. Way, and A. M. Hajjar. 2004. Porphyromonas gingivalis lipopolysaccharide contains multiple lipid A species that functionally interact with both toll-like receptors 2 and 4. Infect Immun 72:5041-5051.

189. Hajishengallis, G. 2009. Porphyromonas gingivalis-host interactions: open war or intelligent guerilla tactics? Microbes Infect 11:637-645. 
190. Jotwani, R., B. S. Moonga, S. Gupta, and C. W. Cutler. Nuclear factorkappaB p50 subunits in chronic periodontitis and Porphyromonas gingivalis lipopolysaccharide-pulsed dendritic cells. Ann N Y Acad Sci 1192:278-285.

191. Domon, H., T. Honda, T. Oda, H. Yoshie, and K. Yamazaki. 2008. Early and preferential induction of IL-1 receptor-associated kinase-M in THP-1 cells by LPS derived from Porphyromonas gingivalis. $J$ Leukoc Biol 83:672-679.

192. Sundqvist, G., D. Figdor, L. Hanstrom, S. Sorlin, and G. Sandstrom. 1991. Phagocytosis and virulence of different strains of Porphyromonas gingivalis. Scand J Dent Res 99:117-129.

193. Slaney, J. M., A. Gallagher, J. Aduse-Opoku, K. Pell, and M. A. Curtis. 2006. Mechanisms of resistance of Porphyromonas gingivalis to killing by serum complement. Infect Immun 74:5352-5361.

194. Brunner, J., N. Scheres, N. B. El Idrissi, D. M. Deng, M. L. Laine, A. J. van Winkelhoff, and W. Crielaard. The capsule of Porphyromonas gingivalis reduces the immune response of human gingival fibroblasts. $B M C$ Microbiol 10:5.

195. Laine, M. L., and A. J. van Winkelhoff. 1998. Virulence of six capsular serotypes of Porphyromonas gingivalis in a mouse model. Oral Microbiol Immunol 13:322-325.

196. Gonzalez, D., A. O. Tzianabos, C. A. Genco, and F. C. Gibson, 3rd. 2003. Immunization with Porphyromonas gingivalis capsular polysaccharide prevents $P$. gingivalis-elicited oral bone loss in a murine model. Infect Immun 71:2283-2287.

197. Vernal, R., R. Leon, A. Silva, A. J. van Winkelhoff, J. A. Garcia-Sanz, and M. Sanz. 2009. Differential cytokine expression by human dendritic cells in response to different Porphyromonas gingivalis capsular serotypes. $J$ Clin Periodontol 36:823-829.

198. Zhao, S., J. Shi, and M. Xiao. 1996. [Effects of capsules on attachment of human periodontal ligament fibroblasts to root surface]. Zhonghua Kou Qiang Yi Xue Za Zhi 31:19-21.

199. Rosen, G., and M. N. Sela. 2006. Coaggregation of Porphyromonas gingivalis and Fusobacterium nucleatum PK 1594 is mediated by capsular polysaccharide and lipopolysaccharide. FEMS Microbiol Lett 256:304-310.

200. Imamura, T., J. Travis, and J. Potempa. 2003. The biphasic virulence activities of gingipains: activation and inactivation of host proteins. Curr Protein Pept Sci 4:443-450.

201. Potempa, J., A. Banbula, and J. Travis. 2000. Role of bacterial proteinases in matrix destruction and modulation of host responses. Periodontol 2000 24:153-192.

202. Muller, H. P. 2000. [Smoking and periodontal health]. Gesundheitswesen 62:400-408.

203. Scott, D. A., and D. L. Singer. 2004. Suppression of overt gingival inflammation in tobacco smokers - clinical and mechanistic considerations. Int J Dent Hyg 2:104-110.

204. Palmer, R. M., J. A. Stapleton, G. Sutherland, P. Y. Coward, R. F. Wilson, and D. A. Scott. 2002. Effect of nicotine replacement and quitting smoking on 
circulating adhesion molecule profiles (sICAM-1, sCD44v5, sCD44v6). Eur J Clin Invest 32:852-857.

205. Pitzer, J. E., G. J. Del Zoppo, and G. W. Schmid-Schonbein. 1996. Neutrophil activation in smokers. Biorheology 33:45-58.

206. Hind, C. R., H. Joyce, G. A. Tennent, M. B. Pepys, and N. B. Pride. 1991. Plasma leucocyte elastase concentrations in smokers. J Clin Pathol 44:232235.

207. Seow, W. K., Y. H. Thong, R. D. Nelson, G. D. MacFarlane, and M. C. Herzberg. 1994. Nicotine-induced release of elastase and eicosanoids by human neutrophils. Inflammation 18:119-127.

208. Liu, K. Z., A. Hynes, A. Man, A. Alsagheer, D. L. Singer, and D. A. Scott. 2006. Increased local matrix metalloproteinase-8 expression in the periodontal connective tissues of smokers with periodontal disease. Biochim. Biophys. Acta 1762:775-780.

209. Persson, L., J. Bergstrom, A. Gustafsson, and B. Asman. 1999. Tobacco smoking and gingival neutrophil activity in young adults. $J$ Clin Periodontol 26:9-13.

210. Loos, B. G., M. T. Roos, P. T. Schellekens, U. van der Velden, and F. Miedema. 2004. Lymphocyte numbers and function in relation to periodontitis and smoking. $J$ Periodontol 75:557-564.

211. Henemyre, C. L., D. K. Scales, S. D. Hokett, M. F. Cuenin, M. E. Peacock, M. H. Parker, P. D. Brewer, and A. H. Chuang. 2003. Nicotine stimulates osteoclast resorption in a porcine marrow cell model. $J$ Periodontol 74:14401446.

212. Tanaka, H., N. Tanabe, M. Shoji, N. Suzuki, T. Katono, S. Sato, M. Motohashi, and M. Maeno. 2006. Nicotine and lipopolysaccharide stimulate the formation of osteoclast-like cells by increasing macrophage colonystimulating factor and prostaglandin E2 production by osteoblasts. Life Sci. 78:1733-1740.

213. Yuhara, S., S. Kasagi, A. Inoue, E. Otsuka, S. Hirose, and H. Hagiwara. 1999. Effects of nicotine on cultured cells suggest that it can influence the formation and resorption of bone. Eur. J. Pharmacol. 383:387-393.

214. Fraser, H. S., R. M. Palmer, R. F. Wilson, P. Y. Coward, and D. A. Scott. 2001. Elevated systemic concentrations of soluble ICAM-1 (SICAM) are not reflected in the gingival crevicular fluid of smokers with periodontitis. $J$ Dent Res 80:1643-1647.

215. McGuire, J. R., M. J. McQuade, J. A. Rossmann, J. J. Garnick, D. E. Sutherland, M. J. Scheidt, and T. E. Van Dyke. 1989. Cotinine in saliva and gingival crevicular fluid of smokers with periodontal disease. $J$ Periodontol 60:176-181.

216. Chen, X., L. Wolff, D. Aeppli, Z. Guo, W. Luan, V. Baelum, and O. Fejeskov. 2001. Cigarette smoking, salivary/gingival crevicular fluid cotinine and periodontal status. A 10-year longitudinal study. J Clin Periodontol 28:331339. 
217. Scott, D. A., R. M. Palmer, and J. A. Stapleton. 2001. Validation of smoking status in clinical research into inflammatory periodontal disease. $J$ Clin Periodontol 28:715-722.

218. Daep, C. A., D. M. James, R. J. Lamont, and D. R. Demuth. 2006. Structural characterization of peptide-mediated inhibition of Porphyromonas gingivalis biofilm formation. Infect Immun 74:5756-5762.

219. Hegde, P., R. Qi, K. Abernathy, C. Gay, S. Dharap, R. Gaspard, J. E. Hughes, E. Snesrud, N. Lee, and J. Quackenbush. 2000. A concise guide to cDNA microarray analysis. Biotechniques 29:548-550, 552-544, 556 passim.

220. James, C. E., Y. Hasegawa, Y. Park, V. Yeung, G. D. Tribble, M. Kuboniwa, D. R. Demuth, and R. J. Lamont. 2006. LuxS involvement in the regulation of genes coding for hemin and iron acquisition systems in Porphyromonas gingivalis. Infect Immun 74:3834-3844.

221. Pierce, D. L., S. Nishiyama, S. Liang, M. Wang, M. Triantafilou, K. Triantafilou, F. Yoshimura, D. R. Demuth, and G. Hajishengallis. 2009. Host adhesive activities and virulence of novel fimbrial proteins of Porphyromonas gingivalis. Infect Immun 77:3294-3301.

222. Heydorn, A., A. T. Nielsen, M. Hentzer, C. Sternberg, M. Givskov, B. K. Ersboll, and S. Molin. 2000. Quantification of biofilm structures by the novel computer program COMSTAT. Microbiology 146 ( Pt 10):2395-2407.

223. Keskinoglu, P., D. Cimrin, and G. Aksakoglu. 2007. The Impact of Passive Smoking on the Development of Lower Respiratory Tract Infections in Children. J Trop Pediatr.

224. Polanska, K., W. Hanke, R. Ronchetti, P. van den Hazel, M. Zuurbier, J. G. Koppe, and A. Bartonova. 2006. Environmental tobacco smoke exposure and child ren's health. Acta Paediatr Suppl 95:86-92.

225. Kum-Nji, P., L. Meloy, and H. G. Herrod. 2006. Environmental tobacco smoke exposure: prevalence and mechanisms of causation of infections in children. Pediatrics 117:1745-1754.

226. Araco, A., G. Gravante, R. Sorge, F. Araco, D. Delogu, and V. Cervelli. 2008. Wound infections in aesthetic abdominoplasties: the role of smoking. Plast Reconstr Surg 121:305e-310e.

227. Jeppesen, D. L., S. D. Nielsen, A. K. Ersboll, and N. H. Valerius. 2008. Maternal Smoking during Pregnancy Increases the Risk of Postnatal Infections in Preterm Neonates. Neonatology 94:75-78.

228. Holt, S. C., and J. L. Ebersole. 2005. Porphyromonas gingivalis, Treponema denticola, and Tannerella forsythia: the "red complex", a prototype polybacterial pathogenic consortium in periodontitis. Periodontol 2000 38:72122.

229. Dye, B. A., K. Choudhary, S. Shea, and P. N. Papapanou. 2005. Serum antibodies to periodontal pathogens and markers of systemic inflammation. $J$ Clin Periodontol 32:1189-1199.

230. Pussinen, P. J., G. Alfthan, P. Jousilahti, S. Paju, and J. Tuomilehto. 2007. Systemic exposure to Porphyromonas gingivalis predicts incident stroke. Atherosclerosis 193:222-228. 
231. Gibson, F. C., 3rd, H. Yumoto, Y. Takahashi, H. H. Chou, and C. A. Genco. 2006. Innate immune signaling and Porphyromonas gingivalis-accelerated atherosclerosis. $J$ Dent Res 85:106-121.

232. Nair, P., G. Sutherland, R. M. Palmer, R. F. Wilson, and D. A. Scott. 2003. Gingival bleeding on probing increases after quitting smoking. $J$ Clin Periodontol 30:435-437.

233. Bostrom, L., L. E. Linder, and J. Bergstrom. 1999. Smoking and cervicular fluid levels of IL-6 and TNF-alpha in periodontal disease. J Clin Periodontol 26:352-357.

234. Erdemir, E. O., I. Duran, and S. Haliloglu. 2004. Effects of smoking on clinical parameters and the gingival crevicular fluid levels of IL-6 and TNFalpha in patients with chronic periodontitis. J Clin Periodontol 31:99-104.

235. Goutoudi, P., E. Diza, and M. Arvanitidou. 2004. Effect of periodontal therapy on crevicular fluid interleukin-1beta and interleukin-10 levels in chronic periodontitis. $J$ Dent 32:511-520.

236. Petropoulos, G., I. J. McKay, and F. J. Hughes. 2004. The association between neutrophil numbers and interleukin-1alpha concentrations in gingival crevicular fluid of smokers and non-smokers with periodontal disease. J Clin Periodontol 31:390-395.

237. Shirodaria, S., J. Smith, I. J. McKay, C. N. Kennett, and F. J. Hughes. 2000. Polymorphisms in the IL-1A gene are correlated with levels of interleukin1alpha protein in gingival crevicular fluid of teeth with severe periodontal disease. $J$ Dent Res 79:1864-1869.

238. Barbour, S. E., K. Nakashima, J. B. Zhang, S. Tangada, C. L. Hahn, H. A. Schenkein, and J. G. Tew. 1997. Tobacco and smoking: environmental factors that modify the host response (immune system) and have an impact on periodontal health. Crit Rev Oral Biol Med 8:437-460.

239. Johnson, G. K., and M. Hill. 2004. Cigarette smoking and the periodontal patient. J Periodontol 75:196-209.

240. Mullally, B. H. 2004. The Influence of Tobacco Smoking on the Onset of Periodontitis in Young Persons. Tobacco Induced Diseases 2:53-65.

241. Rehani, K., D. A. Scott, D. Renaud, H. Hamza, L. R. Williams, H. Wang, and M. Martin. 2008. Cotinine-induced convergence of the cholinergic and PI3 kinase-dependent anti-inflammatory pathways in innate immune cells. Biochim Biophys Acta 1783:375-382.

242. Xu, M., J. E. Scott, K. Z. Liu, H. R. Bishop, D. E. Renaud, R. M. Palmer, A. Soussi-Gounni, and D. A. Scott. 2008. The influence of nicotine on granulocytic differentiation - inhibition of the oxidative burst and bacterial killing and increased matrix metalloproteinase-9 release. BMC Cell Biol 9:19.

243. Stein, S. H., B. E. Green, and M. Scarbecz. 2004. Augmented transforming growth factor-betal in gingival crevicular fluid of smokers with chronic periodontitis. $J$ Periodontol 75:1619-1626.

244. Wang, M., M. A. Shakhatreh, D. James, S. Liang, S. Nishiyama, F. Yoshimura, D. R. Demuth, and G. Hajishengallis. 2007. Fimbrial proteins of porphyromonas gingivalis mediate in vivo virulence and exploit TLR2 and complement receptor 3 to persist in macrophages. J Immunol 179:2349-2358. 
245. Maeda, K., G. D. Tribble, C. M. Tucker, C. Anaya, S. Shizukuishi, J. P. Lewis, D. R. Demuth, and R. J. Lamont. 2008. A Porphyromonas gingivalis Tyrosine Phosphatase is a Multifunctional Regulator of Virulence Attributes. Mol Microbiol.

246. Aduse-Opoku, J., J. M. Slaney, A. Hashim, A. Gallagher, R. P. Gallagher, M. Rangarajan, K. Boutaga, M. L. Laine, A. J. Van Winkelhoff, and M. A. Curtis. 2006. Identification and characterization of the capsular polysaccharide (K-antigen) locus of Porphyromonas gingivalis. Infect Immun 74:449-460.

247. Wu, J., X. Lin, and H. Xie. 2007. Porphyromonas gingivalis short fimbriae are regulated by a FimS/FimR two-component system. FEMS Microbiol Lett 271:214-221.

248. Oralgen. Oral Pathogen Sequence Databases.

249. Lamont, R. J., and H. F. Jenkinson. 1998. Life below the gum line: pathogenic mechanisms of Porphyromonas gingivalis. Microbiol Mol Biol Rev 62:1244-1263.

250. van Winkelhoff, A. J., B. J. Appelmelk, N. Kippuw, and J. de Graaff. 1993. $\mathrm{K}$-antigens in Porphyromonas gingivalis are associated with virulence. Oral Microbiol Immunol 8:259-265.

251. Califano, J. V., R. E. Schifferle, J. C. Gunsolley, A. M. Best, II. A. Schenkein, and J. G. Tew. 1999. Antibody reactive with Porphyromonas gingivalis serotypes K1-6 in adult and generalized early-onset periodontitis. $J$ Periodontol 70:730-735.

252. d'Empaire, G., M. T. Baer, and F. C. Gibson, 3rd. 2006. The K1 serotype capsular polysaccharide of Porphyromonas gingivalis elicits chemokine production from murine macrophages that facilitates cell migration. Infect Immun 74:6236-6243.

253. Curtis, M. A., S. A. Hanley, and J. Aduse-Opoku. 1999. The rag locus of Porphyromonas gingivalis: a novel pathogenicity island. $J$ Periodontal Res 34:400-405.

254. Bonass, W. A., P. D. Marsh, R. S. Percival, J. Aduse-Opoku, S. A. Hanley, D. A. Devine, and M. A. Curtis. 2000. Identification of $\operatorname{rag} A B$ as a temperatureregulated operon of Porphyromonas gingivalis W50 using differential display of randomly primed RNA. Infect Immun 68:4012-4017.

255. Shi, X., S. A. Hanley, M. C. Faray-Kele, S. C. Fawell, J. Adusc-Opoku, R. A. Whiley, M. A. Curtis, and L. M. Hall. 2007. The rag locus of Porphyromonas gingivalis contributes to virulence in a murine model of soft tissue destruction. Infect Immun 75:2071-2074.

256. Hall, L. M., S. C. Fawell, X. Shi, M. C. Faray-Kele, J. Aduse-Opoku, R. A. Whiley, and M. A. Curtis. 2005. Sequence diversity and antigenic variation at the rag locus of Porphyromonas gingivalis. Infect Immun 73:4253-4262.

257. Wei, B., H. Dalwadi, L. K. Gordon, C. Landers, D. Bruckner, S. R. Targan, and J. Braun. 2001. Molecular cloning of a Bacteroides caccae TonB-linked outer membrane protein identified by an inflammatory bowel disease marker antibody. Infect Immun 69:6044-6054. 
258. Daep, C. A., R. J. Lamont, and D. R. Demuth. 2008. Interaction of Porphyromonas gingivalis with oral streptococci requires a motif that resembles the eukaryotic nuclear receptor box protein-protein interaction domain. Infect Immun.

259. Lagente, V., J. M. Planquois, O. Leclerc, F. Schmidlin, and C. P. Bertrand. 2008. Oxidative stress is an important component of airway inflammation in mice exposed to cigarette smoke or lipopolysaccharide. Clin Exp Pharmacol Physiol 35:601-605.

260. Yamaguchi, Y., F. Nasu, A. Harada, and M. Kunitomo. 2007. Oxidants in the gas phase of cigarette smoke pass through the lung alveolar wall and raise systemic oxidative stress. J Pharmacol Sci 103:275-282.

261. Pryor, W. A., M. M. Dooley, and D. F. Church. 1986. The inactivation of alpha-1-proteinase inhibitor by gas-phase cigarette smoke: protection by antioxidants and reducing species. Chem Biol Interact 57:271-283.

262. Ratnayake, D. B., S. N. Wai, Y. Shi, K. Amako, H. Nakayama, and K. Nakayama. 2000. Ferritin from the obligate anaerobe Porphyromonas gingivalis: purification, gene cloning and mutant studies. Microbiology 146 ( Pt 5):1119-1127.

263. Duran-Pinedo, A. E., K. Nishikawa, and M. J. Duncan. 2007. The RprY response regulator of Porphyromonas gingivalis. Mol Microbiol 64:10611074.

264. Bagaitkar, J., D. R. Demuth, and D. A. Scott. 2008. Increased susceptibility to bacterial infections in tobacco smokers. Tobacco Induced Diseases 4.

265. Drannik, A. G., M. A. Pouladi, C. S. Robbins, S. I. Goncharova, S. Kianpour, and M. R. Stampfli. 2004. Impact of cigarette smoke on clearance and inflammation after Pseudomonas aeruginosa infection. Am J Respir Crit Care Med 170:1164-1171.

266. Gensch, E., M. Gallup, A. Sucher, D. Li, A. Gebremichael, H. Lemjabbar, A. Mengistab, V. Dasari, J. Hotchkiss, J. Harkema, and C. Basbaum. 2004. Tobacco smoke control of mucin production in lung cells requires oxygen radicals AP-1 and JNK. $J$ Biol Chem 279:39085-39093.

267. Stringer, K. A., M. Tobias, H. C. O'Neill, and C. C. Franklin. 2007. Cigarette smoke extract-induced suppression of caspase-3-like activity impairs human neutrophil phagocytosis. Am J Physiol Lung Cell Mol Physiol 292:L15721579.

268. Zappacosta, B., S. Persichilli, A. Minucci, E. D. Stasio, P. Carlino, G. Pagliari, B. Giardina, and P. D. Sole. 2001. Effect of aqueous cigarette smoke extract on the chemiluminescence kinetics of polymorphonuclear leukocytes and on their glycolytic and phagocytic activity. Luminescence 16:315-319.

269. Nouri-Shirazi, M., R. Tinajero, and E. Guinet. 2007. Nicotine alters the biological activities of developing mouse bone marrow-derived dendritic cells (DCs). Immunol Lett 109:155-164.

270. Robbins, C. S., F. Franco, M. Mouded, M. Cernadas, and S. D. Shapiro. 2008. Cigarette smoke exposure impairs dendritic cell maturation and $T$ cell proliferation in thoracic lymph nodes of mice. J Immunol 180:6623-6628. 
271. Sayers, N. M., B. P. Gomes, D. B. Drucker, and A. S. Blinkhorn. 1997. Possible lethal enhancement of toxins from putative periodontopathogens by nicotine: implications for periodontal disease. J Clin Pathol 50:245-249.

272. Sayers, N. M., J. A. James, D. B. Drucker, and A. S. Blinkhorn. 1999. Possible potentiation of toxins from Prevotella intermedia, Prevotella nigrescens, and Porphyromonas gingivalis by cotinine. $J$ Periodontol 70:12691275.

273. Andreou, V., M. D'Addario, R. Zohar, B. Sukhu, R. F. Casper, R. P. Ellen, and $H$. C. Tenenbaum. 2004. Inhibition of osteogenesis in vitro by a cigarette smoke-associated hydrocarbon combined with Porphyromonas gingivalis lipopolysaccharide: reversal by resveratrol. $J$ Periodontol 75:939-948.

274. Bagaitkar, J., L. R. Williams, D. E. Renaud, M. R. Bemakanakere, M. Martin, D. A. Scott, and D. R. Demuth. 2009. Tobacco-induced alterations to Porphyromonas gingivalis-host interactions. Environ Microbiol.

275. Davey, M. E., and M. J. Duncan. 2006. Enhanced biofilm formation and loss of capsule synthesis: deletion of a putative glycosyltransferase in Porphyromonas gingivalis. $J$ Bacteriol 188:5510-5523.

276. Yilmaz, O., P. Verbeke, R. J. Lamont, and D. M. Ojcius. 2006. Intercellular spreading of Porphyromonas gingivalis infection in primary gingival epithelial cells. Infect Immun 74:703-710.

277. Eskan, M. A., G. Hajishengallis, and D. F. Kinane. 2007. Differential activation of human gingival epithelial cells and monocytes by Porphyromonas gingivalis fimbriae. Infect Immun 75:892-898.

278. Zhou, Q., T. Desta, M. Fenton, D. T. Graves, and S. Amar. 2005. Cytokine profiling of macrophages exposed to Porphyromonas gingivalis, its lipopolysaccharide, or its FimA protein. Infect Immun 73:935-943.

279. Kuboniwa, M., A. Amano, H. Inaba, E. Hashino, and S. Shizukuishi. 2009. Homotypic biofilm structure of Porphyromonas gingivalis is affected by FimA type variations. Oral Microbiol Immunol 24:260-263.

280. Bagaitkar, J., D. A. Scott, L. R. Williams, D. E. Renaud, C. Daep, M. Martin, and D. R. Demuth. 2008. Tobacco-induced alterations to Porphyromonas gingivalis-host interactions. Environmental Microbiology 11:1242-1253.

281. O'Neill, L. A. 2006. How Toll-like receptors signal: what we know and what we don't know. Curr Opin Immunol 18:3-9.

282. Bergstrom, J., S. Eliasson, and J. Dock. 2000. Exposure to tobacco smoking and periodontal health. $J$ Clin Periodontol 27:61-68.

283. Scott, D. A., and M. Martin. 2006. Exploitation of the nicotinic antiinflammatory pathway for the treatment of epithelial inflammatory diseases. World J Gastroenterol 12:7451-7459.

284. Maeda, K., H. Nagata, Y. Yamamoto, M. Tanaka, J. Tanaka, N. Minamino, and S. Shizukuishi. 2004. Glyceraldehyde-3-phosphate dehydrogenase of Streptococcus oralis functions as a coadhesin for Porphyromonas gingivalis major fimbriae. Infect Immun 72:1341-1348.

285. Nakagawa, I., H. Inaba, T. Yamamura, T. Kato, S. Kawai, T. Ooshima, and A. Amano. 2006. Invasion of epithelial cells and proteolysis of cellular focal 
adhesion components by distinct types of Porphyromonas gingivalis fimbriae. Infect Immun 74:3773-3782.

286. Umeda, J. E., C. Missailidis, P. L. Longo, D. Anzai, M. Wikstrom, and M. P. Mayer. 2006. Adhesion and invasion to epithelial cells by fimA genotypes of Porphyromonas gingivalis. Oral Microbiol Immunol 21:415-419.

287. Kuboniwa, M., A. Amano, E. Hashino, Y. Yamamoto, H. Inaba, N. Hamada, K. Nakayama, G. D. Tribble, R. J. Lamont, and S. Shizukuishi. 2009. Distinct roles of long/short fimbriae and gingipains in homotypic biofilm development by Porphyromonas gingivalis. BMC Microbiol 9:105.

288. Hajishengallis, G., R. I. Tapping, E. Harokopakis, S. Nishiyama, P. Ratti, R. E. Schifferle, E. A. Lyle, M. Triantafilou, K. Triantafilou, and F. Yoshimura. 2006. Differential interactions of fimbriae and lipopolysaccharide from Porphyromonas gingivalis with the Toll-like receptor 2-centred pattern recognition apparatus. Cell Microbiol 8:1557-1570.

289. Zhou, Q., and S. Amar. 2007. Identification of signaling pathways in macrophage exposed to Porphyromonas gingivalis or to its purified cell wall components. J Immunol 179:7777-7790.

290. Murakami, Y., M. Shoji, A. Hirata, S. Tanaka, S. Hanazawa, I. Yokoe, and S. Fujisawa. 2006. An ortho dimer of butylated hydroxyanisole inhibits nuclear factor kappa $B$ activation and gene expression of inflammatory cytokines in macrophages stimulated by Porphyromonas gingivalis fimbriae. Arch Biochem Biophys 449:171-177.

291. de Heens, G. L., R. Kikkert, L. A. Aarden, U. van der Velden, and B. G. Loos. 2009. Effects of smoking on the ex vivo cytokine production in periodontitis. J Periodontal Res 44:28-34.

292. Nagamatsu, K., A. Kuwae, T. Konaka, S. Nagai, S. Yoshida, M. Eguchi, M. Watanabe, H. Mimuro, S. Koyasu, and A. Abe. 2009. Bordetella evades the host immune system by inducing IL-10 through a type III effector, BopN. $J$ Exp Med 206:3073-3088.

293. Billips, B. K., A. J. Schaeffer, and D. J. Klumpp. 2008. Molecular basis of uropathogenic Escherichia coli evasion of the innate immune response in the bladder. Infect Immun 76:3891-3900.

294. Neumann, D., C. Kollewe, K. Resch, and M. U. Martin. 2007. The death domain of IRAK-1: an oligomerization domain mediating interactions with MyD88, Tollip, IRAK-1, and IRAK-4. Biochem Biophys Res Commun 354:1089-1094.

295. Wesche, H., W. J. Henzel, W. Shillinglaw, S. Li, and Z. Cao. 1997. MyD88: an adapter that recruits IRAK to the IL-1 receptor complex. Immunity 7:837847.

296. Chamekh, M., A. Phalipon, R. Quertainmont, I. Salmon, P. Sansonetti, and A. Allaoui. 2008. Delivery of biologically active anti-inflammatory cytokines IL-10 and IL-1 ra in vivo by the Shigella type III secretion apparatus. $J$ Immunol 180:4292-4298.

297. Wolfe, D. N., A. M. Buboltz, and E. T. Harvill. 2009. Inefficient Toll-like receptor-4 stimulation enables Bordetella parapertussis to avoid host immunity. PLoS One 4:e4280. 
298. Qian, Y., M. Commane, J. Ninomiya-Tsuji, K. Matsumoto, and X. Li. 2001. IRAK-mediated translocation of TRAF6 and TAB2 in the interleukin-1induced activation of NFkappa B. J Biol Chem 276:41661-41667.

299. Li, S., A. Strelow, E. J. Fontana, and H. Wesche. 2002. IRAK-4: a novel member of the IRAK family with the properties of an IRAK-kinase. Proc Natl Acad Sci U S A 99:5567-5572.

300. Kobayashi, K., L. D. Hernandez, J. E. Galan, C. A. Janeway, Jr., R. Medzhitov, and R. A. Flavell. 2002. IRAK-M is a negative regulator of Tolllike receptor signaling. Cell 110:191-202.

301. Siedlar, M., M. Frankenberger, E. Benkhart, T. Espevik, M. Quirling, K. Brand, M. Zembala, and L. Ziegler-Heitbrock. 2004. Tolerance induced by the lipopeptide Pam3Cys is due to ablation of IL-1R-associated kinase-1. $J$ Immunol 173:2736-2745.

302. Harokopakis, E., and G. Hajishengallis. 2005. Integrin activation by bacterial fimbriae through a pathway involving CD14, Toll-like receptor 2, and phosphatidylinositol-3-kinase. Eur J Immunol 35:1201-1210.

303. Vanterpool, E., F. Roy, L. Sandberg, and H. M. Fletcher. 2005. Altered gingipain maturation in vimA- and vimE-defective isogenic mutants of Porphyromonas gingivalis. Infect Immun 73:1357-1366.

304. Osbourne, D. O., W. Aruni, F. Roy, C. Perry, L. Sandberg, A. Muthiah, and H. M. Fletcher. Role of vimA in cell surface biogenesis in Porphyromonas gingivalis. Microbiology 156:2180-2193.

305. Nakayama, K., F. Yoshimura, T. Kadowaki, and K. Yamamoto. 1996. Involvement of arginine-specific cysteine proteinase (Arg-gingipain) in fimbriation of Porphyromonas gingivalis. $J$ Bacteriol 178:2818-2824.

306. Khoja, S. M., M. M. El-Merzabani, and A. M. El-Aaser. 1991. Effects of jurak smoke condensate on enzyme activity of the mouse. Ann Saudi Med 11:135-140.

307. Weiner, D., Y. Levy, E. V. Khankin, and A. Z. Reznick. 2008. Inhibition of salivary amylase activity by cigarette smoke aldehydes. $J$ Physiol Pharmacol 59 Suppl 6:727-737.

308. Hajishengallis, G., M. Wang, S. Liang, M. Triantafilou, and K. Triantafilou. 2008. Pathogen induction of CXCR4/TLR2 cross-talk impairs host defense function. Proc Natl Acad Sci U S A 105:13532-13537.

309. Wang, M., J. L. Krauss, H. Domon, K. B. Hosur, S. Liang, P. Magotti, M. Triantafilou, K. Triantafilou, J. D. Lambris, and G. Hajishengallis. Microbial hijacking of complement-toll-like receptor crosstalk. Sci Signal 3:ra11.

310. Platzer, C., C. Meisel, K. Vogt, M. Platzer, and H. D. Volk. 1995. Upregulation of monocytic IL-10 by tumor necrosis factor-alpha and cAMP elevating drugs. Int Immunol 7:517-523.

311. Platzer, C., E. Fritsch, T. Elsner, M. H. Lehmann, H. D. Volk, and S. Prosch. 1999. Cyclic adenosine monophosphate-responsive elements are involved in the transcriptional activation of the human IL-10 gene in monocytic cells. Eur J Immunol 29:3098-3104. 
312. Mansell, A., R. Smith, S. L. Doyle, P. Gray, J. E. Fenner, P. J. Crack, S. E. Nicholson, D. J. Hilton, L. A. O'Neill, and P. J. Hertzog. 2006. Suppressor of cytokine signaling 1 negatively regulates Toll-like receptor signaling by mediating Mal degradation. Nat Immunol 7:148-155.

313. Goulbourne, P. A., and R. P. Ellen. 1991. Evidence that Porphyromonas (Bacteroides) gingivalis fimbriae function in adhesion to Actinomyces viscosus. J Bacteriol 173:5266-5274.

314. Grenier, D. 1992. Demonstration of a bimodal coaggregation reaction between Porphyromonas gingivalis and Treponema denticola. Oral Microbiol Immunol 7:280-284.

315. Ikegami, A., K. Honma, A. Sharma, and H. K. Kuramitsu. 2004. Multiple functions of the leucine-rich repeat protein LrrA of Treponema denticola. Infect Immun 72:4619-4627.

316. Yao, E. S., R. J. Lamont, S. P. Leu, and A. Weinberg. 1996. Interbacterial binding among strains of pathogenic and commensal oral bacterial species. Oral Microbiol Immunol 11:35-41.

317. Chung, W. O., D. R. Demuth, and R. J. Lamont. 2000. Identification of a Porphyromonas gingivalis receptor for the Streptococcus gordonii SspB protein. Infect Immun 68:6758-6762.

318. Maeda, K., H. Nagata, A. Nonaka, K. Kataoka, M. Tanaka, and S. Shizukuishi. 2004. Oral streptococcal glyceraldehyde-3-phosphate dehydrogenase mediates interaction with Porphyromonas gingivalis fimbriae. Microbes Infect 6:1163-1170.

319. Demuth, D. R., D. C. Irvine, J. W. Costerton, G. S. Cook, and R. J. Lamont. 2001. Discrete protein determinant directs the species-specific adherence of Porphyromonas gingivalis to oral streptococci. Infect Immun 69:5736-5741.

320. Kozarov, E., D. Sweier, C. Shelburne, A. Progulske-Fox, and D. Lopatin. 2006. Detection of bacterial DNA in atheromatous plaques by quantitative PCR. Microbes Infect 8:687-693.

321. Kozarov, E. V., B. R. Dorn, C. E. Shelburne, W. A. Dunn, Jr., and A. Progulske-Fox. 2005. Human atherosclerotic plaque contains viable invasive Actinobacillus actinomycetemcomitans and Porphyromonas gingivalis. Arterioscler Thromb Vasc Biol 25:e17-18.

322. Li, L., R. Michel, J. Cohen, A. Decarlo, and E. Kozarov. 2008. Intracellular survival and vascular cell-to-cell transmission of Porphyromonas gingivalis. BMC Microbiol 8:26. 


\section{CURRICULUM VITAE}

Juhi Bagaitkar

University of Louisville

School of Medicine, Department of Microbiology and Immunology

School of Dentistry, Department of Periodontics, Endodontics, and Oral Hygiene

501 South Preston Street, Room 211C

Louisville, KY 40202

Lab: (502) 852-5531

Fax: (502) 852-5572

Email: jabaga01@louisville.edu

\section{Education and training:}

M.S., Microbiology and Immunology, University of Louisville, Louisville, KY. 2008

M.Sc., (Honors) Environmental Sciences, University of Pune, India 2005

B.Sc., Industrial Microbiology, University of Pune, India 2003

\section{Journal publications:}

1) Bagaitkar J, Patel C, Renaud DE, Daep-Amorin C, Demuth DR, Scott DA.

Tobacco exposure augments Porphyromonas gingivalis aggregation and Mfaldependent biofilm formation. Environmental Microbiology (under review, 2010).

2) Scott DA, Palmer RM, Bagaitkar J. Mechanisms underlying tobacco-induced suppression of inflammation in the gingiva. Journal of Clinical Periodontology (under review, 2010).

3) Buduneli N, Larsson L, Biyikoglu B, Bagaitkar J, Renaud DE, Scott DA*. Lipid 
A-derived $\mathrm{C} 12$ and $\mathrm{C} 14$ 3-OH fatty acids are decreased in relation to $\mathrm{C} 133-\mathrm{OH}$ fatty acid in smokers with chronic periodontitis. Journal of Dental Research (in press, 2010).

4) Bagaitkar J, Demuth DR, Daep-Amorin C, Renaud DE, Pierce DL, Scott DA. Tobacco upregulated $P$. gingivalis fimbrial proteins which induce TLR2 hyposensitivity. PLoS One 2010;5:e9323.

5) Bagaitkar J, Williams LR, Renaud DE, Benakanakere MR, Martin M, Scott DA, Demuth DR. Tobacco induced alterations to Porphyromonas gingivalis- host interactions. Environmental Microbiology 2009;11:1242-53.

6) Bagaitkar J, Demuth DR, Scott DA. Tobacco use and susceptibility to bacterial infection. Tobacco Induced Diseases 2008;4:e12.

7) Liu W, Bagaitkar J, Watabe K. Roles of AKT signal in breast cancer. Frontiers in Biosciences 2007; 12:4011-9.

8) Whitehurst B, Flister MJ, Bagaitkar J, Volk L, Bivens CM, Pickett B, Castro-Rivera E, Brekken RA, Gerard RD, Ran S. Anti-VEGF-A therapy reduces lymphatic vessel density and expression of VEGFR-3 in an orthotopic breast tumor model. International Journal of Cancer 2007; 121:2181-91.

\section{Book Chapter:}

\section{Scott DA, Bagaitkar J.}

Tobacco smoke and susceptibility to infectious bacterial diseases. In: "Cigarette Smoke Toxicity" David Bernhard, Editor. Wiley-VCH Verlag GmbH \& Co. KGaA, Weinheim, 
Germany (in press, 2010).

\section{Abstracts:}

1. "Tobacco exposure augments Porphyromonas gingivalis Mfal-dependent biofilm formation" Bagaitkar J, Patel C, Renaud DE, Daep-Amorin C, Demuth DR, Scott DA.

2. Tobacco alkaloids inhibit pro-inflammatory signaling initiated through multiple cell surface TLRs." Bagatikar J, Renaud DE, Scott DA. 2010, ASM, International Society for the Prevention of Tobacco-Induced Diseases, Boston, MA.

3. Tobacco-regulated changes to $P$. gingivalis fimbrial proteins and capsule polysaccharides induce TLR2 hyposensitivity.' Bagaitkar J, Demuth DR, Daep C, Pierce DL Renaud DE, Scott DA. AADR, Washington D.C., 2010 and Gordon Conference on Periodontal Diseases, 2009 and James Graham Brown Annual Research Retreat. Louisville, KY, 2009.

4. Cigarette smoke extract alters the structure and immune function of Porphyromonas gingivalis LPS." Aronica Y. Boyle, Juhi Bagaitkar, Diane E. Renaud, Don R. Demuth, David Scott. James Graham Brown Annual Research Retreat. Louisville, KY, 2009 and AADR, Washington D.C., 2010.

5. Tobacco smoking, innate immunity and susceptibility to bacterial infection." Bagaitkar J, Demuth DR, Scott DA. 2008, ASM, International Society for the Prevention of Tobacco- Induced Diseases, Kyoto, Japan.

6. Tobacco smoke-exposure alters Porphyromonas gingivalis W83-innate cell interactions." Bagaitkar J, Williams LR, Daep C Demuth DR, Scott DA. 2008, ASM, Society for Leukocyte Biology, Denver, Colorado, USA. 


\section{INVITED TALKS/PRESENTATIONS:}

- Invited Speaker at the AADR, Washington D.C., 2010.

- Invited Speaker at the Society for Leukocyte Biology ASM, Vancouver, 2010. Presidential Research Award finalist.

- Invited Presenter at the Gordon Conference on Periodontal Diseases, 2009.

- Invited Presenter to the Senate and Congress of the Commonwealth of Kentucky. 'Annual Graduate Student Research Day', Frankfurt, Kentucky., 2008 .

\section{AWARDS/HONORS:}

- Travel Award for the $43^{\text {rd }}$ Annual meeting of Society for Leukocyte Biology, Vancouver, Canada, 2010.

- First Place: Society for Leukocyte Biology Presidential Research Award, Vancouver, Canada, 2010.

- First Place: Condict Moore Graduate Student Research Prize at the James Graham Brown Cancer Center Annual Research Retreat. Louisville, KY, 2009.

- Travel Award for the $41^{\text {st }}$ Annual Meeting of Society for Leukocyte Biology, Denver, Colorado, 2008.

- Multiple travel awards from the Graduate Student Council (GSC) at the University of Louisville.

- President (2008-2009), Microbiology and Immunology Student Association.

- Student representative on Curriculum Committee, Department of Microbiology and Immunology, 2009-2010. 